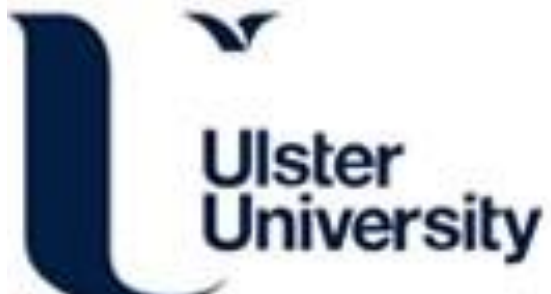

\section{Vertical Planar Liquid-Vapour Thermal Diodes (PLVTD) and their application in building façade energy systems}

Pugsley, A., Zacharopoulos, A., Deb Mondol, J., \& Smyth, M. (2020). Vertical Planar Liquid-Vapour Thermal Diodes (PLVTD) and their application in building façade energy systems. Applied Thermal Engineering, 179, [115641]. https://doi.org/10.1016/j.applthermaleng.2020.115641

Link to publication record in Ulster University Research Portal

\section{Published in:}

Applied Thermal Engineering

Publication Status:

Published (in print/issue): 01/10/2020

DOI:

10.1016/j.applthermaleng.2020.115641

\section{Document Version}

Author Accepted version

\section{General rights}

Copyright for the publications made accessible via Ulster University's Research Portal is retained by the author(s) and / or other copyright owners and it is a condition of accessing these publications that users recognise and abide by the legal requirements associated with these rights.

\section{Take down policy}

The Research Portal is Ulster University's institutional repository that provides access to Ulster's research outputs. Every effort has been made to ensure that content in the Research Portal does not infringe any person's rights, or applicable UK laws. If you discover content in the Research Portal that you believe breaches copyright or violates any law, please contact pure-support@ulster.ac.uk. 
1 Vertical Planar Liquid-Vapour Thermal Diodes (PLVTD) and

2 their application in building façade energy systems

\section{Keywords}

13 Thermal diode; one-way heat transfer; switchable insulation; net zero energy 14 buildings; building facade; solar collector;

Adrian Pugsley (a.pugsley@ulster.ac.uk, +44(0)28 90366264 (corresponding author)

Aggelos Zacharopoulos (a.zacharopoulos@ulster.ac.uk) +44(0)2890368227

Jayanta Deb Mondol (jd.mondol@ulster.ac.uk) +44(0)28 90368037

Mervyn Smyth (m.smyth1@ulster.ac.uk) +44(0)2890368119

Centre for Sustainable Technologies (www.cst.ulster.ac.uk), School of the Built Environment, Ulster University, Newtownabbey, BT37 OQB, Northern Ireland, UK

\section{Highlights}

- Vertical planar thermal diodes realised \& tested at realistic scales $\left(0.15 \& 0.98 \mathrm{~m}^{2}\right)$

- Reverse mode insulation $\left(1.7<\mathrm{U}_{\mathrm{r}}<12 \mathrm{~W} \cdot \mathrm{m}^{-2} \mathrm{~K}^{-1}\right)$ depends primarily on depth $(22<\mathrm{x}<70 \mathrm{~mm})$

- Forward mode heat transfer depends on temperature \& heat flux $\left(50<\mathrm{U}_{\mathrm{f}}<900 \mathrm{~W} \cdot \mathrm{m}^{-2} \mathrm{~K}^{-1}\right)$

- One-dimensional lumped parameter heat transfer model augmented \& validated

- Applications in solar collectors and climate control building envelopes discussed

\section{Abstract}

18 Buildings represent one-third of global energy consumption and corresponding $\mathrm{CO}_{2}$

19 emissions which can be reduced through enhanced insulation and building integrated

20 renewables. Thermal diodes can potentially revolutionise passive heat

21 collection/rejection devices such as Integrated Collector-Storage Solar Water Heaters

22 (ICSSWH) and Climate-Control Building Envelopes (CCBE) employed for

23 decarbonisation. We present novel theoretical and experimental validation work on a

24 lumped parameter heat transfer model of Planar Liquid-Vapour Thermal Diodes

25 (PLVTD) to support development of ICSSWH and CCBE components for building

26 facades. This study augments our previous work on a passive horizontal PLVTD model,

27 by introducing falling film evaporation, vapour convection in vertical rectangular 
enclosures, condensation on vertical plates, and a methodology for evaluating working

29 fluid temperatures. Experimental validations are presented for vertical aluminium

$30\left(A_{p}=0.15 m^{2}, x=22 m m\right)$ and stainless steel $\left(A_{p}=0.98 m^{2}, x=70 m m\right)$ prototypes using

31 two different laboratory test methodologies where temperature setpoints were

32 controlled and measured. The model predicts measured steady state thermal

33 conductances in reverse mode $\left(\mathrm{U}_{\mathrm{r}} \approx 12 \mathrm{~W} \cdot \mathrm{m}^{-2} \mathrm{~K}^{-1}\right.$ and $\mathrm{U}_{\mathrm{r}} \approx 1.7 \mathrm{~W} \cdot \mathrm{m}^{-2} \mathrm{~K}^{-1}$ for $\mathrm{x}=22 \mathrm{~mm}$ and

$34 \mathrm{x}=70 \mathrm{~mm}$ PLVTDs respectively) and forward mode $\left(175<\mathrm{U}_{\mathrm{f}}<730 \mathrm{~W} \cdot \mathrm{m}^{-2} \mathrm{~K}^{-1}\right.$ and

$3550<\mathrm{U}_{\mathrm{LvL}}<900 \mathrm{~W} \cdot \mathrm{m}^{-2} \mathrm{~K}^{-1}$ respectively) with reasonable accuracy across investigated

36 ranges $\left(15<\mathrm{T}_{2}<65^{\circ} \mathrm{C}\right.$ condenser temperatures, $5<-\Delta \mathrm{T}_{12}<25^{\circ} \mathrm{C}$ reverse mode plate-to-

37 plate temperature differences, $50<\mathrm{q} / \mathrm{A}<1000 \mathrm{~W} \cdot \mathrm{m}^{-2}$ forward mode heat fluxes).

38 Forward mode behaviour is determined by working fluid vapour mass flow driven by

39 heat flux and influenced by temperature dependent vapour viscosity. Reverse mode

40 behaviour is determined by vapour convection, plate-to-plate radiation, and

41 envelope/structure conduction. Parametric design influences are theoretically

42 examined and $\varsigma>99 \%$ diodicity relevant to CCBE and ICSSWH applications is

43 demonstrated experimentally. Study findings contribute towards global efforts tackling

44 the climate crisis by enabling commercial R\&D for new Net Zero Energy Building 45 components.

\section{Introduction}

\section{$\begin{array}{lll}47 & 1.1 & \text { Study context }\end{array}$}

48 Approximately one-third of global final energy consumption (125 of 400EJ annually) 49 can be attributed to residential and service sector buildings (IEA, 2018; IEA/UN, 2018) 50 where it is primarily used for space heating \& cooling (40\%) and domestic hot water 51 production (20\%). Buildings are correspondingly responsible for $\sim 39 \%$ of global $\mathrm{CO}_{2}$ 52 emissions which need to be radically and rapidly cut in order to mitigate the climate 53 crisis. Net-Zero Energy Building (NZEB) and Near-Zero Energy Building (nZEB) 
54 concepts aim to reduce $\mathrm{CO}_{2}$ emissions by minimising thermal energy demands through

55 measures such as Climate Control Building Envelopes (CCBE), Building Integrated

56 PhotoVoltaics (BIPV), Building Integrated Solar Thermal Systems (BISTS) and other

57 renewable energy technologies such as heat pumps. We introduce the concept of

58 thermal diodes (Section 1.1) and discuss how they offer significant potential to improve

59 the efficacy of CCBE, BIPV and BISTS components (Sections 1.2 and 1.3). The growing

60 body of literature is briefly reviewed, including work undertaken by Ulster University

61 Centre for Sustainable Technologies regarding Liquid-Vapour Thermal Diodes (LVTD)

62 and their application in Integrated Collector-Storage Solar Water Heaters (ICSSWH).

63 Sections 2 and 3 build directly upon the theoretical and experimental work of Pugsley

64 et al. (2019) by augmenting the proposed model of PLVTD behaviour and providing

65 new validating experimental data for vertically oriented devices. The original work

66 considered a simple PLVTD with a passively wetted evaporator which restricted

67 operation to the horizontal orientation only, whereas the present study examines a

68 pumped falling film evaporator which enables operation in vertical and tilted

69 orientations. Section 4 explores the parametric design of a PLVTD by using the model

70 to examine the influence of temperatures, heat flux, dimensions, orientation and other

71 factors upon its behaviour. Section 5 re-examines experimental data from tests on a

72 large vertical falling film PLVTD incorporated into a flat ICSSWH prototype (Pugsley et

73 al., 2016 \& 2017; Smyth et al., 2019) to provide further validation of the proposed

74 theoretical model and to identify areas for further research.

\section{$\begin{array}{lll}75 & 1.2 & \text { Thermal diodes }\end{array}$}

76 A thermal diode is a unidirectional heat transfer device that operates in a manner

77 analogous to an electrical semiconductor diode by offering low resistance (thermal

78 conductance) in one direction and high resistance (thermal insulation) in the other.

79 Whilst there are many different mechanisms for realising thermal rectification (Go \&

80 Sen, 2010; Roberts \& Walker, 2011; Boreyko \& Chen et al., 2011 \& 2013; Chen et al., 
81 2012; Ben-Abdallah \& Biehs, 2013; Dos Santos Bernardes, 2014; Bairi et al., 2014;

82 Pei et al., 2017; Blet et al., 2017; Avanessian and Hwang, 2018; Traipattanakul et al., 83 2019; Wong et al., 2019) in a variety of different geometric forms and orientations,

84 the present study is concerned with PLVTDs. These devices (see Figures 1 and 2)

85 essentially consist of two parallel plates of area $A=y z$ separated by a cavity of depth $x$

86 which contains a quantity of working fluid maintained in a thermodynamic state close

87 to saturation. During forward mode operation, wetting of the hottest plate (evaporator)

88 through contact with the liquid working fluid generates vapour, which then migrates

89 to the colder plate (condenser) where it releases its latent heat and generates

90 condensate to complete the cycle. During reverse mode operation, the hottest plate is

91 kept dry so that no vapour can be generated, no latent heat transfer occurs, and the

92 partially evacuated cavity acts as an insulator. Forward mode evaporator wetting can

93 be achieved by a variety of active (eg pumped falling film or spray) or passive (eg

94 capillary wick or pockets) techniques. Careful control over plate wetting mechanisms

95 could feasibly enable the operating direction of a thermal diode to be reversed or for

96 forward mode operation to be initiated or supressed on demand, thereby creating

97 components with switchable thermal insulation characteristics.

98

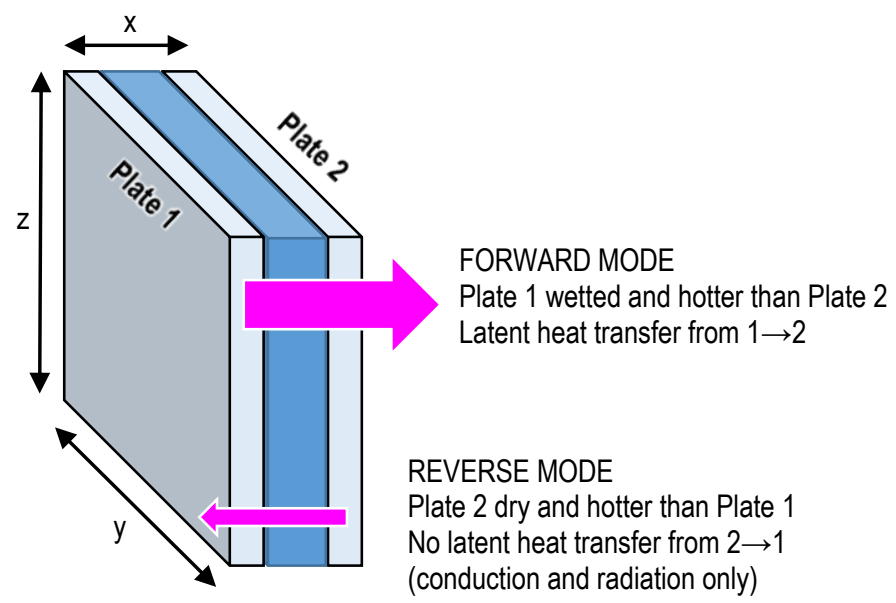



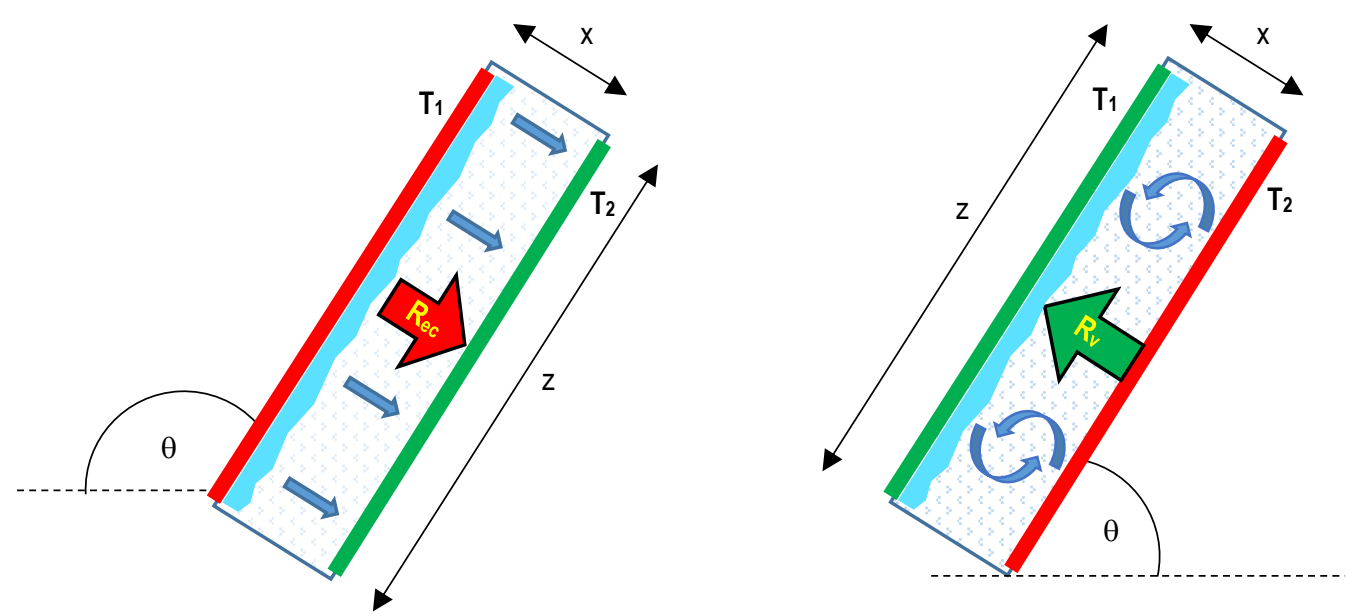

The wetted evaporator plate $\left(T_{1}\right)$ generates vapour during forward mode operation when $T_{1}>T_{2}$ resulting in latent heat being transferred to the condenser plate $\left(T_{2}\right)$ due to the mass flow of vapour induced by the saturation pressure differential. In reverse mode when $T_{2}>T_{1}$ there is no latent heat transfer because the hotter plate is kept dry (no vapour generation) but some degree of sensible heat transfer occurs owing to gaseous conduction and convection through the residual vapour.

The vapour mass transfer $\left(R_{e c}\right)$ and vapour convection $\left(R_{v}\right)$ thermal resistances are dependent upon the height $(z)$ and characteristic dimension $(\mathrm{L} \approx \mathrm{X})$ of the enclosure, the hot plate external tilt angle with respect to horizontal $(\theta)$, and the working fluid thermodynamic properties which are dependent upon plate temperatures $T_{1}$ and $T_{2}$.

Figure 2 - Arrangement and working principles of a PLVTD

\subsection{Climate Control Building Envelopes}

106 Climate Control Building Envelopes (CCBE) can massively reduce space heating \&

107 cooling energy demands and are an essential part of NZEBs (Ascione et al. 2016;

108 Charisi, 2017; Li et al., 2019). In cold climates, a CCBE must be well-insulated to

109 prevent fabric heat losses; use heat recovery ventilation to prevent airflow related heat

110 losses; and should incorporate mechanisms to enable collection of solar and ambient

111 heat. The latter can be achieved through either passive means such as Trombe walls

112 or double-skin facades (Kilaire \& Stacey, 2017; Hu et al., 2017; Yu et al., 2018; Inan

113 \& Basaran, 2019; Agathokleous et al., 2019) or by using active systems such as

114 ground-source, air-source, or solar assisted heat pumps (Good et al., 2015; He et al.,

115 2015; Buonomano et al., 2016; Aguilar et al., 2016; Calise et al., 2016; Poppi et al.,

116 2016; Qu et al., 2016; Kilaire \& Stacey, 2017). In hot climates, a CCBE must 
117 incorporate shading devices to prevent solar heat gains; have appropriate insulation

118 and ventilation which prevents ambient heat gains (eg infiltration of hot outdoor air);

119 and include design features which facilitate free-cooling during night-time periods.

120 Thermal insulation in hot climate CCBEs can be important for preventing unwanted

121 fabric heat gains but conversely acts as "anti-insulation" (Masoso \& Grobler, 2008;

122 Idris \& Mae, 2017) owing to the inherent reduction in potential for passive heat

123 rejection. Climates in many regions of the world are characterised by significant diurnal

124 and seasonal temperature differences which necessitate thermally adaptive CCBEs that

125 combine all the abovementioned features into a multifunctional façade and/or roofing

126 system. In addition to reducing the amount of energy required for space heating and

127 cooling, CCBEs are increasingly being designed with BIPV to generate electricity; BISTS

128 to supply domestic hot water and additional heat for space heating; or Building

129 Integrated PhotoVolatic-Thermal (BIPVT) elements which simultaneously produce both

130 thermal and electrical energy. Thermal diodicity, dynamic insulation, adaptive

131 insulation and switchable insulation concepts (Stazi et al., 2012; Kimber et al., 2014;

132 Berge et al., 2015; Menyhart \& Krarti, 2017; Jin et al. 2017; Koenders et al., 2018;

133 Pflug et al., 2018; Rupp \& Krarti, 2019; Cui \& Overend, 2019) have significant potential

134 to improve the efficacy of CCBEs in respect of their ability to collect solar and ambient

135 heat in cold climates (Figure 3a); reject excess heat in hot climates (Figure 3b); and

136 potentially improve the efficiency of BIPV elements by regulating cell temperatures.

137 The use of thermal diodes in building façade elements has been proposed and

138 investigated by a handful of authors (Kolodziej \& Jaroszynski, 1997; Chen et al., 1998;

139 Varga et al. 2002; Fang \& Xia, 2010; Reay et al., 2014; Villeneuve et al., 2017) but the

140 use of Planar Liquid-Vapour Thermal Diodes (PLVTDs) in CCBEs has yet to be described

141 in detail anywhere in the literature. In Cui \& Overend's (2019) high level study

142 examining possible mechanisms for achieving switchable insulation in thermally

143 adaptive building envelopes they conclude that "Among the five technologies reviewed, 
144 the most thermally efficient one, in terms of switching ratio and the range of

145 controllable heat transfer . . . alternates its heat transfer mechanisms between highly

146 conductive evaporation-condensation circulation to insulated single-phase gaseous

147 conduction" and that "controllable flat-plate heat pipes are a promising direction".

148 These statements align perfectly with the PLVTD concept as described in Section 1.2 149 and provide strong justification for the present study.

\section{I.4 Integrated Collector-Storage Solar Water Heaters}

151 Solar thermal systems offer significant potential to contribute towards meeting both

152 domestic hot water and space heating energy demands. When combined with sufficient

153 energy storage, BISTS have been shown to provide between $10 \%$ and $90 \%$ of

154 residential and commercial building space heating and domestic hot water energy 155 demands in a variety of climates (Smyth et al., 2006; Li et al., 2013; Drosou et al., 156 2014; O'Hegarty et al., 2014; Good et al., 2015; Mehdaoui et al., 2019; Beausoleil-

157 Morrison et al., 2019; Billardo et al., 2019). Solar water heating systems typically have 158 three main components: the collector, the heat transfer system, and the storage 159 vessel. Storage vessels in conventional pumped solar water heating systems tend to 160 be bulky and consume valuable floor space. In hot climates, thermosiphonic solar water 161 heaters with close-coupled storage tanks are popular owing to their passive operation, 162 simple installation, externally located storage tank, and relatively low cost. Integrated 163 Collector-Storage Solar Water Heaters (ICSSWH) are passive systems which combine 164 the collector and storage vessel into one unit by using part of the storage tank envelope 165 as a solar absorber (Smyth et al., 2006; Garnier et al., 2009; Borello et al., 2012; 166 Ziapour et al., 2014; Singh et al., 2016; Billardo et al., 2019). This concept minimises 167 system size and quantity of material required for manufacturing, leading to lower unit 168 costs (Tripanagnostopoulos \& Souliotis, 2006), less embodied energy, and greater 169 space efficiency. The greatest drawback of ICSSWHs and close-coupled thermiosiphon 170 solar water heaters is that a large area of storage vessel surface is inherently exposed 
171 to the outdoor environment and thus susceptible to heat loss in cold and windy

172 climates. Several authors have explored the use of thermal diodes to control heat loss

173 in thermosiphonic solar water heaters. In particular, Mohamad (1997), Faiman et al.

174 (2001) and Sopian et al. (2004) realised thermal diodes by fitting one-way valves which

175 allow water to flow from the hot solar collector outlet to a cooler storage vessel but

176 prevent reverse flow when the collector is cooler than the store. Some authors (Smyth

177 et al., 1999 and Rhee et al., 2010) incorporated thermal diodes in hot water storage

178 vessels to promote stratification and reduce heat loss. A growing body of work on the

179 use of liquid-vapour thermal diodes to reduce heat loss from ICSSWH collectors has

180 developed in recent years (De Beijer, 1998; Quinlan, 2010; Souliotis et al., 2011\&2017;

181 Smyth et al., 2015a\&b, 2017, 2018, 2019; Pugsley et al., 2016 \& 2019; Pugsley, 2017;

182 Muhumuza et al., 2019a \& b). Smyth et al. (2017) designed, fabricated and tested

183 cylindrical ICSSWHs featuring annular thermal diodes which minimised overnight heat

184 loss to $<1 \mathrm{~W} \cdot \mathrm{m}^{-2} \mathrm{~K}^{-1}$. Smyth et al. (2019) demonstrated that an uncovered ICSSWH

185 featuring a vertically oriented PLVTD (see Figure 3c) can achieve a significantly better

186 heat loss coefficient $\left(5.4 \mathrm{~W} \cdot \mathrm{m}^{-2} \mathrm{~K}^{-1}\right)$ during solar collection periods than an equivalent

187 uncovered ICSSWH without a thermal diode $\left(12.9 \mathrm{~W} \cdot \mathrm{m}^{-2} \mathrm{~K}^{-1}\right)$. 


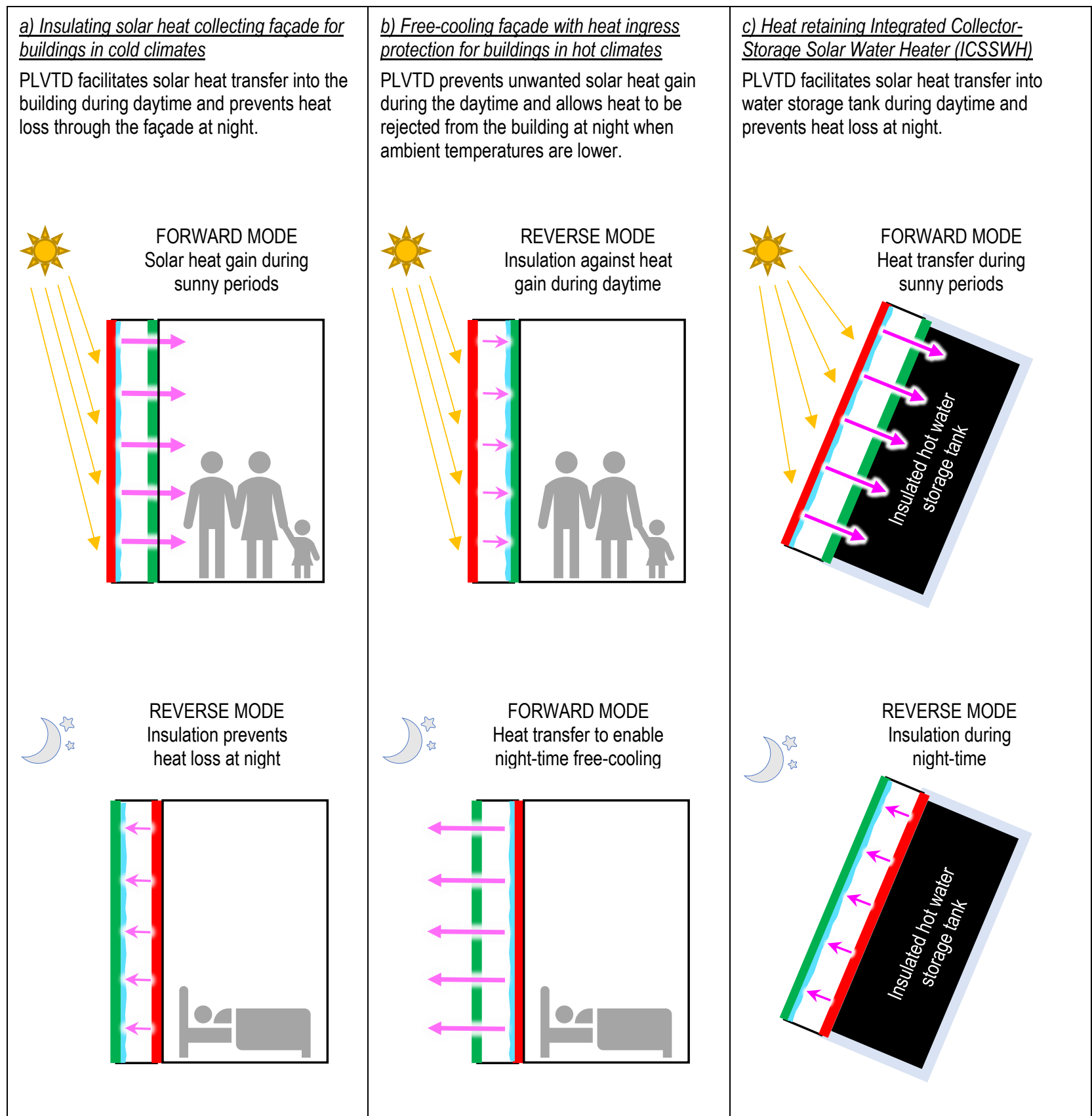

Figure 3 - Practical applications for PLVTDs in Climate Control Building Facades and Integrated Collector-Storage Solar Water Heaters

194 Heat transfer through a PLVTD is driven by the difference in temperature between the

195 two plates $\left(\Delta T_{12}=\left|T_{1}-T_{2}\right|\right)$. The transferred thermal power $\left(q_{12}\right)$, the transferred heat

196 flux $\left(q_{12} / A_{p}\right)$, overall thermal resistance $\left(R_{f r}\right)$, and the overall thermal conductance $\left(U_{\mathrm{fr}}\right)$

197 through the PLVTD are related according to Equation 1 (Pugsley et al., 2019). Figure 4 
198 shows the main heat transfer paths and corresponding thermal resistances through a

199 PLVTD in both forward and reverse modes.

200

$$
U_{f r}=\frac{q_{12}}{y z\left(T_{1}-T_{2}\right)}=\frac{q_{12}}{A_{p} \Delta T_{12}}=\frac{1}{A_{p} R_{f r}}
$$

Equation 1

201 In forward mode, the dominant thermal transmission mechanism is latent heat transfer

202 associated with working fluid liquid-vapour-liquid phase changes and the net transfer

203 of working fluid vapour mass across the cavity between the two plates. In reverse

204 mode, thermal transmission occurs via several different mechanisms including working

205 fluid convection and gaseous conduction; radiation between the plates; and conduction

206 through the external envelope and internal supporting structural elements.

207 In order to transfer heat in forward mode, the working fluid must exist in vapour phase

208 at the evaporator temperature $\left(T_{1}\right)$ and in liquid phase at the condenser temperature

$209\left(\mathrm{~T}_{2}\right)$. If all non-condensable gases are removed, then the resulting pressure inside the

210 PLVTD will be approximately equal to the saturation pressure $\left(P_{L V}\right)$ of the working fluid

211 at the saturation temperature $T_{\text {Lv }}$. This internal pressure will usually be different from

212 the atmospheric pressure outside necessitating internal structures to ensure that the

213 PLVTD envelope can withstand the pressure differential.

\section{$214 \quad 2.2 \quad$ Diodicity}

215 Diodicity coefficient $(\varsigma)$ is a dimensionless measure of thermal rectification and is a

216 useful performance measure for thermal diodes and switchable insulation devices. It

217 is commonly defined according to Equation 2 as a scalar (between zero and unity)

218 based on the performance of the device in forward ( $f$ ) heat transfer mode and reverse

219 ( $r$ ) insulation mode. For convenience, we have chosen to express heat transfer and

220 insulation performances in terms of thermal conductance $\left(U_{f}\right.$ and $\left.U_{r}\right)$ but Equation 2

221 can alternatively be written (Boryeko and Chen, 2013) in terms of thermal conductivity

$222(k=U x)$, thermal power $(q)$, heat flux $(q / A)$, or reciprocal thermal resistance $(1 / R=U / A)$ 
223 where the dimensional quantities $\mathrm{x}$ and $\mathrm{A}$ relate to the cavity depth and surface area

224 of the diode with $A=y z$ applying in the case of a flat plate diode of the form shown in

225 Figure 1. A reasonable target for diodicity of PLVTDs in CCBE applications would be $\varsigma$

$226>97 \%$ based on replicating thermal conductivities of typical building materials such

227 as $\mathrm{k} \approx 0.025 \mathrm{~W} \cdot \mathrm{m}^{-1} \mathrm{~K}^{-1}$ for polyurethane insulation and $\mathrm{k} \approx 1.6 \mathrm{~W} \cdot \mathrm{m}^{-1} \mathrm{~K}^{-1}$ for concrete

228 (Twidell \& Weir, 2006). Applications in solar collectors would ideally require $\varsigma>99 \%$

229 to replicate absorber transparent cover arrangements in ICSSWH devices where the

230 insulation of high quality double glazing is $\mathrm{U} \approx 1.2 \mathrm{~W} \cdot \mathrm{m}^{-2} \mathrm{~K}^{-1}$ and heat transfer across the

231 absorber should be $\mathrm{U}>200 \mathrm{~W} \cdot \mathrm{m}^{-2} \mathrm{~K}^{-1}$ (Dupeyrat et al., 2011, Deng et al., 2019). For

232 reference, Cui and Overend (2019) suggest that switchable insulation devices based on

233 phase change technologies should be capable of achieving Order Of Magnitude (OOM)

234 performance ratios of $10^{2}<0 O M<10^{4}$ which correspond broadly to diodicity of $98.02<$ $235 \varsigma<99.98 \%$.

$$
\boldsymbol{\varsigma}=\frac{\boldsymbol{U}_{\boldsymbol{f}}-\boldsymbol{U}_{\boldsymbol{r}}}{\boldsymbol{U}_{\boldsymbol{f}}+\boldsymbol{U}_{\boldsymbol{r}}} \quad(0 \geq \varsigma \geq 1)
$$

Equation 2

\subsection{Thermal resistance umped parameter model}

239 The thermal resistances associated with working fluid latent heat transport $\left(R_{\mathrm{LvL}}=\mathrm{R}_{\mathrm{e}}\right.$

$240+R_{e c}+R_{c}$ ) are inherently much lower than those associated with sensible heat

241 transport $\left(R_{v}+R_{L}\right.$ when horizontal or $1 /\left[1 / R_{v}+1 / R_{L}\right]$ when vertical $)$. Inspection of the

242 thermal resistance network in Figure 4c suggests that the overall thermal resistance

243 through the PLVTD during forward mode operation $\left(R_{f}\right)$ can be approximated by

244 Equation 3 (Pugsley et al., 2017 and 2019):

$$
R_{f}=1 /\left(\frac{1}{R_{e}+R_{e c}+R_{c}}+\frac{1}{R_{w}}+\frac{1}{R_{S}}+\frac{1}{R_{R}}\right)+2 R_{p}
$$

Equation 3

246 No latent heat transfer occurs in reverse mode because the evaporator plate is dry.

247 The evaporation and condensation resistances therefore tend towards infinity so that 
$2481 /\left(R_{e}+R_{e c}+R_{c}\right) \rightarrow 0$. Inspection of the thermal resistance network in Figure 4c suggests 249 that overall thermal resistance through the PLVTD during reverse mode can be 250 approximated (Pugsley, 2017 ) by Equation $4 \mathrm{a}$ when horizontal $\left(\mathrm{R}_{\mathrm{r}, \mathrm{h}}\right)$ or by Equation $4 \mathrm{~b}$ 251 when vertical $\left(R_{r, v}\right)$ :

252

$$
R_{r, h}=1 /\left(\frac{1}{R_{w}}+\frac{1}{R_{s}}+\frac{1}{R_{R}}+\frac{1}{R_{L, h}+R_{v}}\right)+R_{p e}+R_{p c}
$$

253

$$
R_{r, V}=1 /\left(\frac{1}{R_{w}}+\frac{1}{R_{v}}+\frac{1}{R_{S}}+\frac{1}{R_{R}}+\frac{1}{R_{L, V}}\right)+R_{p e}+R_{p c}
$$

Equation $4 b$ 

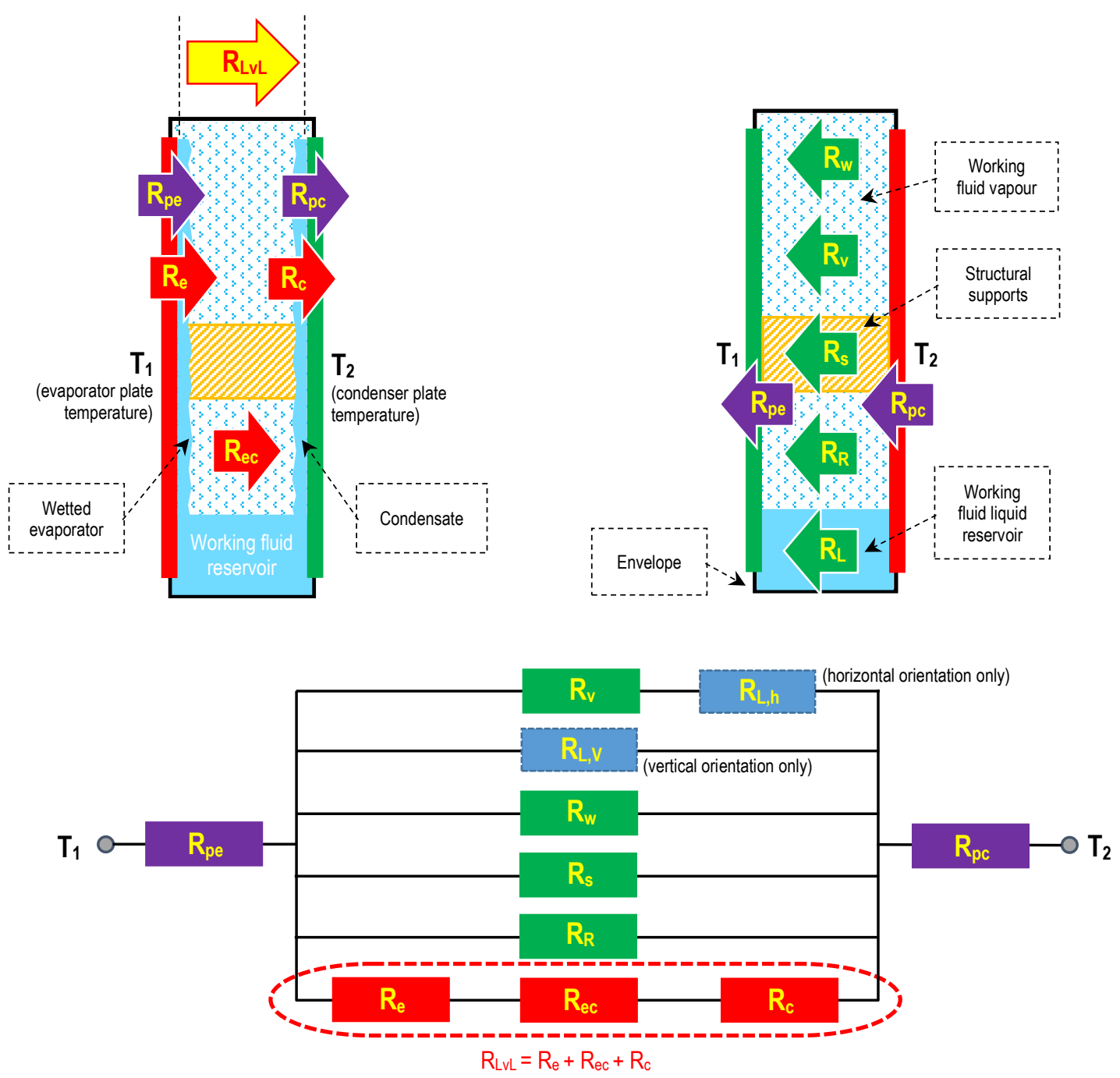

\section{c) Thermal resistance network describing heat transfer behaviour}

\section{Descriptions of thermal resistances used in the model}

$\begin{array}{ll}\mathrm{R}_{\mathrm{pe}} & \begin{array}{l}\text { Conductive thermal resistance through the plate } \\ \text { which acts as the evaporator in forward mode }\end{array} \\ \mathrm{R}_{\mathrm{pc}} & \begin{array}{l}\text { Conductive thermal resistance through the plate } \\ \text { which acts as the condenser in forward mode }\end{array} \\ \mathrm{R}_{\mathrm{e}} \quad \begin{array}{l}\text { Resistance associated with working fluid } \\ \text { evaporation occurring at the evaporator surface }\end{array} \\ \mathrm{R}_{\mathrm{c}} \quad \begin{array}{l}\text { Resistance associated with working fluid } \\ \text { condensation occurring at the condenser surface }\end{array} \\ \mathrm{R}_{\mathrm{ec}} \quad \begin{array}{l}\text { Mass transfer resistance associated with the flow } \\ \text { of vapour from the evaporator to the condenser }\end{array}\end{array}$

$\begin{array}{ll}R_{W} & \begin{array}{l}\text { Conductive thermal resistance through four sidewalls } \\ \text { of the PLVTD envelope }\end{array} \\ R_{S} & \begin{array}{l}\text { Conductive thermal resistance through the structural } \\ \text { members which support the PLVTD envelope }\end{array} \\ R_{V} & \begin{array}{l}\text { Resistance associated with vapour phase natural } \\ \text { convection of the working fluid }\end{array} \\ R_{L} & \quad \begin{array}{l}\text { Resistance associated with Liquid phase natural } \\ \text { convection of the working fluid }\end{array} \\ R_{R} \quad \begin{array}{l}\text { Resistance associated with heat transfer via long wave } \\ \text { electromagnetic radiation between the two plates }\end{array}\end{array}$

$\mathrm{R}_{\mathrm{LvL}} \quad$ Overall Liquid-vapour-Liquid phase change heat transfer resistance 
257 The PLVTD envelope and structure conductive thermal resistances can be evaluated

258 using conventional Fourier methods. Assuming a basic rectangular box form (as per

259 Figure 1) and an internal supporting structure formed of an array of cylindrical struts 260 similar to that used in vacuum glazing panels (Collins and Fischer-Cripps, 1991; Fang 261 et al., 2014) the thermal conductances and corresponding resistances of the 262 evaporator and condenser plates $\left(U_{p e} \approx U_{p c}\right)$, the envelope sidewalls $\left(U_{w}\right)$, and the 263 internal structure $\left(U_{s}\right)$, can be evaluated according to Equations 5 to 9 (Pugsley et al., 2642017 and 2019).

265 The various dimensional terms are defined in full in the Nomenclature section. The 266 symbols $U, R, k, A$ and $d$ refer to thermal conductance, thermal resistance, thermal 267 conductivity, area and distance respectively. The symbols and subscripts $x, y, z$ refer 268 to dimensions in the respective axes defined on Figure 1 . The subscripts $p, w$, and $s$ 269 relate to the plate, wall and struts respectively. The term $\mathrm{N}_{\mathrm{s}}$ refers to the number of 270 struts in the internal supporting structural array where each strut is assumed to be a 271 cylindrical tube with diameter $d_{s}$, wall thickness $d_{s w}$, and length $x$. The term $d_{s s}$

272 describes the centre-to-centre spacing between adjacent struts and terms $d_{s x y}$ and $d_{s x z}$

273 refer to spacings between struts and adjacent sidewalls.

$$
U_{p}=\frac{1}{A_{p} R_{p}}=\frac{k_{p}}{x_{p}}
$$

$$
U_{w}=\frac{1}{A_{p} R_{w}}=\frac{2 z_{w}\left(y+z-2 z_{w}\right) k_{w}}{x y z}
$$

$$
U_{S}=\frac{1}{A_{p} R_{S}}=\frac{N_{S} A_{s} k_{S}}{x y z}
$$

$$
A_{s}=\pi\left(\frac{d_{s}}{2}\right)^{2}-\pi\left(\frac{d_{s}-2 d_{s w}}{2}\right)^{2}
$$

$$
N_{s}=\left(\frac{y-2 d_{s x y}}{d_{s s}}+1\right)\left(\frac{z-2 d_{s x z}}{d_{s s}}+1\right)=\left(\frac{y-x}{d_{s s}}+1\right)\left(\frac{z-x}{d_{s s}}+1\right)
$$


279 Radiative heat transfer resistance between the two parallel plates can be determined 280 using Equation 10 (Twidell \& Weir, 2006) based on the PLVTD absolute operating 281 temperatures in Kelvin degrees $\left(T_{12}=0.5 T_{1}+0.5 T_{2}\right)$, emissivities of the wet or dry plates $282\left(\varepsilon_{1}\right.$ and $\left.\varepsilon_{2}\right)$, the Stefan-Boltzmann constant $\left(\chi=5.67 \times 10^{-8} \mathrm{~W} \cdot \mathrm{m}^{-2} \mathrm{~K}^{-4}\right)$ and the area 283 over which radiative heat exchange occurs $A_{p}$.

$$
R_{R}=\frac{1 / \varepsilon_{1}+1 / \varepsilon_{2}-1}{4 \chi A\left(T_{12}\right)^{3}}
$$

Equation 10

\subsection{Heat transfer via the working fluid}

286 Heat transfer through the PLVTD via the working fluid is dependent upon a number of

287 different mechanisms:

- Working fluid evaporation $\left(R_{e}\right)$ in forward mode.

- Latent heat transfer due to net vapour mass flow between the plates in forward mode $\left(R_{e c}\right)$. Fluid motion is primarily driven by the vapour pressure differential $\left(\Delta \mathrm{P}_{12}\right.$ arising from $\left.\Delta \mathrm{T}_{12}\right)$ and to a lesser extent by corresponding buoyancy forces.

- Working fluid condensation $\left(R_{c}\right)$ in forward mode.

- Sensible heat transfer via buoyancy driven natural convection of the working

296 Working fluid thermal resistances and corresponding conductances can be evaluated 297 from Equation 11 (Cengel \& Boles, 2006) using relevant Nusselt number correlations $298(\mathrm{Nu})$, characteristic dimensions (L) and working fluid thermal conductivities (k).

$$
R=\frac{1}{A_{p} U}=\frac{L}{A_{p} k \cdot N u}
$$

300 The evaporation thermal resistance $\left(R_{e}\right)$ can be evaluated using the composite 301 evaporation Nusselt number described by Equation 12 which accounts for conduction $302\left(\mathrm{Nu}_{\mathrm{dL}}\right)$ across the liquid layer thickness $\left(\mathrm{d}_{\mathrm{Le}}\right)$; natural convection $\left(\mathrm{NU}_{\mathrm{Ra}}\right)$ within the liquid 
303 layer; forced convection ( $\left.\mathrm{Nu}_{\mathrm{Re}}\right)$ in cases where the liquid is flowing; and nucleate boiling

$304\left(\mathrm{Nu}_{\mathrm{Nu}}\right)$ if the evaporator is significantly hotter than the liquid. Equation 12 combines

305 the natural and forced convection Nusselt numbers using the method offered by Cengel

$306 \&$ Boles (2006). Whilst thermal conductance through the liquid layer can simply be

307 calculated by dividing its thermal conductivity $\left(\mathrm{k}_{\mathrm{L}}\right)$ by its thickness ( $\left.\mathrm{d}_{\mathrm{Le}}\right)$, it is 308 mathematically convenient to express this quantity in the form of a Nusselt number $309\left(\mathrm{Nu}_{\mathrm{dLe}}\right)$ which has the same characteristic dimension as that used for the convection 310 and nucleate boiling Nusselt numbers ( $\mathrm{Nu}_{\mathrm{Ra}}, \mathrm{Nu}_{\mathrm{Re}}$ and $\left.\mathrm{Nu} \mathrm{Nu}_{\mathrm{Nu}}\right)$. Suitable Nusselt number 311 correlations are given in Table 1 (Equations 15a-i based on expressions offered by 312 Cengel \& Boles, 2006) which are dependent upon the Rayleigh number (Ra), Reynolds 313 number $(\mathrm{Re})$, Prandtl number $(\operatorname{Pr})$, hot plate tilt angle relative to horizontal $(\theta)$, and 314 the plate dimensions ( $y$ and $z$ ). Rayleigh number quantifies the magnitude of natural 315 convection resulting from buoyancy and frictional effects within the liquid layer in 316 contact with the evaporator plate and is calculated in the conventional way using 317 Equation 13 based on gravitational acceleration $\left(\mathrm{g}=9.81 \mathrm{~m} / \mathrm{s}^{2}\right.$ at sea level) and the 318 plate-to-liquid temperature difference $\left(\Delta T_{L 1}=T_{1}-T_{L 1}\right)$. Reynolds number quantifies the 319 magnitude of forced convection and is calculated using Equation 14 (after Zhou et al., $3202009)$ based on the liquid film mass flow rate $\left(M_{L}\right)$ which spreads across the evaporator 321 plate width $(y)$. All thermodynamic properties $(k, v, \operatorname{Pr}, \beta, \rho)$ of evaporating working 322 fluid involved in evaluation of $R_{e}$ relate to liquid state at temperature $T_{L 1}$, the value of 323 which can be evaluated according to the iterative procedure proposed in Section 2.6.

324 In vertical and tilted PLVTDs featuring flowing film evaporators, the liquid layer 325 thickness ( $d_{\text {Le }}$ according to Equation $15 \mathrm{~h}$ ) is largely dependent upon the same 326 parameters as the Reynolds number but is additionally affected by gravity. In 327 horizontal PLVTDs where the evaporator is covered by a non-flowing pool of liquid, the 328 liquid layer thickness ( $\mathrm{d}_{\mathrm{Le}}$ according to Equation $15 \mathrm{i}$ ) is primarily determined by the 329 mass of working fluid $\left(\mathrm{m}_{\mathrm{L}}\right)$ and the evaporator plate area $(\mathrm{yz})$ but also by the PLVTD 
330 volume (xyz) and the relative densities of working fluid in both liquid $\left(\rho_{L}\right)$ and vapour

$331\left(\rho_{v}\right)$ states. Given the low heat fluxes (typically $q / A<1000 \mathrm{~W} \cdot \mathrm{m}^{-2}$ ) associated with

332 PLVTDs used for CCBE and ICSSWH applications the temperature difference between

333 the evaporator plate surface and the liquid working fluid is usually too low $\left(T_{1}-T_{L} \leq 5^{\circ} \mathrm{C}\right)$

334 for nucleate boiling to occur which means that free-surface evaporation mechanisms

335 typically prevail and $\mathrm{Nu}_{\mathrm{Nu}}$ can usually be ignored. A correlation for $\mathrm{Nu} \mathrm{Nu}_{\mathrm{Nu}}$ is however 336 provided in Equation 19j (Table 3) for completeness.

$$
N u_{e}=\left(N u_{d L}{ }^{3}+N u_{R a^{3}}+N u_{R e^{3}}+N u_{N u^{3}}\right)^{1 / 3}
$$

The vapour mass transfer thermal resistance $\left(R_{e c}\right)$ can be evaluated using the Nusselt

341 number correlations given in Table 2 (Equations 15j-q) which describe fluid convection

342 in rectangular enclosures of the form illustrated in Figure 2 (dimensions $x, y, z$ and tilt

343 angle $\theta$ ). These correlations are conventionally used in sensible heat transfer scenarios

344 where the thermal conductivity $(k)$ is a temperature dependent property of the working

345 fluid in a fully saturated liquid or vapour state and gravity $(\mathrm{g}$ ) is the driving force

346 determining the natural convection Rayleigh number ( $R a)$. However, given that $R_{e c}$ is

347 associated with a liquid-vapour-liquid phase change, modified definitions of Rayleigh

348 number $\left(\mathrm{Ra}^{*}\right)$ and thermal conductivity $\left(\mathrm{k}^{*}\right)$ are required. The familiar forcing term

349 (g) typically used for determining Ra (Equation 13) is supplemented when calculating

350 Ra* (Equation 16) by an additional forcing term ( $P_{L v} / \rho L$ ) which accounts for the

351 dominant effect of the vapour pressure differential $\Delta P_{12}=\left|P_{1}-P_{2}\right|$ associated with the

352 plate-to-plate temperature difference. Equation 17 reflects the fact that the effective

353 thermal conductivity $\left(\mathrm{k}^{*}\right)$ of the vapour flowing during forward mode operation of the

354 PLVTD has both sensible and latent components. 
Table 1 - Nusselt number correlations for natural and forced convection of fluid heated by plates

\begin{tabular}{|c|c|}
\hline Geometry and convection type & Nusselt number (Nu) correlation and characteristic dimension (L) \\
\hline \multirow{3}{*}{$\begin{array}{l}\text { Natural convection heating of fluid above a horizontal } \\
\text { plate (or cooling of fluid below a horizontal plate) }\end{array}$} & Equation 15a $\quad N u_{R a}=0.54 R a^{0.25}$ \\
\hline & $\begin{array}{ll}\text { Where: } & 10^{4} \leq R a<10^{7} \\
\text { and: } & L=\frac{y z}{2(y+z)}\end{array}$ \\
\hline & $\begin{array}{l}\text { Equation 15b } \quad N u_{R a}=0.15 R a^{1 / 3} \\
\text { Where: } 10^{7} \leq R a \leq 10^{11} \\
\text { and: } \quad L=\frac{y z}{2(y+z)}\end{array}$ \\
\hline $\begin{array}{l}\text { Natural convection cooling of fluid above a horizontal } \\
\text { plate (or heating of fluid below a horizontal plate) }\end{array}$ & $\begin{array}{l}\text { Equation 15c } \quad N u_{R a}=0.27 R a^{0.25} \\
\text { Where: } 10^{5} \leq R a<10^{11} \\
\text { and: } \quad L=\frac{y z}{2(y+z)}\end{array}$ \\
\hline $\begin{array}{l}\text { Natural convection heating or cooling } \\
\text { of fluid adjacent to a vertical plate } \\
\text { or above a tilted plate }\end{array}$ & $\begin{array}{l}\text { Equation 15d } \\
\qquad N u_{R a}=\left[0.825+\frac{0.387 R a^{0.167}}{\left[1+\left(0.492 /{ }_{P r}\right)^{0.563}\right]^{0.296}}\right]^{2} \\
\text { Where: } \quad L=z\end{array}$ \\
\hline \multirow[t]{2}{*}{$\begin{array}{l}\text { Forced convection heating } \\
\text { of fluid flowing over a tilted } \\
\text { or vertical plate }\end{array}$} & $\begin{array}{l}\text { Equation 15e } \\
\qquad N u_{R e}=0.644 \operatorname{Re}^{0.5} \operatorname{Pr}^{1 / 3} \\
\text { Where: } R e<5 \times 10^{5} \\
\text { and: } \quad L=z\end{array}$ \\
\hline & $\begin{array}{l}\text { Equation } 15 f \\
\qquad N u_{R e}=\left(0.037 \operatorname{Re}^{0.8}-871\right) \operatorname{Pr}^{1 / 3} \\
\text { Where: } 5 \times 10^{5} \leq R e \leq 10^{7} \\
\text { and: } \quad 0.6 \leq \operatorname{Pr} \leq 60 \\
\text { and: } \quad L=z\end{array}$ \\
\hline Pure conduction through a layer of stagnant fluid & $\begin{array}{l}\text { Equation 15g } \\
\qquad N u_{d L}=\frac{L}{d_{L}}\end{array}$ \\
\hline $\begin{array}{l}\text { Thickness of the liquid layer in cases where the plate is } \\
\text { covered by a flowing film }\end{array}$ & $\begin{array}{l}\text { Equation 15h } \\
\qquad d_{L}=\left(\frac{3 v_{L} M_{L}}{y \rho_{L} g \sin (\theta)}\right)^{1 / 3}\end{array}$ \\
\hline $\begin{array}{l}\text { Total thickness of the liquid layer(s) in an enclosure filled } \\
\text { with working fluid existing in two phase states }\end{array}$ & $\begin{array}{l}\text { Equation 15i } \\
\qquad d_{L}=\frac{m_{L v}-x y z \rho_{v}}{y z \rho_{L}}\end{array}$ \\
\hline $\begin{array}{l}\text { Notes } \\
\text { - Nucleate boiling correlation ( } \mathrm{NuNu} \text { ) is given in T } \\
\text { number (Ra) should be replaced by g.cos( } 90 \text { - } € \\
\text { - Equations } 15 \mathrm{a}-\mathrm{f} \text { are based on those offered by } \\
\text { al. (2003), Zhou et al. (2009) and Pugsley ( } 201 \\
\text { - Flowing film liquid layer thickness estimates ma } \\
\text { Equations } 15 \mathrm{f} \text { and } 15 \mathrm{~h} \text { which are intended to b }\end{array}$ & $\begin{array}{l}\text { le } 3 \text { and is only relevant when evaporator plate is }>5^{\circ} \mathrm{C} \text { hotter than the liquid. } \\
\text { izontal (see Figure 2) then gravity term ( } \mathrm{g} \text { ) used for determination of Rayleigh } \\
\text { as suggested by Cengel \& Boles ( } 2006 \text { ). } \\
\text { engel \& Boles (2006) whereas Equations } 15 \mathrm{~g} \text {-i are based on work by Zaitsev et } \\
\text { become unreliable for plate tilt angles outside the range of known validity of } \\
\text { used for cases where } 90^{\circ} \leq \theta \leq 175^{\circ}\end{array}$ \\
\hline
\end{tabular}


Table 2 - Nusselt number correlations for fluid filled rectangular enclosures

\begin{tabular}{|c|c|c|}
\hline Orientation & Nusselt number correlation & Limits \\
\hline $\begin{array}{l}\text { Horizontal with } \\
\text { cold plate at top } \\
(\theta=0)\end{array}$ & $N u_{\theta=0}=1+1.44\left[1-\frac{1708}{R a}\right]^{+}+\left[\frac{R a^{1 / 3}}{18}-1\right]^{+}$ & $\begin{array}{r}0.1<P r<10 \\
R a<10^{8}\end{array}$ \\
\hline $\begin{array}{l}\text { Tilted with cold } \\
\text { plate at top } \\
\left(0<\theta<90^{\circ}\right)\end{array}$ & $N u=1+1.44\left[1-\frac{1708}{R a \cdot \cos (\theta)}\right]^{+}\left(1-\frac{1708[\sin (1.8 \theta)]^{1.6}}{R a \cdot \cos (\theta)}\right)+\left[\frac{[R a \cdot \cos (\theta)]^{1 / 3}}{18}-1\right.$ & $\begin{array}{r}z / x \geq 12 \\
R a<10^{5} \\
\theta<70\end{array}$ \\
\hline & $N u=N u_{\theta=0}\left(\frac{N u_{\theta=90}}{N u_{\theta=0}}\right)^{\left(\frac{\theta}{\theta_{c r}}\right)}\left[\sin \left(\theta_{c r}\right)\right]^{\left(\frac{\theta}{4 \theta_{c r}}\right)}$ & $\begin{array}{r}z / x<12 \\
R a<10^{5} \\
0<\theta<\theta_{c r}\end{array}$ \\
\hline & $N u=N u_{\theta=90}[\sin (\theta)]^{0.25}$ & $\begin{aligned} z / x & <14 \\
\theta_{c r} & <\theta<90\end{aligned}$ \\
\hline \multirow{6}{*}{ Vertical $(\theta=90)$} & $N u_{\theta=90}=0.18\left(\frac{P r}{0.2+P r} R a\right)^{0.29}$ & $\begin{array}{r}1<z / x<2 \\
\operatorname{RaPr} /(0.2+\operatorname{Pr})>10^{3}\end{array}$ \\
\hline & $N u_{\theta=90}=0.22\left(\frac{P r}{0.2+P r} R a\right)^{0.28}\left(\frac{z}{x}\right)^{-0.25}$ & $\begin{array}{r}2<z / x<10 \\
R a<10^{10}\end{array}$ \\
\hline & $N u_{\theta=90}=0.42 R a^{0.25} \operatorname{Pr}^{0.012}\left(\frac{Z}{x}\right)^{-0.3}$ & $\begin{aligned} & 10<z / x<40 \\
& 1<\operatorname{Pr}<20 \mathrm{k} \\
& 10^{4}<R a<10^{7}\end{aligned}$ \\
\hline & $N u_{\theta=90}=0.46 R a^{1 / 3}$ & $\begin{array}{r}1<z / x<40 \\
1<\operatorname{Pr}<20 \\
10^{6}<R a<10^{9}\end{array}$ \\
\hline & $N u_{\theta=90}=\frac{\left[\left[\left(\frac{R a_{\text {trans }}}{R a}\right) 0.42 R a^{0.25} P r^{0.012}\left(\frac{Z}{x}\right)^{-0.3}\right]^{3}+\left[\left(\frac{R a}{R a_{\text {trans }}}\right) 0.46 R a^{1 / 3}\right]^{3}\right]^{\frac{1}{3}}}{\frac{R a_{\text {trans }}}{R a}+\frac{R a}{R a_{\text {trans }}}}$ & $\begin{array}{r}1<z / x<40 \\
1<\operatorname{Pr}<20 \\
10^{5}<R a<10^{8}\end{array}$ \\
\hline & $N u_{\theta=90}=0.171 R a^{0.265}\left(\frac{z}{x}\right)^{-0.205}$ & $\begin{array}{r}4<z / x<200 \\
10^{2}<R a<10^{5}\end{array}$ \\
\hline $\begin{array}{l}\text { Tilted with cold } \\
\text { plate at bottom } \\
\left(90<\theta<180^{\circ}\right)\end{array}$ & $N u=1+\left(N u_{\theta=90}-1\right) \sin (\theta)$ & $90<\theta<180$ \\
\hline $\begin{array}{l}\text { Horizontal with } \\
\text { cold plate at } \\
\text { bottom }(\theta=180)\end{array}$ & (Equation 15u) & $\begin{array}{r}\text { No } \\
\text { limits }\end{array}$ \\
\hline \multicolumn{3}{|c|}{ e limits of validity for Equations $15 p$ and $15 q$, a suitable value for the transition Rayleigh number is Ratrans $=5 \times 10^{6}$} \\
\hline
\end{tabular}


358 The latent component $\left(\mathrm{k}_{\mathrm{LV}}\right)$ is determined using Equation 18 based upon the latent

359 heat of phase change $\left(\mathrm{h}_{\mathrm{LV}}\right)$, thermal diffusivity $(\vartheta)$, working fluid molar mass $(\mathcal{M})$, and 360 universal gas constant $(\mathcal{R})$. Equations 16 to 18 are based upon expressions proposed 361 by Pugsley (2017) drawing upon the work of Stein et al. (1985) and Peterson (1996)

362 and can be used in cases where all non-condensable gases have been removed from 363 the PLVTD cavity to enable the working fluid to exist in a mixed phase state close to 364 the saturation pressure $\left(P_{L V}\right)$ corresponding to the saturation temperature $\left(T_{L V}\right)$ which 365 can be evaluated using the iterative procedure proposed in Section 2.6. All working 366 fluid thermodynamic properties $(\mathrm{k}, \mathrm{v}, \operatorname{Pr}, \vartheta, \beta, \rho)$ relate to vapour state at temperatures 367 close to $T_{L v}$. An alternative set of equations enabling evaluation of $R_{e c}$ in cases where non-condensable gases are present is given in Appendix 1.

$$
R a^{*}=\frac{\left[\frac{P L v}{\rho \cdot L}+g\right] \beta \cdot \Delta T_{12} \cdot L^{3}}{v^{2}} \operatorname{Pr}
$$

$$
k^{*}=k_{v}+k_{L v}
$$

Equation 17

$$
k_{L v}=\frac{h_{L v}{ }^{2} \cdot P_{L v} \cdot \mathcal{M}^{2} \cdot \vartheta}{\mathcal{R}^{2} \cdot T_{12}{ }^{3}}
$$

372 The condensation thermal conductance $\left(U_{c}\right)$, corresponding thermal resistance $\left(R_{c}\right)$ and 373 associated condensate film thickness $\left(d_{L c}\right)$ for PLVTDs oriented in a variety of tilt angles 374 can be evaluated using the expressions given in Table 3 (Equations 19a-i).

375 Condensation occurring on the surface of a flat plate will create a downward flowing 376 film of condensate. Equations describing condensate flows across vertical and tilted 377 plates are based on expressions given by Cengel \& Boles (2006) whereas equations 378 relevant to droplet flows from downwards-facing horizontal surfaces are based on 379 expressions given by Stein et al. (1985) and Gerstmann \& Griffith (1967). Key 380 parameters include the saturated fluid-to-plate temperature difference $\left(T_{L v}-T_{2}\right)$, 381 gravitational acceleration $(\mathrm{g})$, plate tilt angle $(\theta)$, plate height dimension $(\mathrm{z})$, 382 condensate film Rayleigh and Reynolds numbers ( $R a_{c}$ and $R_{c}$ ), and various 
383 temperature dependent working fluid thermodynamic properties including latent heat

384 of evaporation ( $\left.h_{\llcorner V}\right)$ and saturated vapour pressure $\left(P_{L V}\right)$. The difference in the liquid 385 and vapour densities ( $\rho\left\llcorner\right.$ and $\rho_{v}$ ) plays an important role in these expressions alongside 386 the liquid kinematic viscosity $\left(V_{L}\right)$, dynamic viscosity $(\mu \mathrm{L})$, surface tension $\left(\sigma_{\mathrm{L}}\right)$, thermal 387 conductivity $\left(\mathrm{k}_{\mathrm{L}}\right)$, specific heat capacity $\left(\mathrm{C}_{\mathrm{pL}}\right)$ and Prandtl number ( $\left.\operatorname{Pr} \mathrm{L}\right)$. Liquid 388 thermodynamic properties (subscript " $L$ ") are evaluated at the condensate film 389 temperature $T_{L 2}$. Vapour thermodynamic properties (subscript " $\mathrm{V}^{\prime \prime}$ ) and saturation 390 condition thermodynamic properties (subscript "Lv") are evaluated at estimated 391 saturation temperature $\left(T_{L V}\right)$. Section 2.6 describes methods for evaluating the fluid 392 temperatures $T_{L 1}, T_{L v}$ and $T_{L 2}$. 


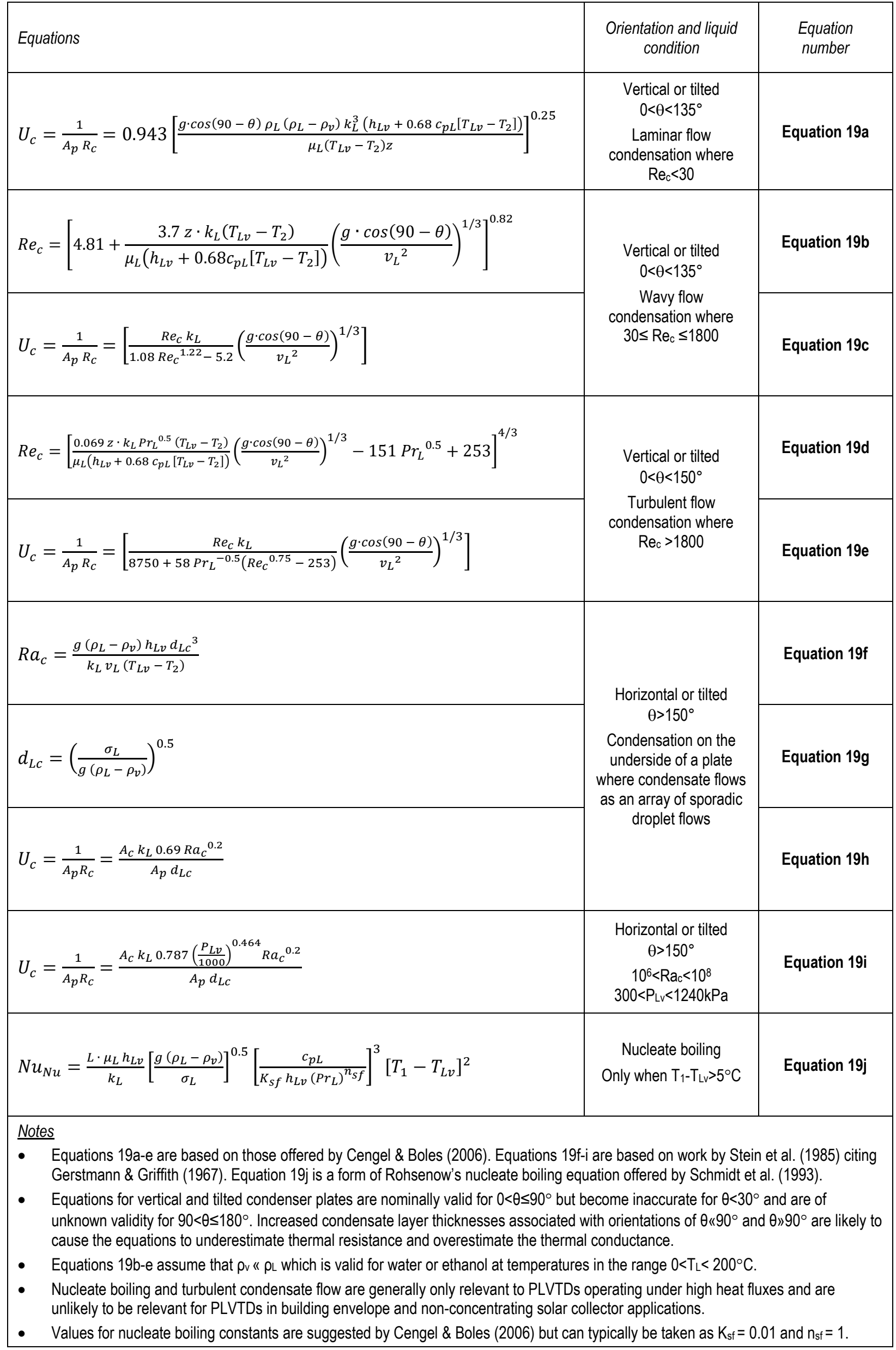


394 The liquid and vapour thermal resistances $R_{L, h}, R_{L, V}$ and $R_{v}$ which describe heat transfer

395 through the working fluid in reverse mode are evaluated using the general form of

396 Equations 11 and 13 together with the Nusselt number correlations given in Tables 1

397 and 2. The aim is for these resistances to be as large as possible to avoid unwanted

398 heat transfer in reverse mode when the PLVTD is intended to operate as an insulator.

399 In a horizontal PLVTD the liquid thermal resistance $\left(R_{L, h}\right)$ is usually insignificant

400 because it acts in series with a much larger vapour thermal resistance $\left(R_{v}\right)$ and can

401 usually be ignored. In a vertical or tilted PLVTD it is preferable for $R_{L, V}$ to be made

402 insignificant by locating the working fluid reservoir completely outside of the PLVTD

403 (as per Pugsley, 2017 and the device discussed in Section 3 of this study) or by adding

404 a suitable thermal break to separate the working fluid reservoir from the condenser 405 plate (as per Pugsley et al., 2017 and the device discussed in Section 5 of this study).

\section{$406 \quad 2.6 \quad$ Determination of working fluid temperatures}

407 Convection and radiation within the PLVTD are driven by the overall temperature 408 differential $\left(\Delta \mathrm{T}_{12}\right)$. Evaluation of Equations 10 to 19 requires knowledge of the absolute 409 and relative temperatures of the evaporator surface $\left(T_{1}\right)$, condenser surface $\left(T_{2}\right)$, liquid 410 in the working fluid reservoir $\left(T_{L}\right)$, evaporating liquid $\left(T_{L 1}\right)$, condensate $\left(T_{L 2}\right)$, and 411 saturated vapour $\left(T_{L V}\right)$. The proposed one-dimensional model (refer to Figure 4)

412 essentially assumes that these temperatures form a gradient $\mathrm{T}(\mathrm{d})$ across the depth of 413 the PLVTD $(0<d<x)$. The form of this temperature gradient is determined by the 414 relative magnitudes of the thermal resistances $\left(R_{e}, R_{e c}, R_{c}, R_{w}, R_{s}, R_{R}, R_{p}, R_{L}\right.$ and $\left.R_{v}\right)$ 415 which are in turn dependent upon the various properties of the working fluid ( $c_{p}, h_{L v}$, $416 \mathrm{k}_{1} \mathrm{~m}_{\mathrm{Lv}}, \mathrm{M}_{\mathrm{L}}, \mathrm{P}_{\mathrm{Lv}}, \operatorname{Pr}, \mathrm{v}, \vartheta, \mathcal{M}, \beta, \rho, \mu$, and $\sigma$ in liquid, gaseous and saturated states); 417 plate surfaces and orientation ( $\mathrm{x}_{\mathrm{p}}, \mathrm{y}, \mathrm{z}, \theta, \mathrm{g}, \mathrm{k}_{\mathrm{p}}, \varepsilon_{1}, \varepsilon_{2}, \mathrm{n}_{\mathrm{sf}}$ and $\left.\mathrm{K}_{\mathrm{sf}}\right)$; and materials 418 forming the envelope and structure $\left(x, z_{w}, k_{w}, k_{s}, N_{s}\right.$ and $\left.A_{s}\right)$. The temperature gradient 419 can be expressed using Equation 20a in cases where $T_{1}$ and $T_{2}$ are both known, or 
420 using Equation $20 \mathrm{~b}$ in cases where the heat flux $\left(q_{12} / A\right)$ and either of the driving

421 temperatures is known ( $T_{1}$ is often unknown in CCBE, BIPV and BISTS applications).

$T(d)=T_{1}, T_{2}, d ;\left\{\begin{array}{c}c_{p, L}, c_{p, v}, h_{L v}, k_{L}, k_{v}, m_{L v}, M_{L}, P_{L v}, P r_{L}, P r_{v}, v_{L}, v_{v}, \vartheta_{v}, \mathcal{M}, \beta_{L}, \beta_{v}, \rho_{L}, \rho_{v}, \mu_{L}, \sigma_{L} \\ x_{p}, y, z, \theta, g, k_{p}, \varepsilon_{1}, \varepsilon_{2}, n_{s f}, k_{S f} \\ x, z_{w}, k_{w}, k_{S}, N_{S}, A_{S}\end{array}\right\}$ Eq. 20a

$423 T(d)=q_{12}, T_{2}, d ;\left\{\begin{array}{c}c_{p, L}, c_{p, v}, h_{L v}, k_{L}, k_{v}, m_{L v}, M_{L}, P_{L v}, P r_{L}, P r_{v}, v_{L}, v_{v}, \vartheta_{v}, \mathcal{M}, \beta_{L}, \beta_{v}, \rho_{L}, \rho_{v}, \mu_{L}, \sigma_{L} \\ x_{p}, y, z, \theta, g, k_{p}, \varepsilon_{1}, \varepsilon_{2}, n_{s f}, k_{s f} \\ x, z_{w}, k_{w}, k_{S}, N_{S}, A_{S}\end{array}\right\}$ Eq. 20b

424 During steady state forward mode operation, the temperature gradient is likely to be 425 ordered such that $T_{1}>T_{L 1}>T_{L} \approx T_{L V}>T_{L 2}>T_{2}$ and in reverse mode it will be ordered as $426 \mathrm{~T}_{1}<\mathrm{T}_{\mathrm{L} 1}<\mathrm{T}_{\mathrm{L}}<\mathrm{T}_{\mathrm{LV}}<\mathrm{T}_{2}$. Coarse fluid temperature estimates can be made by interpolating 427 between plate temperatures such that $T_{L}=T_{L V}=T_{12}=\left(T_{1}+T_{2}\right) / 2$ and $T_{L 1}=\left(T_{1}+T_{L}\right) / 2$ and $428 T_{L 2}=\left(T_{2}+T_{L}\right) / 2$. Whilst reasonably robust in cases where $\Delta T_{12}$ is small, these 429 interpolative fluid temperature estimates could generate significant errors in $R_{e}$ and $R_{c}$ 430 under high heat flux scenarios when $\Delta T_{12}$ is large. A more detailed estimate of forward 431 mode $T_{L v}$ can be made by considering the balance of energy and working fluid mass 432 flows within the PLVTD as illustrated on Figure 5 and described by Equation 21 433 (proposed by Pugsley, 2017) assuming that thermal power flow $\left(q_{12}\right)$ is conserved such 434 that the input thermal power ( $q_{e}$ causing evaporation) is the same as the thermal 435 output power ( $q_{c}$ released by condensation). Given that $q_{e}$ is transferred through $U_{e}$ 436 across $T_{1}-T_{L v}$ for nucleate boiling and across $T_{1}-T_{L 1}$ for free-surface evaporation, and 437 that $q_{c}$ is transferred through $U_{c}$ across $T_{L v}-T_{2}$ during condensation (as described by 438 Equations 3, 11, 12, 15 and 19) it follows that $T_{L v}$ can be determined by iteration to 439 satisfy Equation 22 (proposed by Pugsley, 2017). Ignoring minor differences in $c_{p, L}$ of 440 working fluid flows, the steady state liquid temperature $\left(T_{L}\right)$ can be evaluated using 441 Equation 23 (from Pugsley, 2017) and the iterative routine described on Figure 6. 
$443\left[\left(\frac{k_{L} N u_{N u}}{L}\left(T_{1}-T_{L v}\right)\right)^{3}+\left(\frac{k_{L} N u_{d L e}}{L}\left(T_{1}-T_{L}\right)\right)^{3}+\left(\frac{k_{L} N u_{R a}}{L}\left(T_{1}-T_{L}\right)\right)^{3}+\left(\frac{k_{L} N u_{R e}}{L}\left(T_{1}-T_{L}\right)\right)^{3}\right]^{\frac{1}{3}}=U_{c}\left(T_{L v}-T_{2}\right) \quad$ Equation 22

$444 \quad T_{L}=\frac{T_{L 1} M_{L e S}+T_{L 2} M_{L c S}}{M_{L e S}+M_{L c S}}=\frac{T_{L 1}\left(M_{L S e}-\left[\frac{q_{e}}{h_{L v}}\right]\right)+T_{L 2}\left[\frac{q_{c}}{h_{L v}}\right]}{M_{L S e}}$

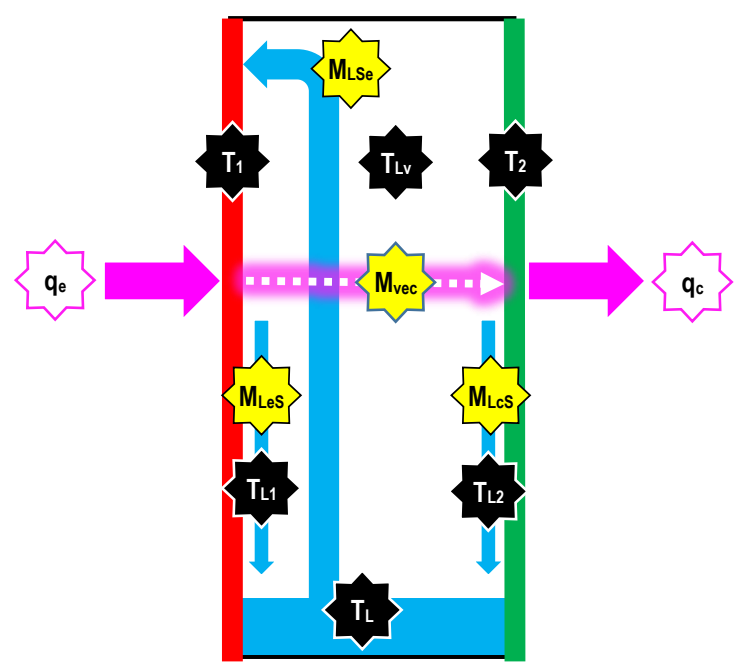

Figure 5 - Working fluid temperatures, mass flows and energy flows

START

Set initial estimate values for $T_{L v}$ and

$T_{L}$ by interpolating $T_{1}$ and $T_{2}$

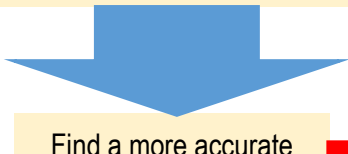

estimate of $T_{L v}$ by

iteration in the bounds

$T_{1}<T_{L v}<T_{2}$ in order to

satisfy Equation 20

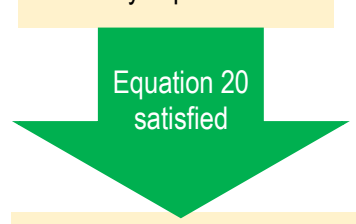

Evaluate new value for $T_{L}$ calculated according to either:

- $T_{L}=\left(T_{1}+T_{L V}\right) / 2$ if the PLVTD has is Horizontal, or

- Equation 22 if the PLVTD is Vertical or Tilted

Current $T_{L}$

notequal

to last

estimate

Repeat until

"FINISH"

(convergence)

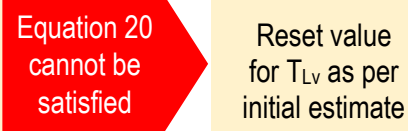

inial estimate

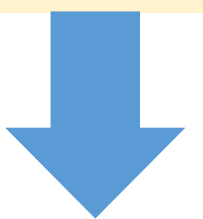




\section{$452 \quad 3.1 \quad$ Methodology and apparatus}

453 Experimental validation of the model for the case of a horizontal PLVTD was presented 454 by Pugsley et al. (2019) using specially designed apparatus consisting of two parallel 455 isothermal plates $\left(A_{p}=0.15 m^{2}\right)$ with integral serpentine heat exchangers and external 456 insulation. A hermetically sealed PLVTD cavity of variable depth was formed between

457 the plates by inserting a sidewall spacer frame. Temperature difference between the 458 plates was controlled by connecting each heat exchanger to a separate heating-cooling 459 fluid circuit. Fluid flow and return temperatures were measured along with flow rates 460 to enable determination of the delivered thermal power. Small amounts of heat loss 461 from the PLVTD were quantified and corrected for by considering the difference in 462 thermal power supplied to the heating plate and that recovered by the cooling plate. 463 Plate and ambient temperatures were also measured to enable determination of 464 forward and reverse mode thermal conductances as well as heat loss coefficients under 465 various temperature difference and heat flux operating scenarios. Experiments 466 featured in the present study were undertaken using a modified version (see Figure 7) 467 of the apparatus which enabled the PLVTD to operate in a vertical orientation. This was 468 facilitated by the addition of a falling-film evaporator wetting mechanism which 469 consisted of linear nozzle fed with working fluid pumped from an external reservoir. 470 The general arrangement of the apparatus, instrumentation and the experimental 471 methodology was similar to that described by Pugsley et al. (2017 and 2019). Non472 condensable gases were removed from the PLVTD cavity using a vacuum pump before 473 and after injection of the working fluid (deionised water). A brief summary description 474 of the modified PLVTD and instrumentation is given below and in Table 4: 
conductivity enabling heat spreading to achieve broadly isothermal phase change heat transfer surfaces. Uniform heat addition/removal was achieved via serpentine flows of hot and cold water pumped through specially arranged parallel flow channels milled into the rear surface of each $12 \mathrm{~mm}$ plate. The front surface of each plate featured a channel for an O-ring seal that formed the hermetic enclosure of the PLVTD. The evaporator and condenser plate area and thickness was selected so as to withstand implosion forces associated with vacuum pressures inside the PLVTD.

- Cavity sidewall spacer frames: These were detachable and reconfigurable to facilitate investigation of different cavity depths. The results presented here relate to tests undertaken with a $x_{w}=22 \mathrm{~mm}$ thick aluminium spacer. The intervening cavity was kept free from structural elements which might otherwise affect working fluid convection patterns and/or cause thermal bridging.

- Evaporator wetter nozzle, working fluid reservoir, and pump: The wetter nozzle consisted of a $10 \mathrm{~mm}$ thick aluminium plate with trunk-and-branch fluid flow distribution channels milled into its surface. This was bolted to the front surface of the evaporator plate (see Figure 7) and acted as a diffuser to distribute a film of working fluid liquid evenly across the evaporator plate surface. The working fluid reservoir contained a total fluid mass of $m_{\llcorner v}=0.25 \mathrm{~kg}$. Wetter nozzle fluid flow $\left(M_{\mathrm{LSe}} \approx 0.01 \mathrm{~kg} / \mathrm{s}\right)$ was provided by a small electrically driven centrifugal pump drawing from the base of the reservoir (shown on Figure 7 with insulation omitted). Run-off flows from the evaporator (MLes) and 
Table 4 - Summary details of experimental apparatus and instrumentation

\begin{tabular}{|c|c|c|}
\hline Element & Dimensions and measurement uncertainties & Descriptions and notes \\
\hline $\begin{array}{l}\text { Evaporator and } \\
\text { condenser plates }\end{array}$ & $\begin{array}{l}\text { Whole PLVTD: } \mathrm{y}=0.50 \mathrm{~m}, \mathrm{z}=0.30 \mathrm{~m}, \mathrm{~A}=0.15 \mathrm{~m}^{2} \\
\text { Free evaporator surface: } \mathrm{dy}_{\mathrm{y}}=0.40 \mathrm{~m}, \mathrm{~d}_{\mathrm{z}}=0.24 \mathrm{~m}, \mathrm{~A}=0.106 \mathrm{~m}^{2} \\
\text { Free condenser surface: } \mathrm{d}_{\mathrm{y}}=0.44 \mathrm{~m}, \mathrm{~d}_{\mathrm{z}}=0.24 \mathrm{~m}, \mathrm{~A}=0.096 \mathrm{~m}^{2} \\
\text { Port holes diameter: } 16 \mathrm{~mm} \text { (KF16 vacuum fitting) }\end{array}$ & $\begin{array}{l}\text { Heat transfer surfaces were bare aluminium } \\
\text { (standard smooth, dull, mill finish) cleaned } \\
\text { using isopropyl alcohol to remove any grease. } \\
\text { Evaporator area was smaller than condenser } \\
\text { area owing to the evaporator wetter nozzle. } \\
\text { Vacuum port located at top of condenser } \\
\text { plate. Reservoir port located at bottom of } \\
\text { evaporator plate (refer to Figure } 7 \text { ). }\end{array}$ \\
\hline $\begin{array}{l}\text { Serpentine heat } \\
\text { exchangers }\end{array}$ & $\begin{array}{l}\text { Total length of fluid channel: } 7 \mathrm{~m} \text { (each plate) } \\
\text { Cross-section of fluid channel: } 4 \mathrm{~mm} \times 4 \mathrm{~mm} \\
\text { Flow \& return ports: } 1 / 2 " \text { BSP (at centre of plate) }\end{array}$ & $\begin{array}{l}\text { Fluid conduits for serpentine heat exchangers } \\
\text { formed by milling a square section channel } \\
\text { into the rear side of the heat transfer plate. } \\
\text { Refer to Pugsley (2017) for details. }\end{array}$ \\
\hline $\begin{array}{l}\text { Evaporator wetting } \\
\text { mechanism }\end{array}$ & $\begin{array}{l}\text { Reservoir capacity: } 0.8 \text { Litre (max) } \\
\text { Pump-to-nozzle connection: } 550 \mathrm{~mm} \text { long, } 6 \mathrm{~mm} \text { inner } \varnothing \\
\text { Nozzle trunk channel: } d_{x}=8 \mathrm{~mm}, d_{y}=230 \mathrm{~mm}, d_{z}=6 \mathrm{~mm} \\
\text { Nozzle branches: } 12 \text { channels each } d_{x}=2 \mathrm{~mm}, d_{y}=4 \mathrm{~mm}, d_{z}=6 \mathrm{~mm} \\
\text { Nozzle aperture width: } d_{x}=0.5 \mathrm{~mm} \\
\text { Nozzle aperture length: } d_{y}=230 \mathrm{~mm} \\
\text { Volume flow rate: } 0.6 \pm 0.1 \text { Litre } / \text { second }\end{array}$ & $\begin{array}{l}\text { PLVTD working fluid stored in external } \\
\text { reservoir formed from } 100 \mathrm{~mm} \text { long ISO100 } \\
\text { vacuum fitting. Fluid flow driven by TCS } \\
\text { M400M centrifugal pump. Nozzle formed from } \\
10 \mathrm{~mm} \text { thick aluminium plate with trunk-and- } \\
\text { branch fluid flow distribution channels milled } \\
\text { into its surface. Refer to Pugsley (2017). }\end{array}$ \\
\hline $\begin{array}{l}\text { Temperature } \\
\text { sensors }\end{array}$ & $\begin{array}{l}\text { Number of thermocouples on each plate: } 3 \\
\text { Number of thermocouples at each flow \& return port: } 1 \\
\text { Thermocouple specification: T-type (spot-welded tip) } \\
\text { Temperature uncertainty each thermocouple: } \pm 1.0^{\circ} \mathrm{C} \\
\text { Temperature uncertainty thermocouple pairs: } \pm 0.3^{\circ} \mathrm{C} \\
\text { Sampling regime: Reading taken every } 5 \text { seconds, with average } \\
\text { value recorded every } 30 \text { seconds }\end{array}$ & $\begin{array}{l}\text { The magnitude of uncertainty in absolute } \\
\text { temperatures recorded for each thermocouple } \\
\text { is primarily caused by the uncertainty } \\
\text { associated with the DeltaT DL2e datalogger's } \\
\text { internal thermistor. Uncertainty associated } \\
\text { with thermocouple pairs used for temperature } \\
\text { difference measurements is therefore lower. }\end{array}$ \\
\hline $\begin{array}{l}\text { Heating and cooling } \\
\text { fluid circuits and } \\
\text { flow rate sensors }\end{array}$ & $\begin{array}{l}\text { Flow rate uncertainty: } \pm 9 \% \text { in measured range } \\
\text { Flow meter signal output: } 2250 \text { Pulse/Litre } \\
\text { Sampling regime: Continuous pulse count with average value } \\
\text { recorded every } 30 \text { seconds }\end{array}$ & $\begin{array}{l}\text { Flows through each serpentine heat } \\
\text { exchanger were monitored using a Nixon OG1 } \\
\text { oval gear volumetric flow meter with active } \\
\text { pulse output monitored by DeltaT DL2e } \\
\text { datalogger. Flow rates were set by pump } \\
\text { speed switch and manual ball valves. }\end{array}$ \\
\hline $\begin{array}{l}\text { Vacuum pump and } \\
\text { pressure sensor }\end{array}$ & $\begin{array}{l}\text { Pressure uncertainty (dry air at } 2 \mathrm{kPa} \text { ): } \pm 3 \% \\
\text { Pressure uncertainty (water vapour at } 2 \mathrm{kPa} \text { ): } \pm 20 \%\end{array}$ & $\begin{array}{l}\text { Vacuum created by an Edwards XDS5 scroll } \\
\text { pump which was isolated by gate value during } \\
\text { tests. Pressure measured using a Druck } \\
\text { DPI-104 diaphragm pressure gauge. }\end{array}$ \\
\hline
\end{tabular}

Reverse mode performance

504 Figure 8 shows the measured temperature, pressure and flow rate time history for the reverse mode tests on the vertical PLVTD with $22 \mathrm{~mm}$ aluminium spacer. For continuity, results have been presented in a similar manner to those reported previously by

507 Pugsley et al. (2019) for the horizontal PLVTD with $11 \mathrm{~mm}$ nylon spacer. Average 508 temperatures of the heating and cooling plates are denoted by $\mathrm{T}_{\mathrm{HC}}$ and $\mathrm{T}_{\mathrm{CH}}$ respectively. 509 Hot and cold supply temperatures are denoted by $T_{H(H C)}$ and $T_{C(C H)}$ respectively with 510 corresponding return flow temperatures denoted by $\mathrm{T}_{\mathrm{C}(\mathrm{HC})}$ and $\mathrm{T}_{\mathrm{H}(\mathrm{CH}) \text {. The numbered }}$ 511 labels show seven condenser plate temperature setpoints corresponding to 512 approximately $\mathrm{T}_{2}=25,30,35,38,41,44,47^{\circ} \mathrm{C}$ with evaporator plate temperatures 513 being maintained $\Delta \mathrm{T}_{12}=20 \pm 5^{\circ} \mathrm{C}$ cooler. It proved difficult to control exact plate 514 temperature setpoints as this required very fine manual adjustments to heating and 
515 cooling circuit flow control values (hence the noted $\pm 5^{\circ} \mathrm{C}$ variability) but temperatures

516 typically became very stable after allowing for initial 20-30 minute transients after

517 each setpoint change. Measured pressures $P_{(\text {meas })}$ increased with increasing

518 temperature and correspond closely to estimated saturation pressures $\mathrm{P}_{\mathrm{Lv}(\mathrm{HCCH})}$ which

519 were determined from thermodynamic tables using the average operating temperature

$520 \mathrm{~T}_{\mathrm{HCCH}}=\left(\mathrm{T}_{\mathrm{HC}}+\mathrm{T}_{\mathrm{CH}}\right) / 2$ as a lookup variable. The supply temperatures and flow rates

$521\left(\mathrm{M}_{\mathrm{HC}}=\mathrm{M}_{\mathrm{CH}}=0.3 \pm 0.05 \mathrm{~L} / \mathrm{min}\right.$, slight decrease with increasing temperature $)$ of fluids

522 controlling the plate temperatures were kept broadly constant throughout the tests by

523 Julabo FM33A automatically controlled heating-cooling circulators. Figure 9 shows the

524 derived thermal powers and conductances corresponding to the raw data presented on

525 Figure 8. Steady state thermal power of $\mathrm{q}_{\mathrm{HC}}=-\mathrm{q}_{\mathrm{CH}}=35 \pm 8 \mathrm{~W}$ was maintained during

526 each measurement subsequent to each setpoint change transient. Corresponding

527 steady state reverse mode thermal conductances for the PLVTD with 22mm aluminium

528 spacer were consistently $U_{r}=12 \mathrm{~W} \cdot \mathrm{m}^{-2} \mathrm{~K}^{-1}$, increasing slightly with increasing

529 temperature. As indicated on Figure 10, these results are consistent with the

530 theoretical model and, as expected, are slightly higher than those achieved for the

531 horizontal PLVTD with $11 \mathrm{~mm}$ nylon spacer (Pugsley et al., 2019). Interrogation of the

532 model suggest that this is primarily due to increased conduction through the sidewalls

$533\left(\mathrm{U}_{\mathrm{w}}=10.7 \mathrm{~W} \cdot \mathrm{m}^{-2} \mathrm{~K}^{-1}\right.$ for $22 \mathrm{~mm}$ aluminium spacer with rubber O-ring seals compared to

$534 \mathrm{U}_{\mathrm{w}}=6.7 \mathrm{~W} \cdot \mathrm{m}^{-2} \mathrm{~K}^{-1}$ for the $11 \mathrm{~mm}$ nylon spacer). Gaseous conduction through the vapour

535 also has an influence on overall performance $\left(U_{v}=0.9 \mathrm{~W} \cdot \mathrm{m}^{-2} \mathrm{~K}^{-1}\right.$ for $22 \mathrm{~mm}$ vertical

536 cavity compared to $\mathrm{U}_{\mathrm{v}}=1.8 \mathrm{~W} \cdot \mathrm{m}^{-2} \mathrm{~K}^{-1}$ for the $11 \mathrm{~mm}$ horizontal cavity). Vapour

537 convection appears to have a very minimal role except at the highest temperatures in

538 the vertical case. Measured results are broadly consistent with the modelled

539 phenomenon of radiant heat transfer being greater for horizontal PLVTDs

$540\left(U_{R}=1.1 \mathrm{~W} \cdot \mathrm{m}^{-2} \mathrm{~K}^{-1}\right)$ than for vertical PLVTDs $\left(U_{R}=0.6 \mathrm{~W} \cdot \mathrm{m}^{-2} \mathrm{~K}^{-1}\right)$. This occurs because

541 dry metal surfaces (vertical evaporator plate, wetter pump inactive in reverse mode)

542 have lower emissivity than wet surfaces (evaporator plate is permanently wet in a

543 horizontal PLVTD). 


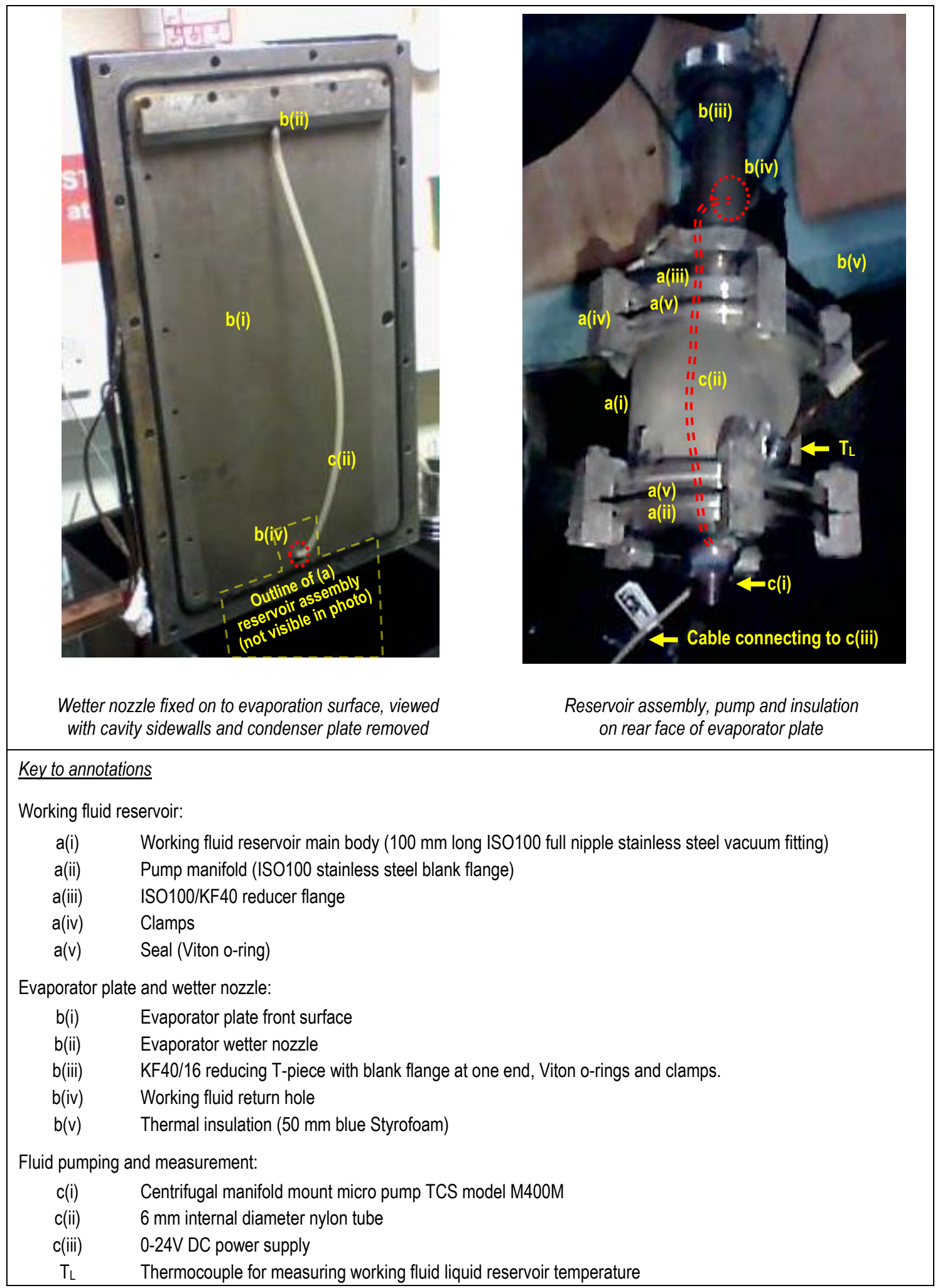

544

Figure 7 - Photographs of vertical PLVTD prototype 


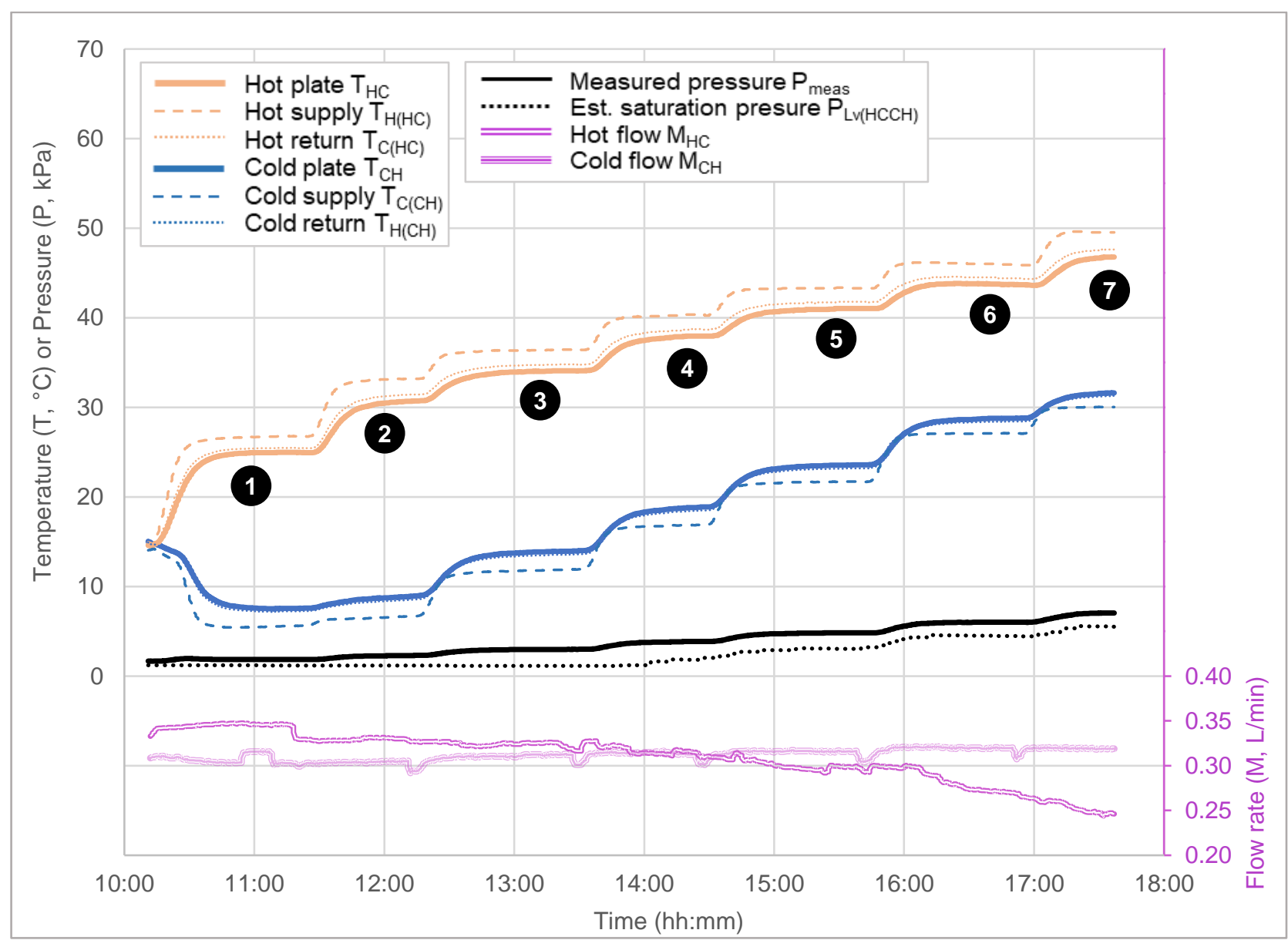

546

Figure 8 - Time history of measured temperatures, pressures and flow rates during reverse mode test

547

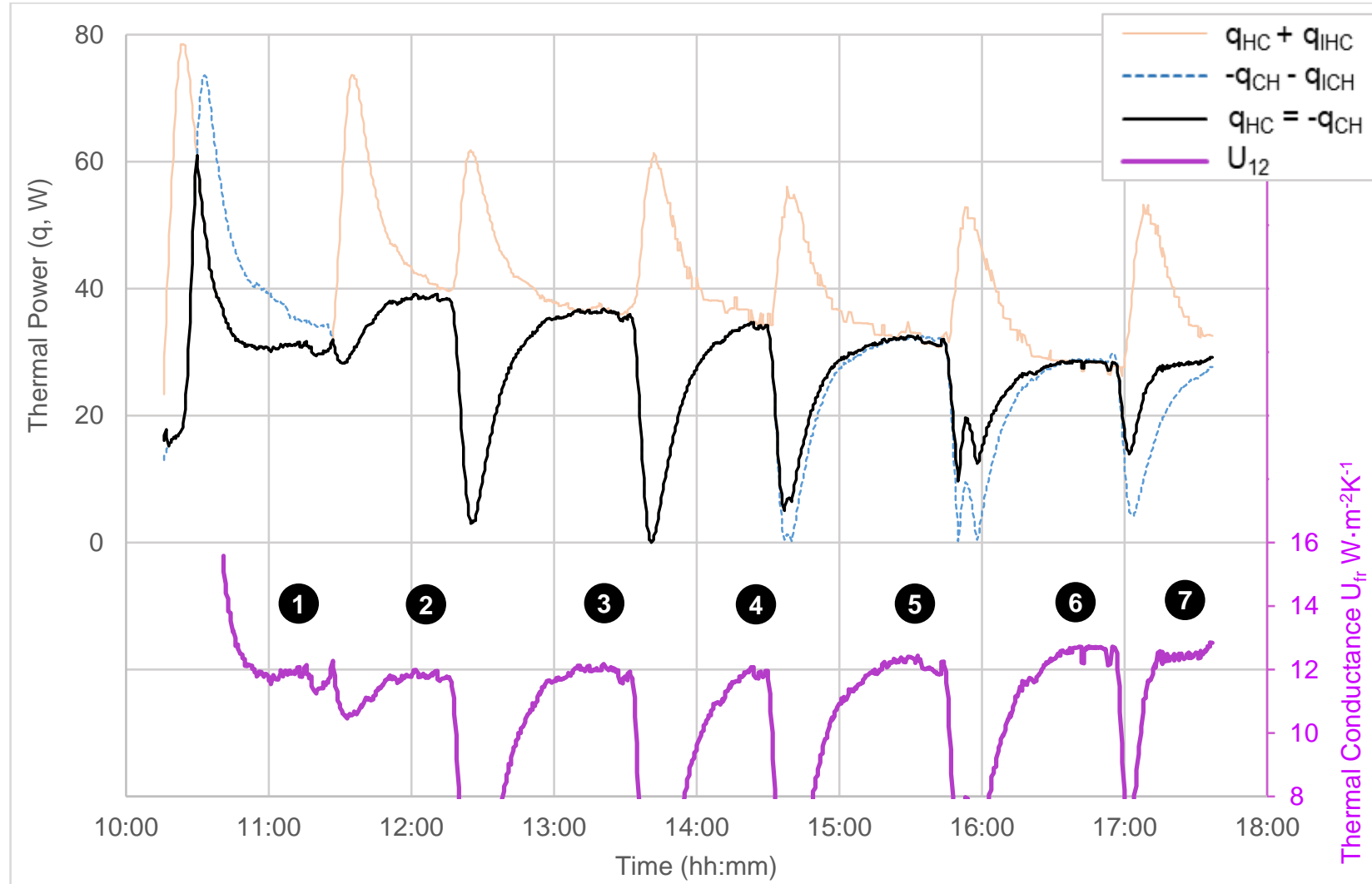




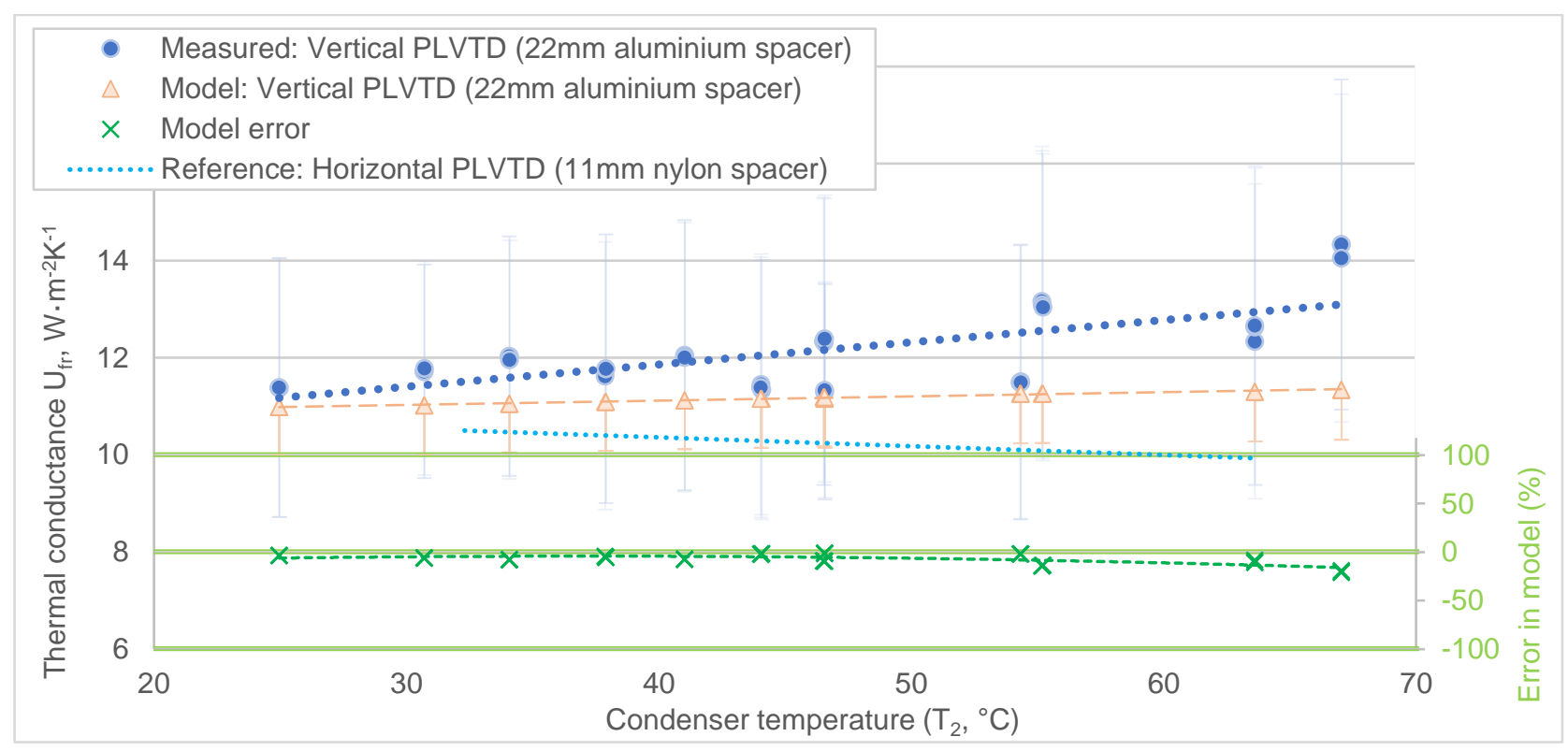

Figure 10 - Reverse mode performance of $22 \mathrm{~mm}$ aluminium spacer vertical PLVTD

\section{$553 \quad 3.3 \quad$ Forward mode performance}

554 Tests were undertaken to determine how forward mode thermal conductance varies

555 with driving heat flux ( $q_{H C} / A_{p}$ by varying plate-to-plate temperature difference $\Delta T_{12}$ )

556 and operating temperature (by varying condenser plate temperature $T_{2}$ ). As noted in

557 Section 3.2, it was very difficult to establish exact plate temperature setpoints, but

558 temperatures typically remained steady after each initial stabilisation transient. Results

559 on Figure 11 show behaviour for constant $\mathrm{T}_{2}=33 \pm 4^{\circ} \mathrm{C}$ with setpoint steps in the range

$5600.5<\Delta T_{12}<8^{\circ} \mathrm{C}$ to achieve $216<\mathrm{q}_{\mathrm{HC}} / \mathrm{A}_{\mathrm{p}}<4913 \mathrm{~W} \cdot \mathrm{m}^{-2}$. Reliable measurements at lower

561 heat fluxes were not possible owing to limitations of temperature measurement

562 accuracy (discussed further in Section 3.4). Steady state forward mode thermal

563 conductance remained broadly constant at $\mathrm{U}_{\mathrm{f}} \approx 400 \mathrm{~W} \cdot \mathrm{m}^{-2} \mathrm{~K}^{-1}$ for heat fluxes in the

564 primary range of interest for CCBE and ICSSWH applications $\left(0.5<\Delta \mathrm{T}_{12}<2.5^{\circ} \mathrm{C}\right.$ 565 corresponding to $\left.\mathrm{q}_{\mathrm{HC}} / \mathrm{A}_{\mathrm{p}}<1000 \mathrm{~W} \cdot \mathrm{m}^{-2}\right)$. At $\Delta \mathrm{T}_{12} \approx 5.3^{\circ} \mathrm{C}\left(\mathrm{q}_{\mathrm{HC}} / \mathrm{A}_{\mathrm{p}} \approx 3000 \mathrm{~W} \cdot \mathrm{m}^{-2}\right)$ the 566 measured result of $\mathrm{U}_{\mathrm{f}} \approx 560 \mathrm{~W} \cdot \mathrm{m}^{-2} \mathrm{~K}^{-1}$ corresponds to a $40 \%$ increase per of trebling of 567 heat flux. This effect is broadly consistent with the model which suggests that 568 increasing plate-to-plate temperature difference increases convection driving forces 569 thereby decreasing evaporation thermal resistance $\left(R_{e}\right)$ and vapour mass flow 
570 resistance $\left(R_{e c}\right)$ to cause overall thermal conductance to increase (refer to Figure 15 ).

571 Results on Figure 12 show behaviour for constant $\Delta \mathrm{T}_{12}=4.5 \pm 1.5^{\circ} \mathrm{C}$ (corresponding to

$\left.572 \mathrm{q}_{\mathrm{HC}} / \mathrm{A}_{\mathrm{p}} \approx 2000 \mathrm{~W} \cdot \mathrm{m}^{-2}\right)$ and stepped condenser temperature setpoints $\left(13<\mathrm{T}_{2}<57^{\circ} \mathrm{C}\right)$.

573 Steady state forward mode thermal conductance increased proportionally with

574 condenser plate temperature from $\mathrm{U}_{\mathrm{f}} \approx 175 \mathrm{~W} \cdot \mathrm{m}^{-2} \mathrm{~K}^{-1}$ at $\mathrm{T}_{2} \approx 15^{\circ} \mathrm{C}$ up to $\mathrm{U}_{\mathrm{f}} \approx 720 \mathrm{~W} \cdot \mathrm{m}^{-2} \mathrm{~K}^{-1}$

575 at $\mathrm{T}_{2} \approx 45^{\circ} \mathrm{C}$, an increase of about $4-5 \%$ per degree. The model suggests this trend is

576 primarily due to decreased vapour mass flow resistance $\left(R_{e c}\right)$ caused by working fluid

577 viscosity decreasing with increasing temperature (refer to Figure 16). The highest

578 recorded performance was $\mathrm{U}_{\mathrm{f}} \approx 1200 \mathrm{~W} \cdot \mathrm{m}^{-2} \mathrm{~K}^{-1}$ at $\mathrm{T}_{2} \approx 55^{\circ} \mathrm{C}$ with $\Delta \mathrm{T}_{12} \approx 2.2^{\circ} \mathrm{C}$

579 corresponding to $\mathrm{q}_{H C} / \mathrm{A}_{\mathrm{p}} \approx 2800 \mathrm{~W} \cdot \mathrm{m}^{-2}$.

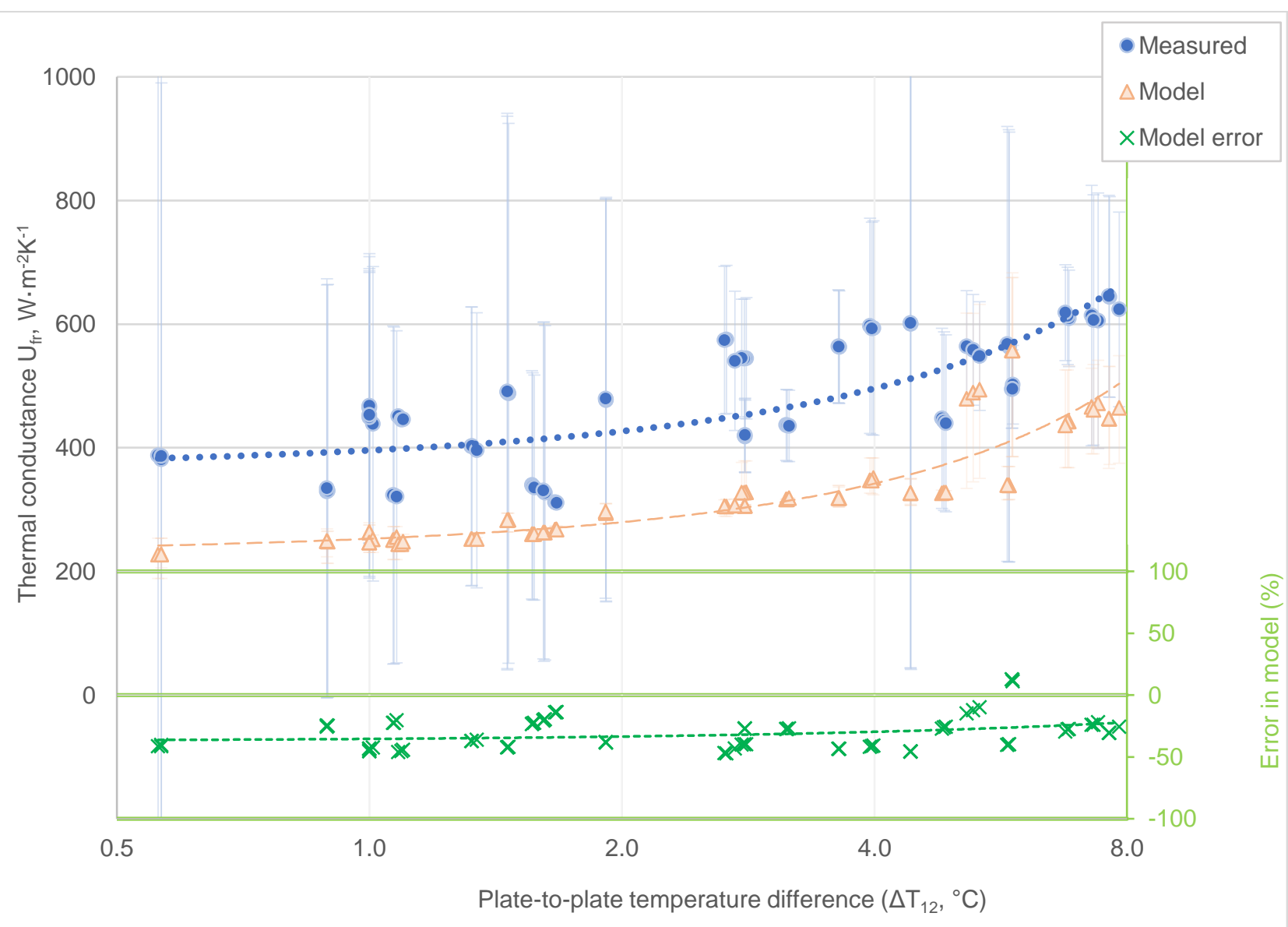




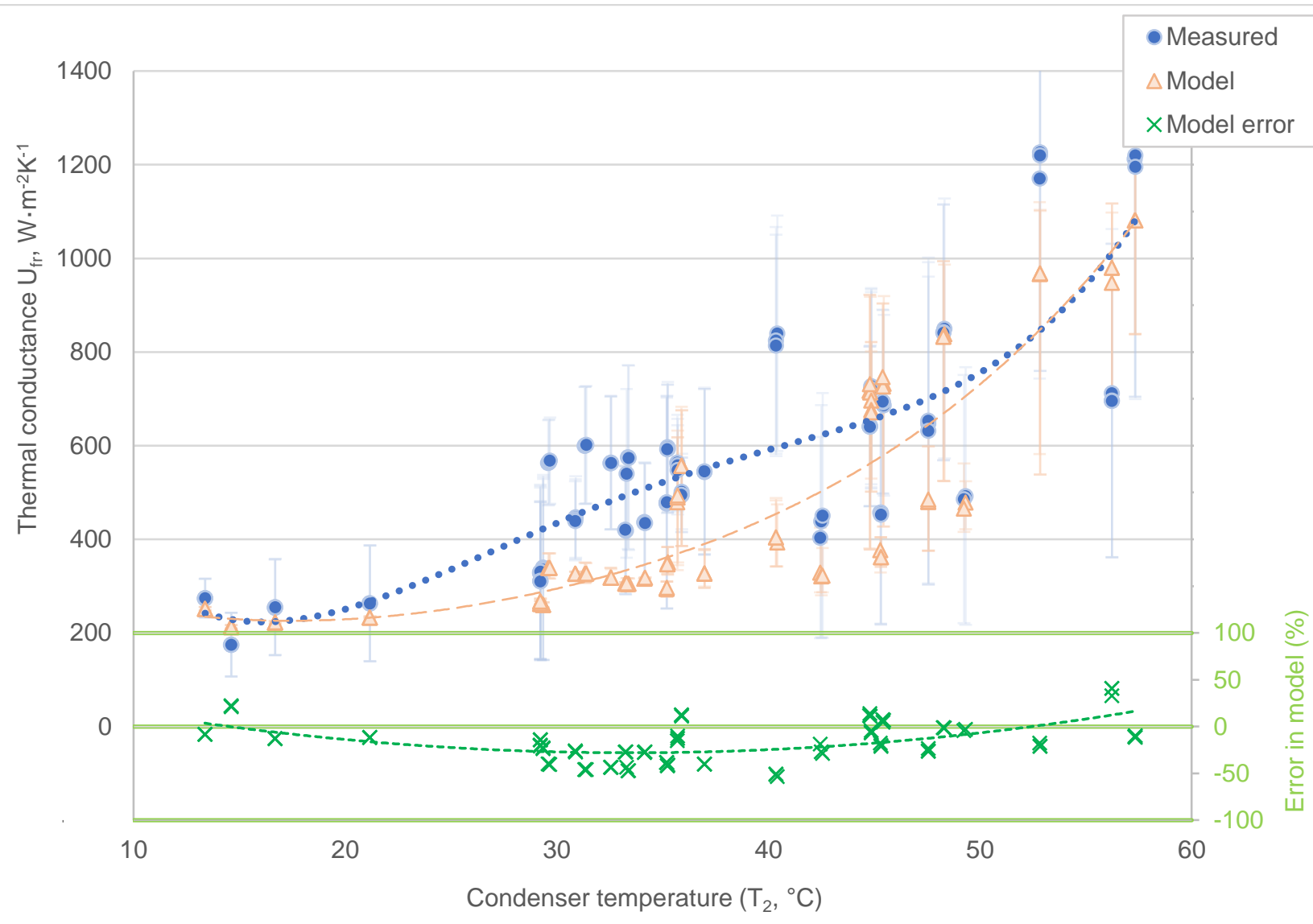

Figure 12 - Forward mode performance of $22 \mathrm{~mm}$ aluminium spacer vertical PLVTD (varying condenser temperature)

$585 \quad 3.4 \quad$ Uncertainty and validity

586 As indicated by the error bars on Figures 10,11 and 12, measurement uncertainty in

587 the derived thermal conductance results is typically $\pm 25 \%$. This uncertainty is primarily

588 a manifestation of temperature measurement uncertainties $\left( \pm 0.3^{\circ} \mathrm{C}\right.$ for $\Delta \mathrm{T}$ between 589 any two thermocouples, see Table 4) which propagate into derived results. Uncertainty 590 becomes more significant for scenarios involving small plate-to-plate $\left(\Delta \mathrm{T}_{12}<1^{\circ} \mathrm{C}\right)$ or 591 flow-to-return $\left(\Delta \mathrm{T}_{\mathrm{HC}}<2^{\circ} \mathrm{C}\right)$ temperature differences. Whilst this is clearly significant in 592 the context of individual results, the overall trends apparent in the data are considered 593 robust owing to the relatively large number of data points and repeated tests 594 undertaken. A thorough discussion and explanation concerning the treatment of 595 uncertainty is presented by Pugsley et al. (2017 and 2019).

596 Comparison of measured and modelled data indicates that the reverse mode model is 597 a good predictor, with average model error being only $-8 \%$. This represents a slight 598 underprediction bias, which, on the basis that it worsens steadily with increasing 
599 temperature (as apparent on Figure 10) is thought to be related to sidewall effects 600 upon vapour convection (refer to Corcione, 2003) which are not accounted for in the 601 model. The forward mode model appears to be a less accurate predictor (average 602 modelling error -24\%) but the anticipated behavioural trends are very clearly apparent 603 in the experimental data. One possible explanation for the "apparent" modelling error 604 could be that the model is actually correct, but that the measured forward mode 605 thermal conductances suffer from a $+24 \%$ bias error. This explanation is consistent 606 with the estimated $\pm 25 \%$ uncertainty for measured thermal conductances and could 607 feasibly occur if plate temperature measurement uncertainties manifest as biases 608 which cause true $\Delta \mathrm{T}_{12}$ values to be underestimated. Another possible explanation is 609 that the vapour convection calculations become inaccurate during the laminar-to610 turbulent transition $\left(\operatorname{Ra} \approx 10^{6}\right)$. Results on Figure 12 suggest that the model predicts 611 reasonably accurately at the lowest and highest condenser temperature setpoints 612 where the vapour convection Nusselt numbers are calculated using Equation 15q (low 613 temperatures corresponding to $\mathrm{Ra}<10^{5}$ ) and Equation $15 \mathrm{~s}$ (high temperatures 614 corresponding to $\mathrm{Ra}>10^{8}$ ) respectively, but consistently underpredicts for mid-range 615 temperature setpoints (in the transition region where Equation $15 \mathrm{r}$ applies). Evidence 616 that the model predicts accurately for laminar vapour convection cases $\left(\mathrm{Ra}<10^{5}\right.$ for all 617 datapoints on Figure 10) but consistently underpredicts for turbulent transition vapour 618 convection cases ( $R a>10^{6}$ for all datapoints on Figure 12 ) supports this explanation 619 and suggests that further refinement of Equation $15 r$ should be sought.

620 Experimental work to date has focussed on validating the proposed model for the cases 621 of horizontally (Pugsley et al., 2019) and vertically (the present study) oriented PLVTDs 622 with all non-condensable gases removed. The validity of the model in respect of tilted 623 orientations will need to be examined as part of further experimental work. Likewise, 624 further work to augment early experimental validation (reported by Pugsley, 2017) is 625 required in respect of the proposed model variant (refer to Appendix $A$ ) which accounts 626 for non-condensable gases. 


\section{Parametric design considerations}

628 The theoretical model can be used to examine the effect of key PLVTD design

629 parameters to develop an optimised design for CCBE and ICSSWH applications.

630 Figure 13 shows how reverse mode thermal conductance $\left(U_{v}\right)$ of water vapour is

631 dependent upon the cavity depth ( $x$ ) for various aspect ratios $(z / x)$ and orientations

$632(\theta)$ under nominal assumed operating conditions $\left(T_{1}=10^{\circ} \mathrm{C}\right.$ and $\left.T_{2}=60^{\circ} \mathrm{C}\right)$. Calculations

633 consider plate-to-plate cavity depths in the range $10 \leq x \leq 200 \mathrm{~mm}$ and plate height

634 dimensions of $200<z<4000 \mathrm{~mm}$. The $\theta=180^{\circ}$ horizontal PLVTD offers the lowest (best)

635 vapour convection thermal conductance because the heat source is at the top of the 636 cavity and the resulting vapour stratification prevents convection (gaseous conduction

637 only). Conversely, the $\theta=0^{\circ}$ horizontal orientation promotes convection and results in

638 the highest (worst) thermal conductances. Vertical and tilted PLVTDs yield

639 conductances in the range between these extremes with high aspect ratios $(z / x>12)$

640 and high tilt angles $\left(\theta>45^{\circ}\right)$ giving the best reverse mode performances. Cavity depths

641 in the range $30<x<200 \mathrm{~mm}$ result in $U_{v}<0.7 \mathrm{~W} \cdot \mathrm{m}^{-2} \mathrm{~K}^{-1}$ for all orientations, irrespective

642 of aspect ratio and heat transfer occurs via gaseous conduction only for plate-to-plate

643 cavity depths of $x<40 \mathrm{~mm}$ (irrespective of $\theta$ or $z / x$ ). Cavity depth of $x \approx 50 \mathrm{~mm}$ yields

644 optimal effective reverse mode thermal conductivity $(\mathrm{k}=\mathrm{U} \cdot \mathrm{x})$ for tilted PLVTDs whereas

$645 \mathrm{x} \approx 75 \mathrm{~mm}$ is more suitable for high aspect ratio vertical PLVTDs $(\mathrm{z} / \mathrm{x}>12)$. 


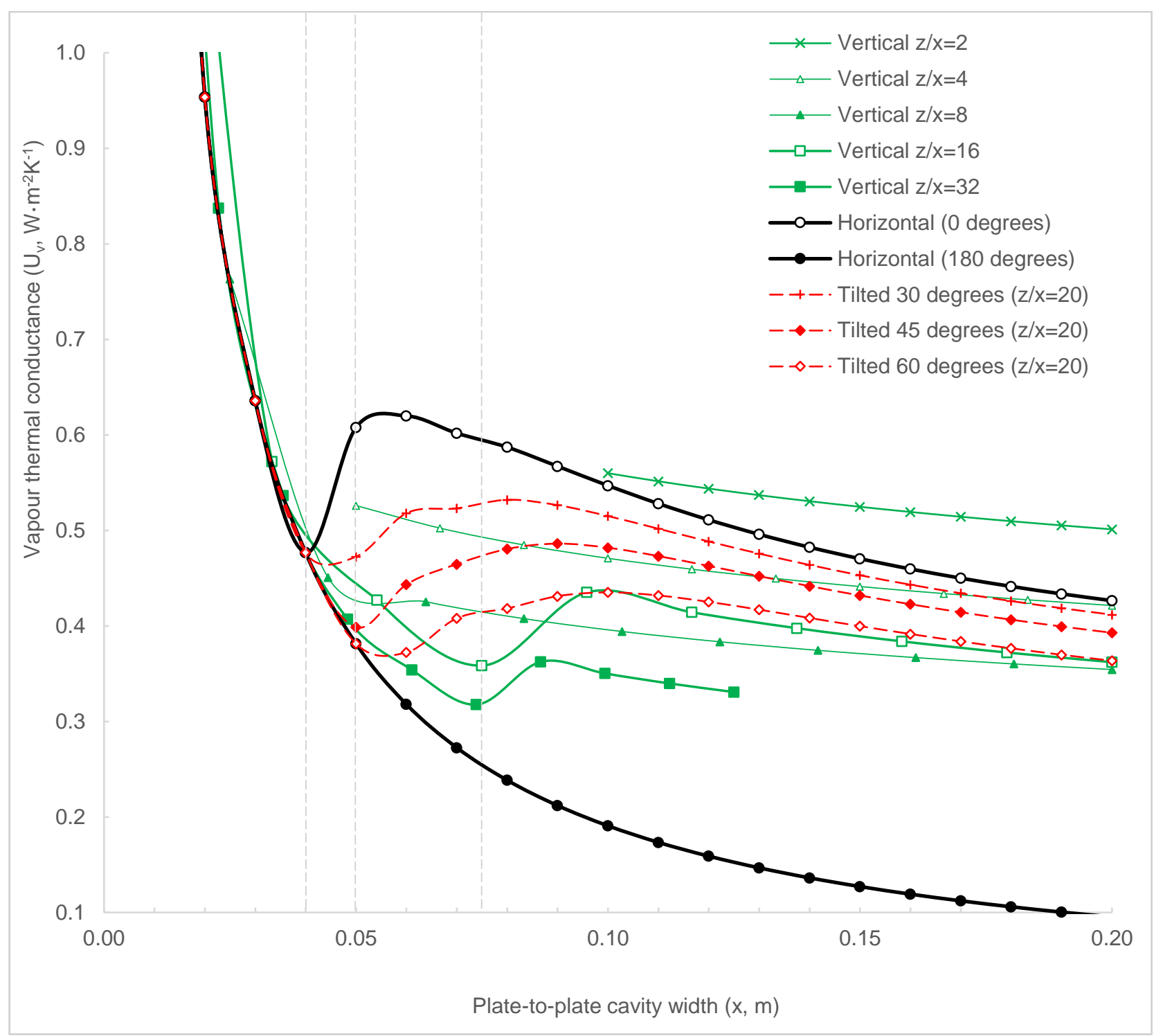

Figure 13 - Dependence of reverse mode water vapour thermal conductance on orientation and dimensions 
$\longrightarrow$ Vertical $2<z / x<9$ and $0.1<y / z<10$

- - +- - Tilted $30 \mathrm{z} / \mathrm{x}=20, \mathrm{y} / \mathrm{z}=1$

- - - Tilted $45 \mathrm{z} / \mathrm{x}=20, \mathrm{y} / \mathrm{z}=1$

- - $\diamond$ - Tilted $60 \mathrm{z} / \mathrm{x}=20, \mathrm{y} / \mathrm{z}=1$

$\longrightarrow$ Horizontal $2<\mathrm{z} / \mathrm{x}<40$ and $0.1<\mathrm{y} / \mathrm{z}<10$

$\longrightarrow$ Vertical $9<\mathrm{z} / \mathrm{x}<40$ and $0.1<\mathrm{y} / \mathrm{z}<10$

Tilted $30 \mathrm{z} / \mathrm{x}=8, \mathrm{y} / \mathrm{z}=1$

Tilted $45 \mathrm{z} / \mathrm{x}=8, \mathrm{y} / \mathrm{z}=1$

Tilted $60 \mathrm{z} / \mathrm{x}=8, \mathrm{y} / \mathrm{z}=1$
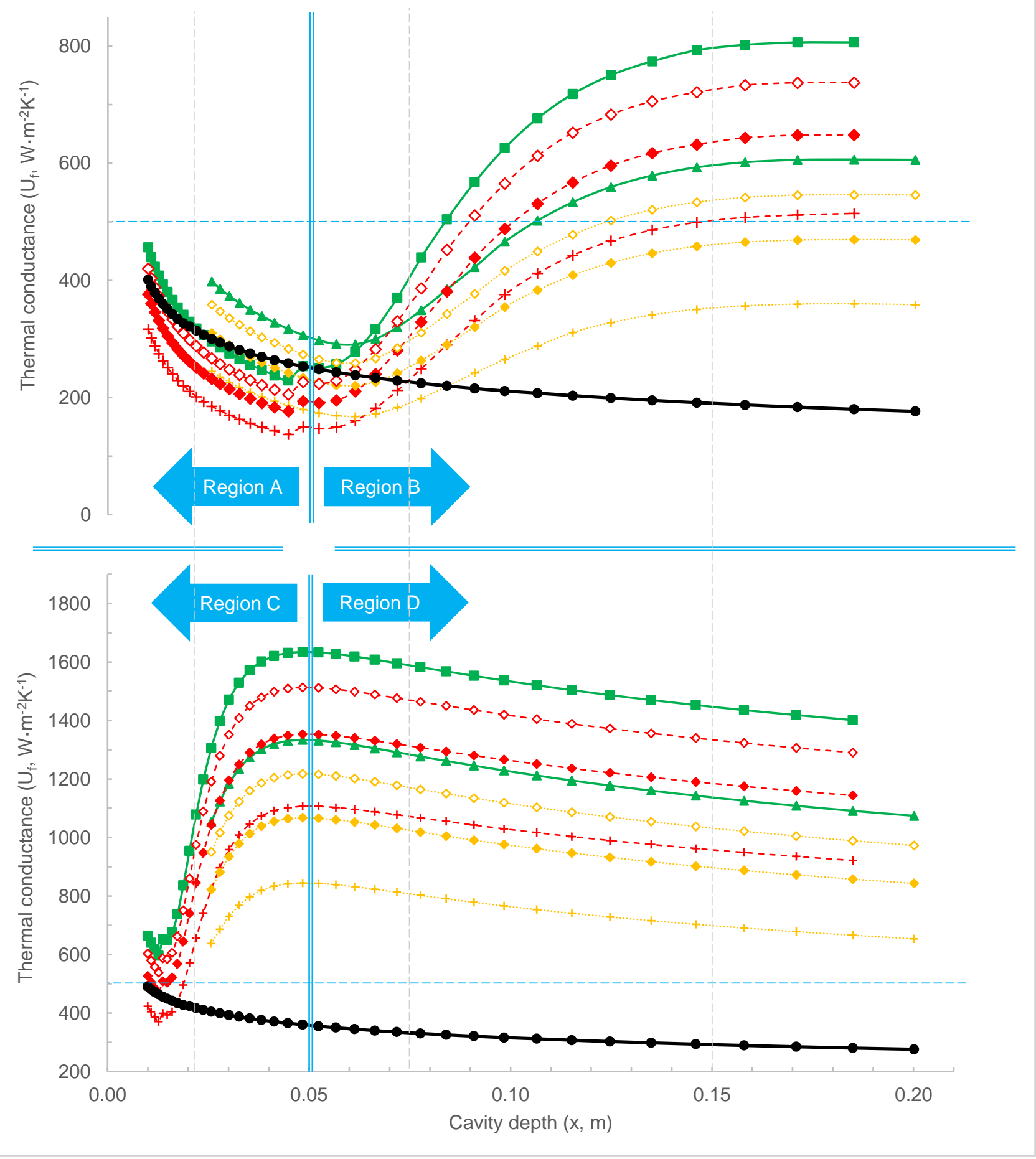

Figure 14 - Forward mode thermal conductances in PLVTDs with different orientations and dimensions (Upper graph: $\mathrm{T}_{2}=15^{\circ} \mathrm{C}$ at $655 \Delta \mathrm{T}_{12}=5^{\circ} \mathrm{C}$, Lower graph: $\mathrm{T}_{2}=60^{\circ} \mathrm{C}$ at $\Delta \mathrm{T}_{12}=1^{\circ} \mathrm{C}$ ) 
658 Figure 14 shows how overall forward mode thermal conductance $\left(U_{f}\right)$ is dependent 659 upon cavity depth $(10<x<200 \mathrm{~mm})$ for horizontal, tilted, squat vertical, and slender 660 vertical PLVTDs ( $200<$ y $\& z<4000 \mathrm{~mm}$ ). The upper graph describes operation with

$661 \mathrm{~T}_{2}=15^{\circ} \mathrm{C}$ condenser plate and heat fluxes corresponding to $500<\mathrm{q} / \mathrm{A}<2500 \mathrm{~W} \cdot \mathrm{m}^{-2}$ in 662 Region " $\mathrm{A}$ " and $750<\mathrm{q} / \mathrm{A}<4000 \mathrm{~W} \cdot \mathrm{m}^{-2}$ in Region " $\mathrm{B}$ " whereas the lower graph (Regions 663 " $\mathrm{C}$ " and " $\mathrm{D}$ ") describe operation at $\mathrm{T}_{2}=60^{\circ} \mathrm{C}$ and $250<\mathrm{q} / \mathrm{A}<2000 \mathrm{~W} \cdot \mathrm{m}^{-2}$. Calculations 664 assume water as working fluid ( $m_{\llcorner v} / y z=1 \mathrm{~kg} / \mathrm{m}^{2}$ ) distributed evenly across the 665 evaporator surface at a flow rate of $M_{L} / y=0.1 \mathrm{~kg} \cdot \mathrm{m}^{-1} \mathrm{~s}^{-1}$ with all non-condensable gases 666 removed. Cross-checking against Figures 11 and 12 confirms that the modelling 667 predictions for a vertical PLVTD with $x=22 \mathrm{~mm}$ and $\mathrm{z} / \mathrm{x}=20$ are broadly consistent with 668 the experimental results. The following can be concluded from Figure 14:

- Vertical PLVTDs generally achieve higher (better) forward mode thermal conductances than PLVTDs in horizontal and (most) tilted orientations.

- Conductance decreases with increasing cavity depth for horizontal PLVTDs and for vertical/tilted PLVTDs within Regions " $A$ " \& "D" but increases with increasing cavity depth for vertical/tilted PLVTDs within Regions "B" \& "C".

- Vertical and tilted PLVTDs generally achieve maximum conductance when combined with relatively tall plates $(z / x>9)$ giving the PLVTD a "slender" form, although "squat forms" tend to perform better within Region " $A$ " (conditions with low temperatures and low heat fluxes).

678 These conclusions suggest that PLVTD dimensions can be optimised to suit expected 679 operating conditions. Forward mode thermal conductances of $U_{f}>100 \mathrm{~W} \cdot \mathrm{m}^{-2} \mathrm{~K}^{-1}$ appear 680 achievable irrespective of orientation or operating condition and with little regard to 681 optimising dimensions. It appears possible to achieve $\mathrm{U}_{\mathrm{f}}>500 \mathrm{~W} \cdot \mathrm{m}^{-2} \mathrm{~K}^{-1}$ for 682 vertical/tilted PLVTDs across the temperature range by designing them with $\mathrm{x}=150 \mathrm{~mm}$ 683 cavities and slender aspect ratios $(z / x \approx 20)$. If the cavity of a vertical PLVTD is set at 
$68475 \mathrm{~mm}$ (optimal for reverse mode performance, as per Figure 13) and aspect ratio is 685 set at $\mathrm{z} / \mathrm{x}=20$ then forward mode conductances of $400<\mathrm{U}_{\mathrm{f}}<1600 \mathrm{~W} \cdot \mathrm{m}^{-2} \mathrm{~K}^{-1}$ can be 686 expected for $15<\mathrm{T}_{2}<60^{\circ} \mathrm{C}$ and $1500<\mathrm{q} / \mathrm{A}<2000 \mathrm{~W} \cdot \mathrm{m}^{-2}$ operating conditions. 687 Figures 15 and 16 illustrate how forward mode thermal conductance (overall $\mathrm{U}_{\mathrm{f}}$ and 688 individual components $U_{e}, U_{e c}$ and $U_{c}$ ) of a PLVTD of dimensions $x=75 \mathrm{~mm}, y=750 \mathrm{~mm}$ 689 and $z=1500 \mathrm{~mm}$ constructed of $1 \mathrm{~mm}$ stainless plates and sidewalls with internal 690 supporting structure formed of stainless steel tubular struts spaced at $d_{\mathrm{ss}}=0.075 \mathrm{~m}$ 691 centres, would be expected to vary with heat flux and temperature. Figure 17 shows 692 calculated temperature and heat flux dependence of the overall reverse mode thermal 693 conductance of the same device. Results suggest that reverse mode conductances of $6941.7<U_{\mathrm{r}}<2.5 \mathrm{~W} \cdot \mathrm{m}^{-2} \mathrm{~K}^{-1}$ can be expected for average operating temperatures of $6955<\mathrm{T}_{12}<50^{\circ} \mathrm{C}$ (corresponding to $15<\mathrm{T}_{2}<60^{\circ} \mathrm{C}$ when $\Delta \mathrm{T}_{12}=20^{\circ} \mathrm{C}$ ) which implies diodicity 696 of $\varsigma>99 \%$ across the temperature range.

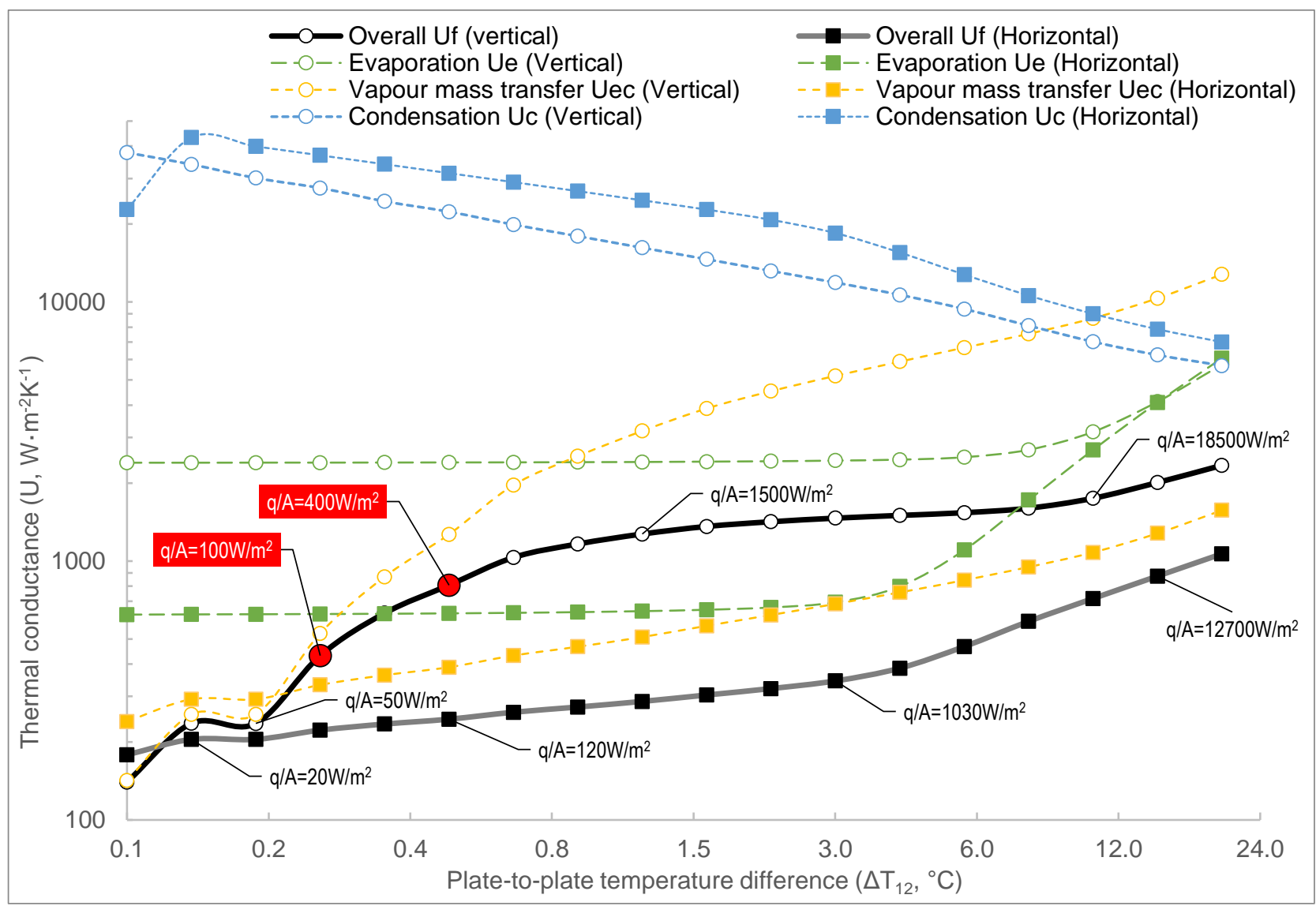

Figure 15-Dependence of forward mode thermal conductance upon plate-to-plate temperature difference (for $x=0.075, y=0.75, z=1.5 \mathrm{~m}$ stainless steel PLVTD at fixed $T_{2}=45^{\circ} \mathrm{C}$ condenser temperature) 


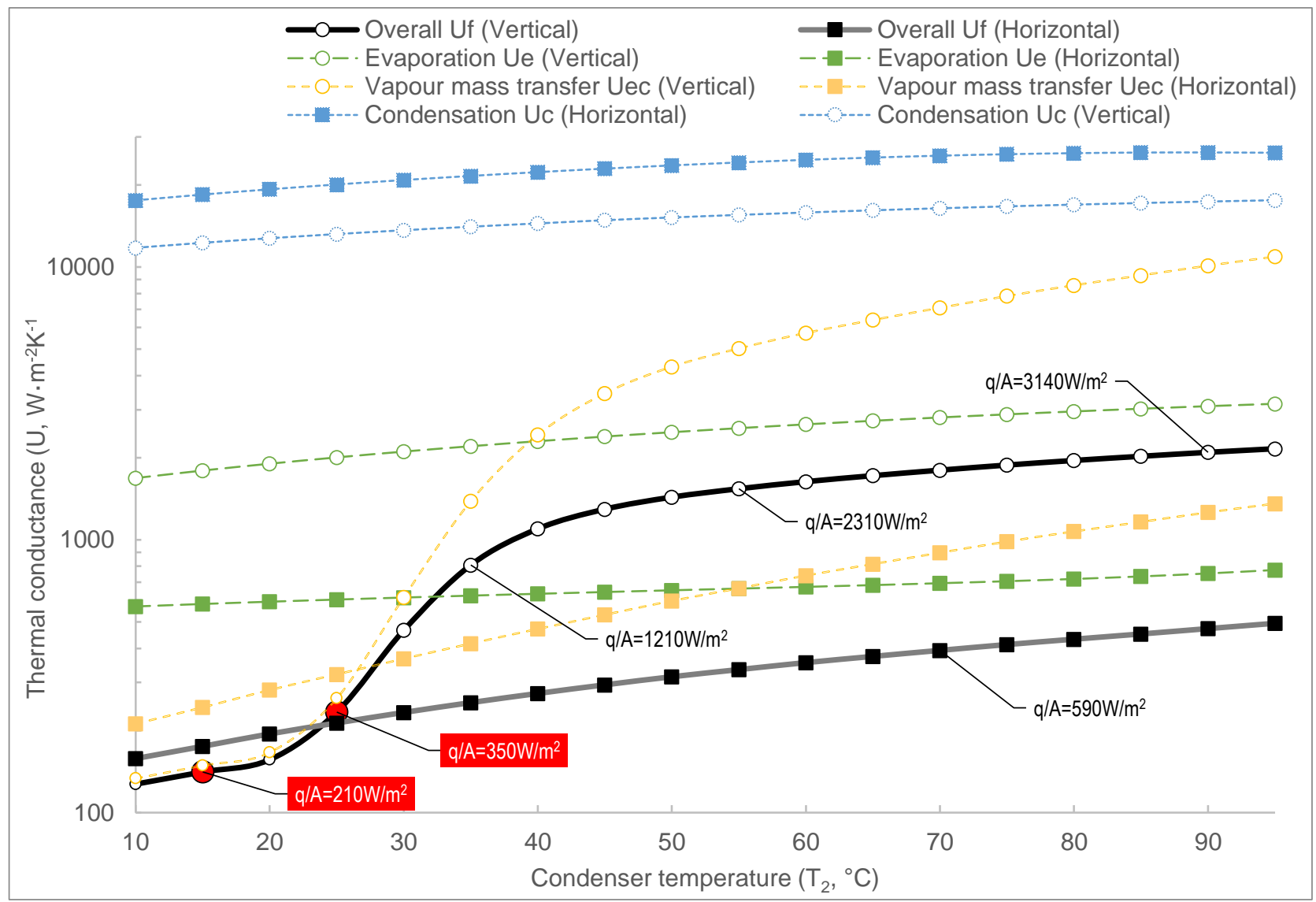

Condenser temperature $\left(\mathrm{T}_{2},{ }^{\circ} \mathrm{C}\right)$

701 Figure 16- Dependence of forward mode thermal conductance upon condenser temperature (for $x=0.075, y=0.75, z=1.5 \mathrm{~m}$ stainless steel $702 \quad P L V T D$ at fixed $\Delta T_{12}=1.5^{\circ} \mathrm{C}$ plate-to-plate temperature difference)

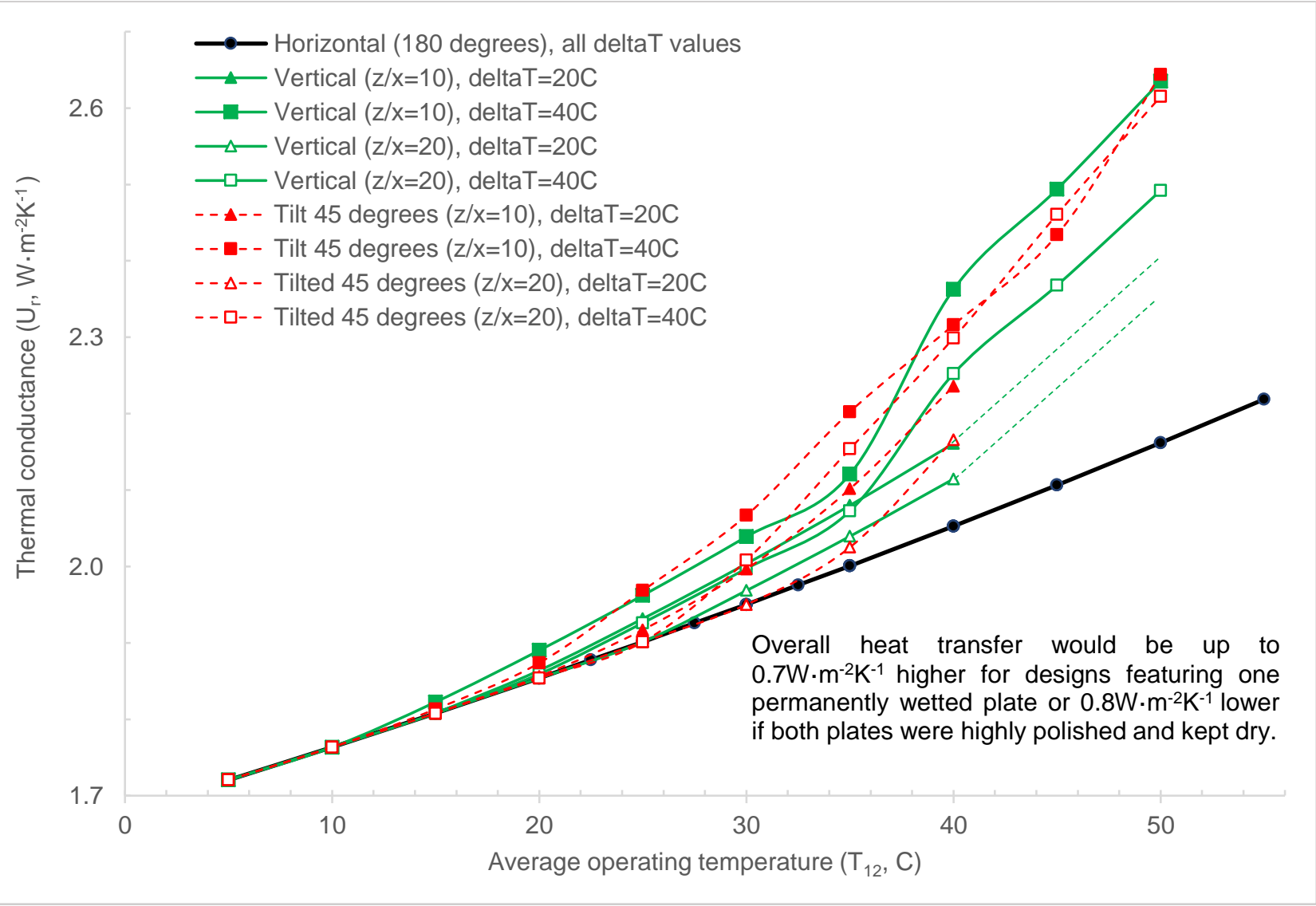

704 Figure 17 - Reverse mode temperature and heat flux dependence for $x=0.075, y=0.75, z=1.5 m$ stainless steel PLVTD 
706 A large-scale prototype PLVTD $(x=70 \mathrm{~mm}, y=700 \mathrm{~mm}$ and $z=1400 \mathrm{~mm})$ was designed,

707 fabricated and tested as an integral part of a novel PVT-PLVTD-ICSSWH hybrid solar

708 collector. Pugsley et al. (2016 \& 2017) and by Smyth (2019) describe the device and

709 present results of initial tests focused on characterization of the solar energy collection

710 behaviour. Two further papers are currently under peer-review for anticipated

711 publication in Solar Energy journal. The present paper provides detailed analysis

712 concerning the forward and reverse mode behaviour of the PLVTD component.

\section{$713 \quad 5.1 \quad$ Description of the prototype}

714 The prototype PVT-PLVTD-ICSSWH (see Figure 18) consisted of: 1) Removable

715 Transparent acrylic cover to minimise solar absorber heat loss; 2) Solar absorber

716 formed of quartered crystalline silicon photovoltaic cells covered by $2 \mathrm{~mm}$ transparent

717 acrylic pieces bonded to the matt black painted PLVTD evaporator plate using

718 transparent silicone resin; 3) Stainless steel PLVTD constructed of $0.9 \mathrm{~mm}$ plates and

719 sidewalls with tubular internal support struts and a falling film evaporator; 4) Hot water

720 storage tank (100L capacity) formed of a 4-sided rectangular box welded to the PLVTD

721 condenser plate and insulated externally with polystyrene foam (150mm thick).

722 Further details of the PLVTD are shown on Figure 19 including the evaporator wetting

723 mechanism and the arrangement of the thermal break incorporated to separate the

724 working fluid reservoir from the condenser plate (to reduce unwanted heat transfer

725 through $R_{L, V}$ ). The evaporator wetting system consisted of a small manifold-mount

726 centrifugal pump fitted to the base of the reservoir with a stainless steel pipe supplying

727 working fluid $\left(\mathrm{M}_{\llcorner} / \mathrm{y}=0.08 \mathrm{~kg} \cdot \mathrm{m}^{-1} \mathrm{~s}^{-1}\right.$ flow rate) to a linear distribution nozzle (of similar

728 to that described in Table 4) located at the head of the evaporator plate. The internal

729 supporting structure of the PLVTD consisted of $N_{s}=190$ tubular struts each ( $x=70 \mathrm{~mm}$

730 long, $d_{s}=8 \mathrm{~mm}$ diameter and $d_{s w}=0.9 \mathrm{~mm}$ wall thickness) spaced $d_{s s}=70 \mathrm{~mm}$ from one 
731 another and $d_{s x y}=d_{s x z}=35 \mathrm{~mm}$ from sidewalls. After repairing minor envelope vacuum

732 leaks at welded joints, the PLVTD enclosure was evacuated to $0.01 \mathrm{kPa}$, which removed

733 non-condensable gases and enabled injection of $m_{\llcorner v}=0.9 \mathrm{~kg}$ working fluid through an

734 arrangement of valves. Photographs showing the fabrication and initial testing of the

735 PLVTD and water tank are shown in Figure 20.

736

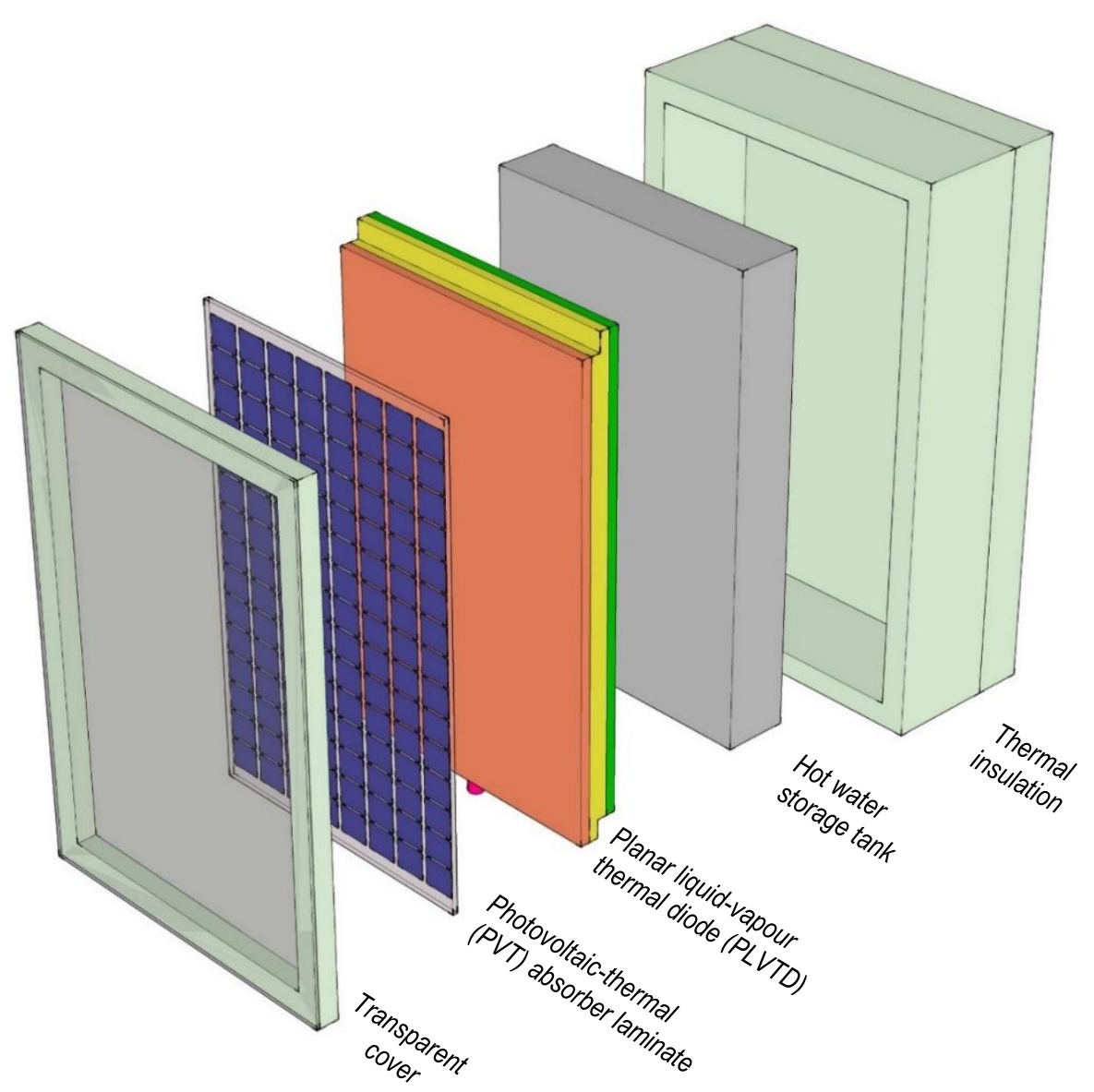

737

738 Figure 18 - Key components of the PVT-PLVTD-ICS solar collector prototype 


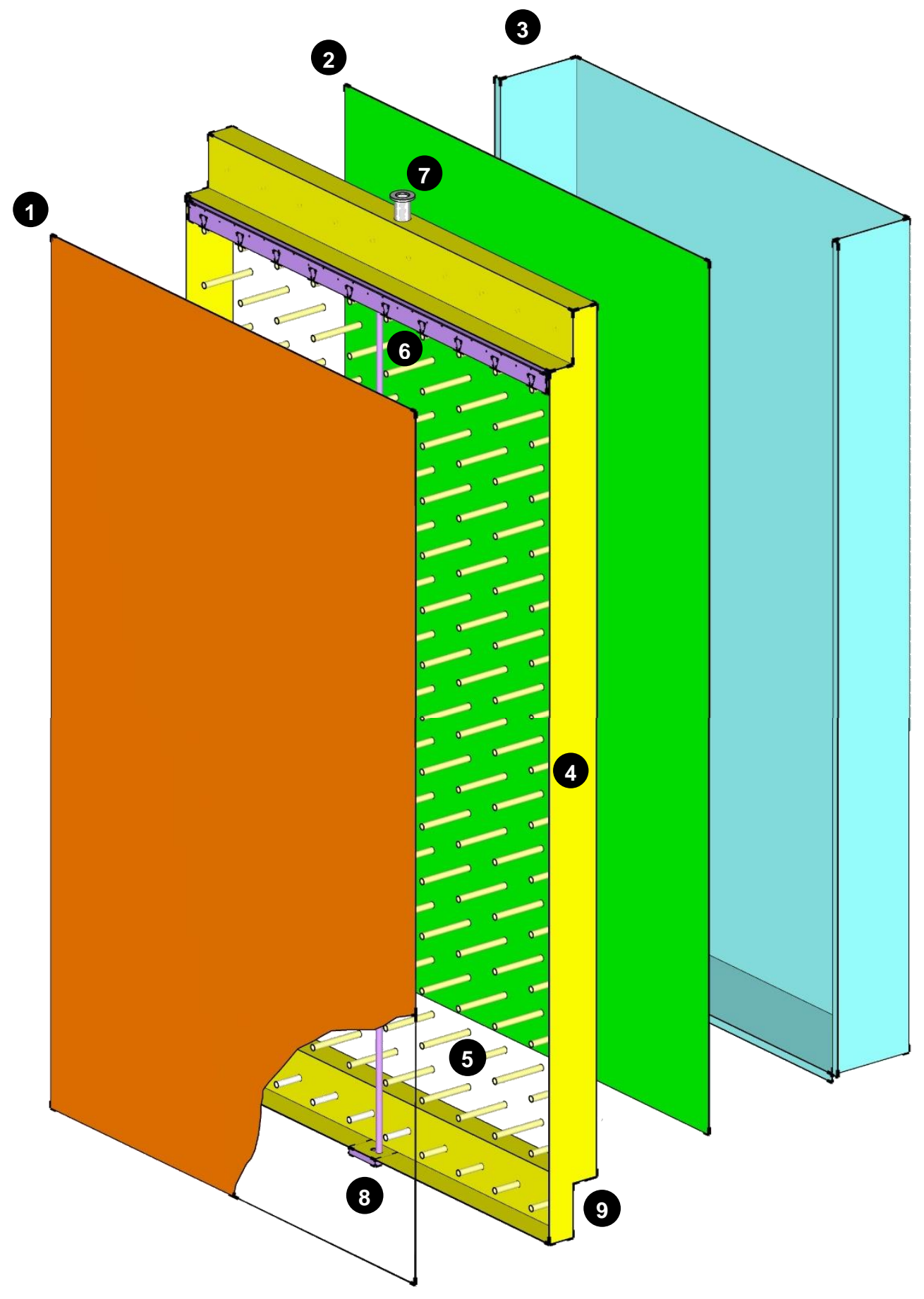

1) Absorber-Evaporator plate (12 thermocouples bonded to front surface to measure temperature $T_{1}$ )

2) Condenser-tank plate (12 thermocouples bonded to rear surface to measure temperature $T_{2}$ )

3) Water storage tank back, sides and base ( 5 submerged thermocouples measuring $T_{3}$ )

4) Sidewalls forming the top, bottom and sides of the PLVTD envelope

5) Array of tubular struts forming internal structure

6) Evaporator wetter distributer and diffuser nozzle

7) Spigot for vacuum pump connection and working fluid injection

8) Evaporator wetter pump mounting plate

9) Working fluid reservoir with thermal break separating from condenser plate ( 3 thermocouples bonded to base to measure $T L$ )

10) Insulation around tank and sides of PLVTD (omitted from illustration for clarity) 

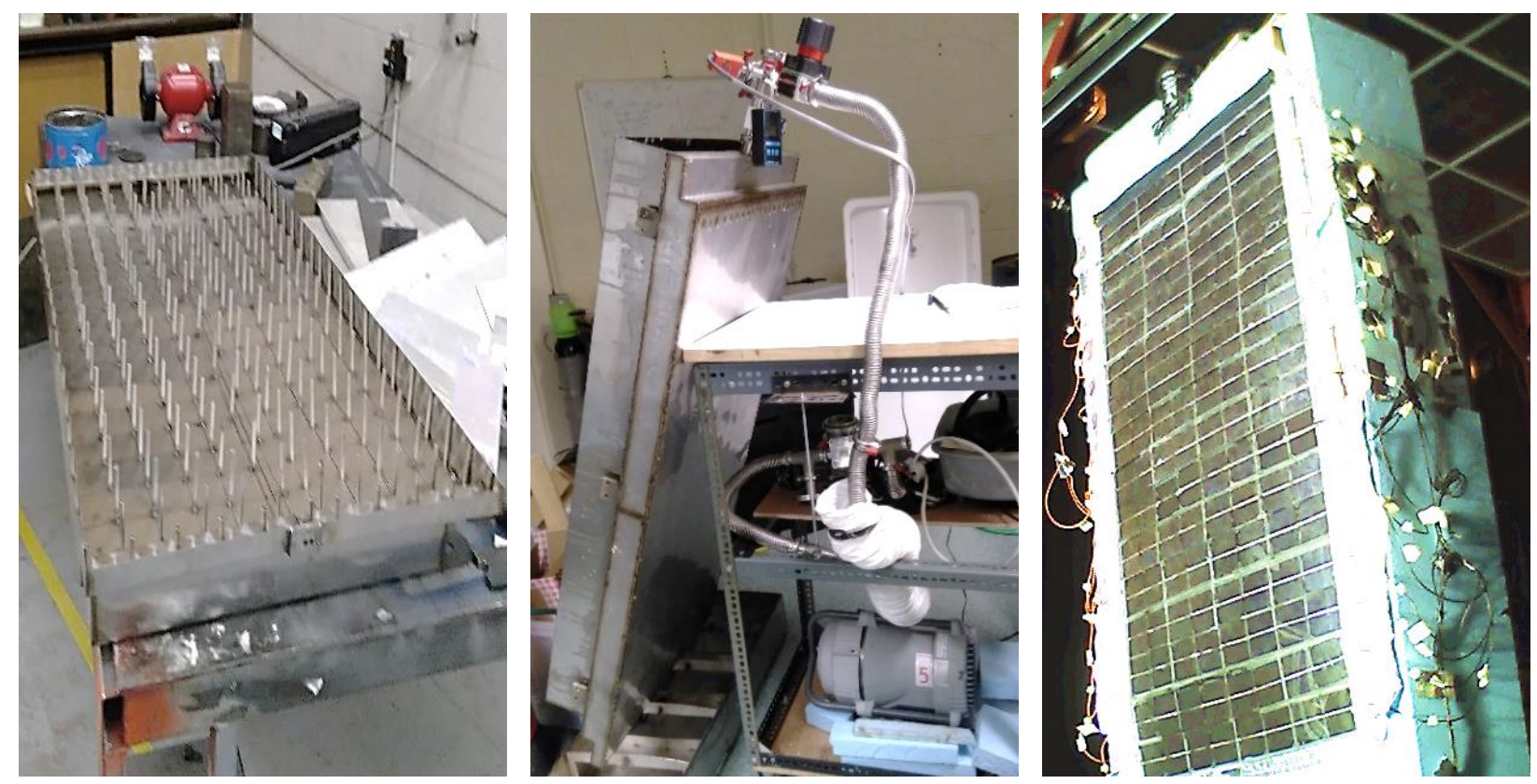

Figure 20 - Photographs of steelwork fabrication (a); leak testing (b); prototype complete with PV/T absorber surface and insulation (c)

\section{$745 \quad 5.2 \quad$ Experimental methodology}

746 The experimental methodology largely follows the precedents set by Smyth et al.

747 (2015b \& 2019) whereby the PVT-PLVTD-ICSSWH prototype is exposed to constant

748 vertical plane solar irradiance for 6 hours to simulate a daytime solar heat collection

749 period and is then left to cool overnight for 18 hours. Details of the experimental

750 procedure are described thoroughly by Pugsley et al. (2016 and 2017). The prototype

751 was fitted with 50 thermocouples (details as per Table 4, locations as per Figure 19)

752 to enable spatial temperature variations throughout the various components to be

753 monitored. Approximately half of the thermocouples were bonded to the outer surfaces

754 of the PLVTD to measure evaporator and condenser plate temperatures $\left(T_{1}\right.$ and $\left.T_{2}\right)$

755 and the working fluid liquid temperature $\left(T_{L}\right)$. These thermocouples were covered by

756 foam strips to shield them from unintended influences such as incident solar radiation

757 on $\mathrm{T}_{1}$ and direct contact with convecting water at $\mathrm{T}_{2}$. Most of the remaining

758 thermocouples were submerged in the water tank to measure the thermal store

759 temperature $\left(T_{3}\right)$ or distributed around the prototype to measure local ambient 
760 temperatures $\left(T_{a}\right)$. All thermocouples were connected to a datalogger (Delta-T devices

761 DL2e) which was configured to monitor continuously and record average temperatures

762 at 5 minute intervals. Initial tests were undertaken to determine thermal conductance

763 of the insulated water storage tank and PLVTD sidewalls by covering the evaporator

764 plate with $300 \mathrm{~mm}$ of insulation, filling the tank with water at $70^{\circ} \mathrm{C}$, and measuring the

765 time taken to cool to $\mathrm{T}_{\mathrm{a}}=23^{\circ} \mathrm{C}$ room temperature. Measurement results suggested

766 residual heat loss of $U_{3 a}=1.1 \mathrm{~W} \cdot \mathrm{m}^{-2} \cdot \mathrm{K}^{-1}$ over an area of $A_{3 a}=2.3 \mathrm{~m}^{2}$ decreasing with time

767 to $\mathrm{U}_{3 \mathrm{a}}=0.6 \mathrm{~W} \cdot \mathrm{m}^{-2} \cdot \mathrm{K}^{-1}$ as the tank temperature reduced towards ambient. After removing

768 the $300 \mathrm{~mm}$ insulation, the prototype was then positioned in front of a large vertically

769 oriented solar simulator (Zacharopoulos et al., 2009) and measurements of solar

770 irradiance across the absorber-evaporator plate were made for several different light

771 source setpoints $\left(\mathrm{G}=870,610\right.$ and $370 \mathrm{~W} \cdot \mathrm{m}^{-2}$ with $\pm 10 \%$ uniformity over the whole

772 surface) using a calibrated pyranometer (Kipp \& Zonen CM4). Multiday tests were then

773 undertaken with the prototype exposed to each irradiance setpoint for several

774 consecutive days. One multiday test (see time history on Figure 24) was undertaken

775 with the transparent cover in place but the majority (Figures 21 to 23) were undertaken

776 with it removed. The storage tank temperature $\left(T_{3}\right)$ change with time (t) was used to

777 calculate the instantaneous thermal power $\left(\mathrm{q}_{3}\right)$ and hence the instantaneous heat flux

778 through the thermal diode ( $q_{12} / A_{p}$ according to Equation 24$)$ allowing for PLVTD surface

779 area $\left(A_{p}=0.98 \mathrm{~m}^{2}\right)$, specific heat capacity of water $\left(c_{p}=4180 \mathrm{~J} \cdot \mathrm{kg}^{-1} \cdot \mathrm{K}^{-1}\right)$ and the mass

780 of water contained in the tank $\left(m_{3}=100 \mathrm{~kg}\right)$.

$781 \quad \frac{q_{12}}{A_{p}}=\frac{q_{3}}{A_{p}}=\frac{m_{3} c_{p} \Delta T_{3}}{A_{p} \Delta t}$

Equation 24 


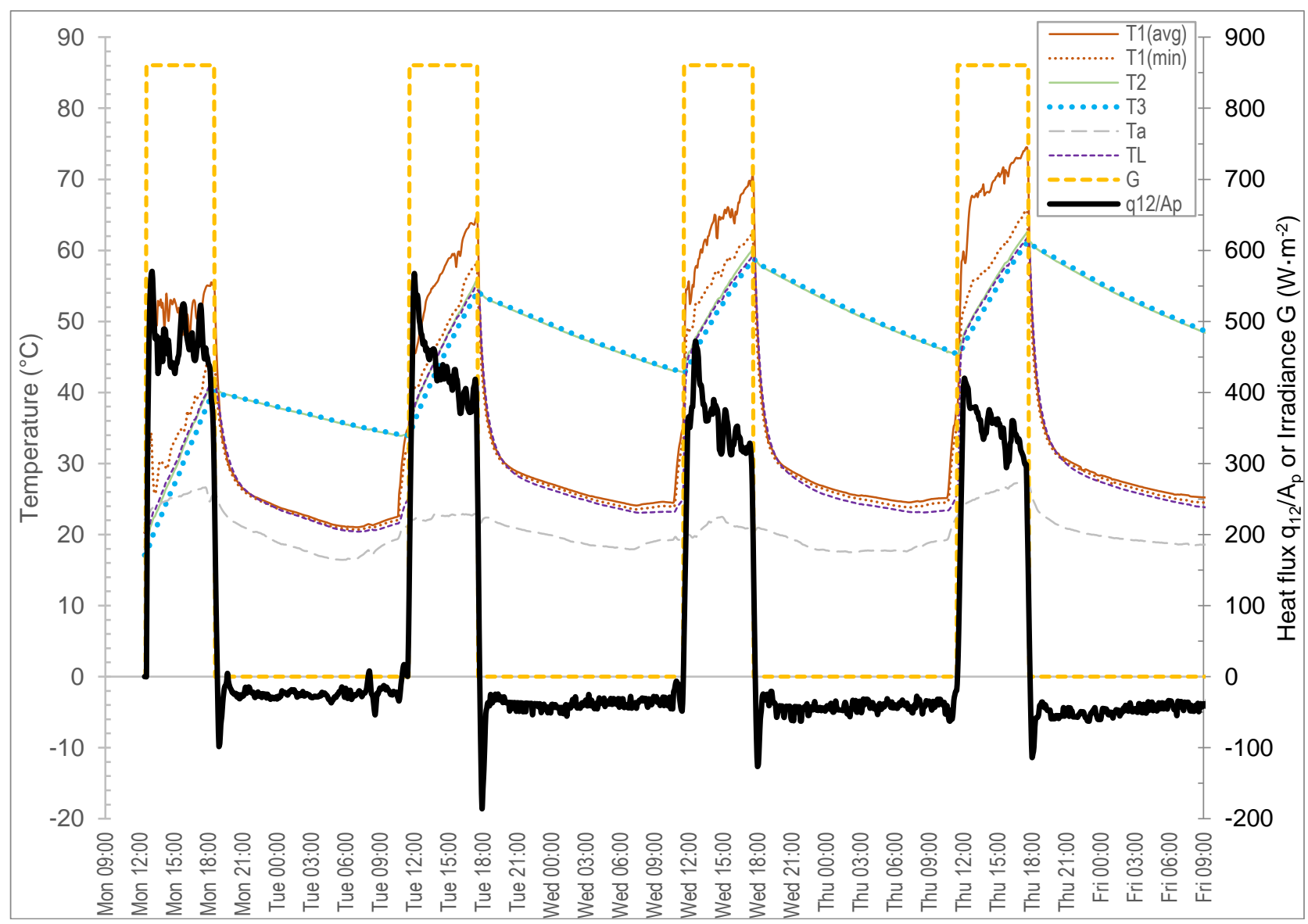

Figure 21 - Temperature and heat flux time history results for tests under high irradiance without absorber transparent cover

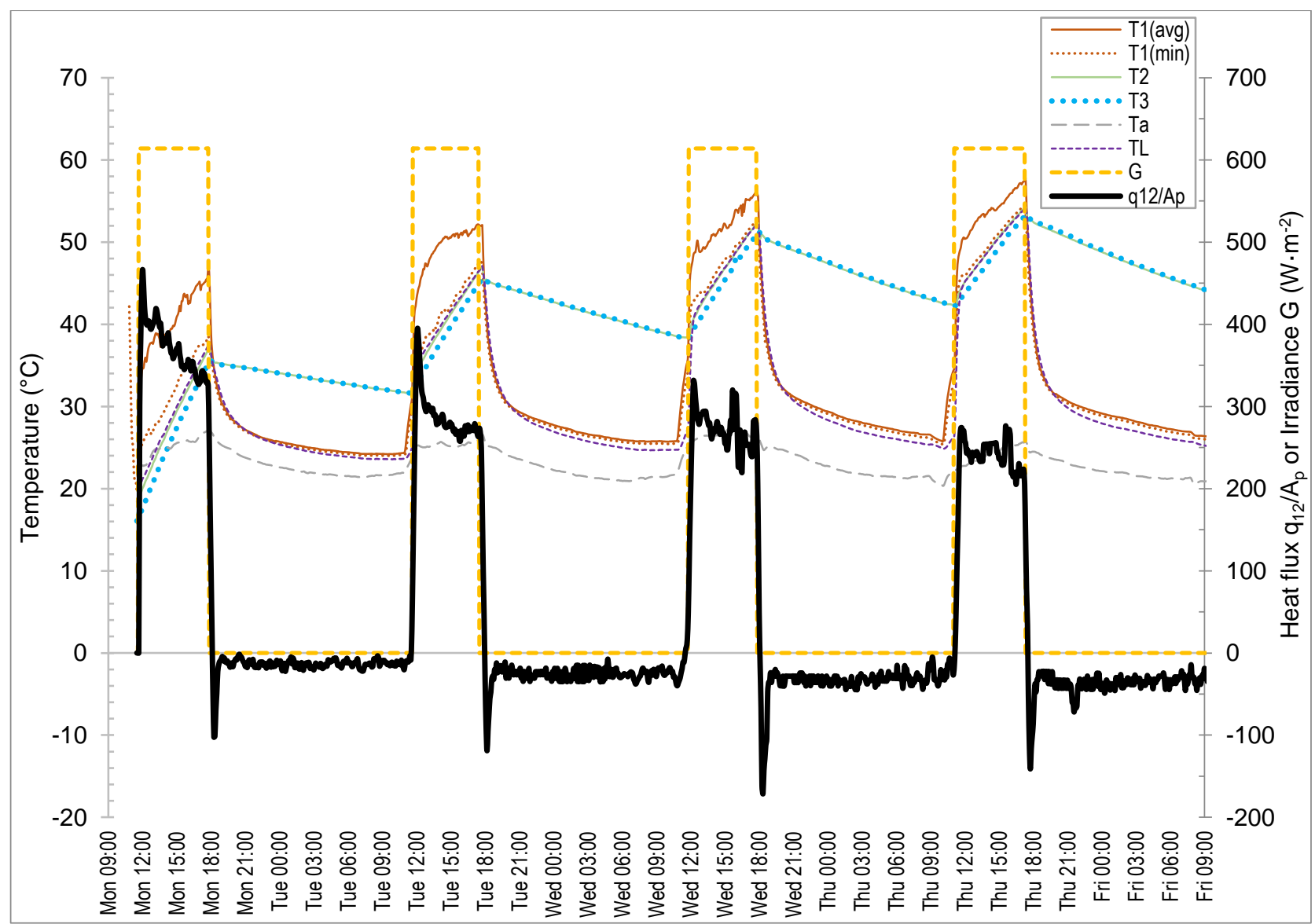




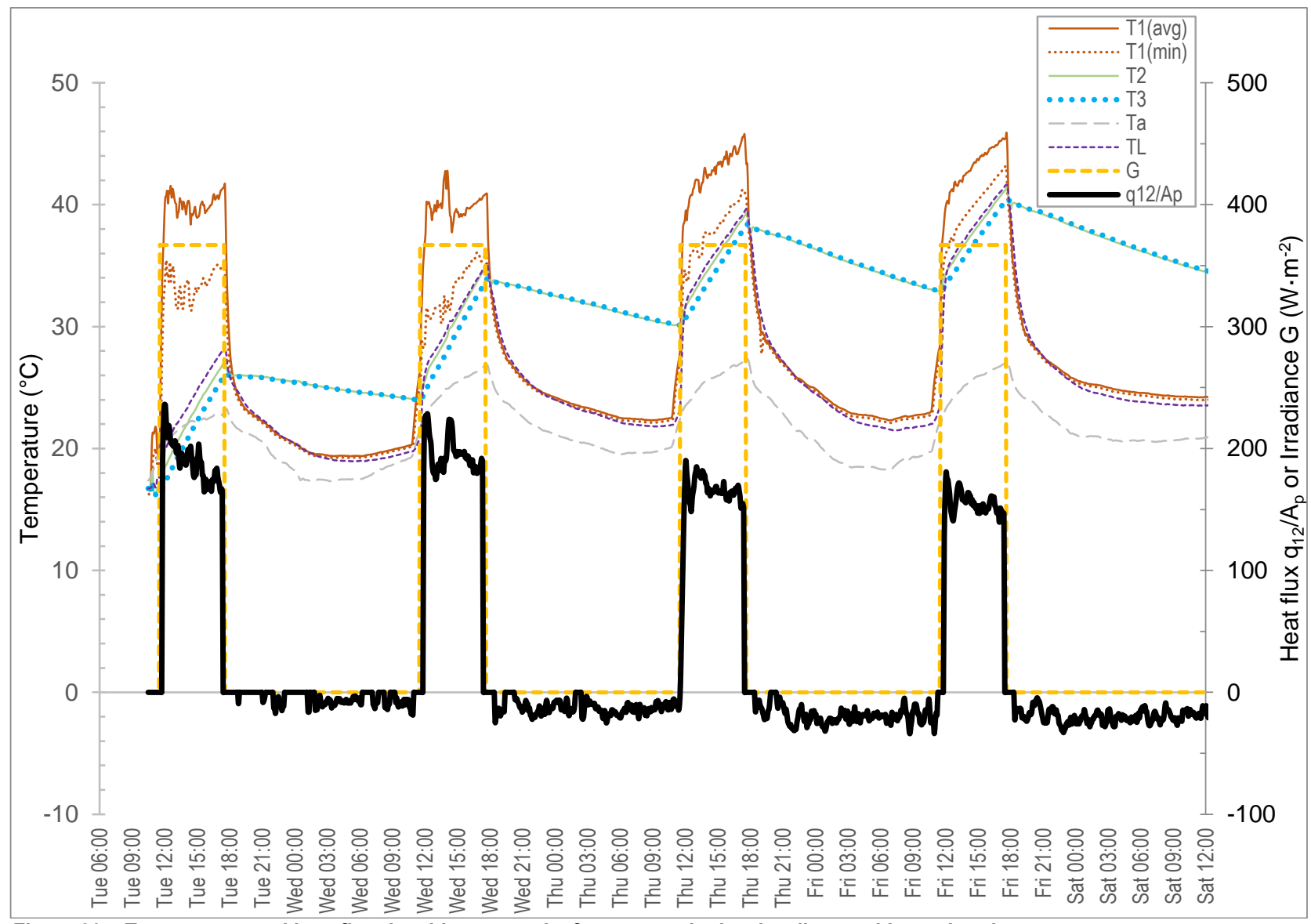

Figure 23 - Temperature and heat flux time history results for tests under low irradiance without absorber transparent cover

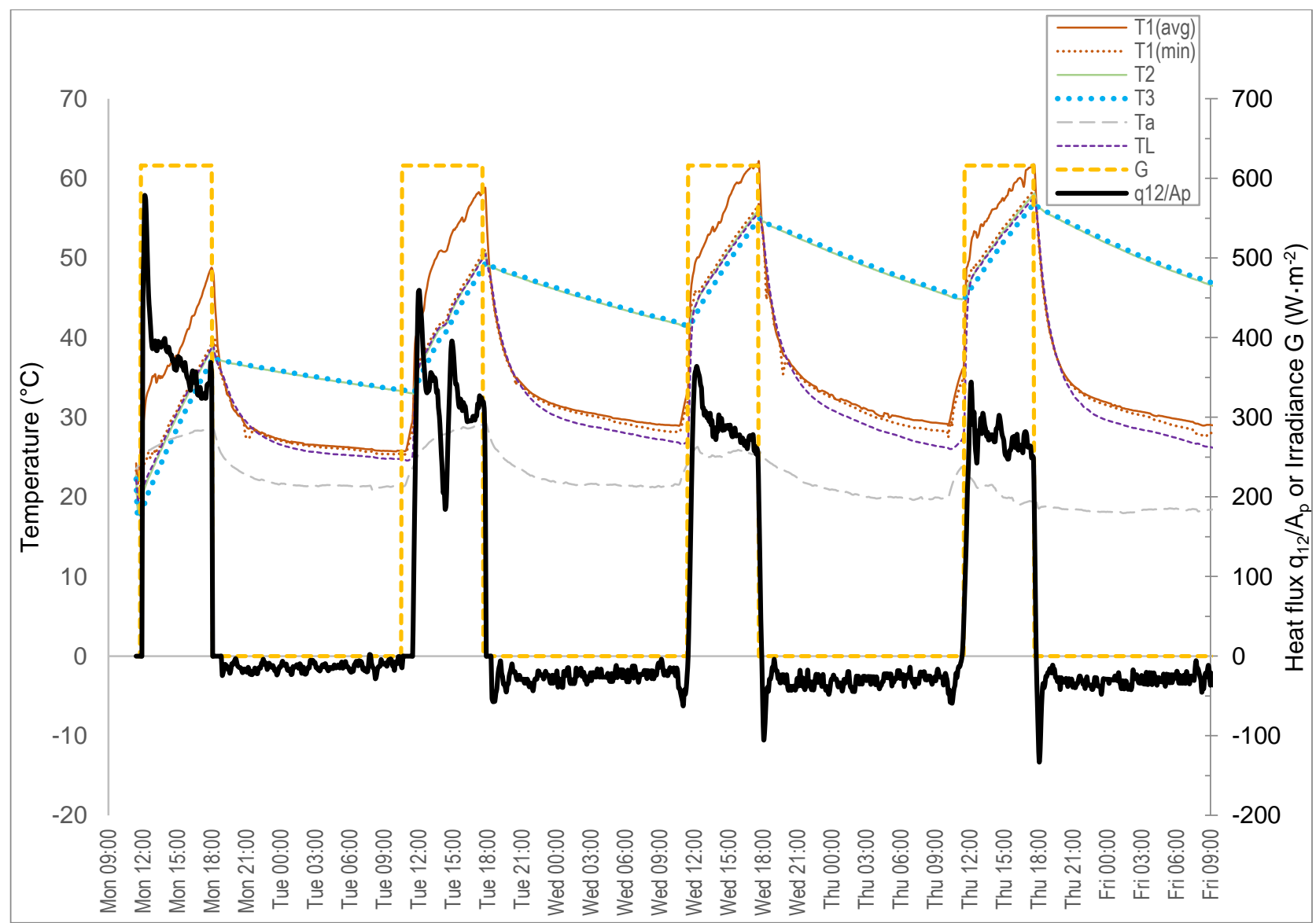




\section{$791 \quad 5.3 \quad$ Results}

792 The PLVTD's diodic behaviour is evident on Figures 21 to 24 . Forward mode occurs

793 when the prototype is exposed to irradiance (G) which causes the absorber-evaporator 794 plate temperature $\left(T_{1}\right)$ to rise and for heat flux $\left(50<q_{12} / A_{p}<600 \mathrm{~W} \cdot \mathrm{m}^{-2}\right)$ to be 795 transmitted to the condenser-tank plate $\left(T_{2}\right)$ across the plate-to-plate temperature 796 difference $\left(3<\Delta \mathrm{T}_{12}<30^{\circ} \mathrm{C}\right)$ causing a steady increase in water storage tank 797 temperature $\left(T_{3}\right)$. Reverse mode occurs when irradiance ceases $(G=0)$ causing the 798 absorber-evaporator plate temperature to fall below that of the condenser-tank plate $799\left(5<-\Delta T_{12}<25^{\circ} \mathrm{C}\right)$ and for a steady heat loss flux $\left(15<-\mathrm{q}_{12} / \mathrm{A}_{\mathrm{p}}<60 \mathrm{~W} \cdot \mathrm{m}^{-2}\right)$ to develop 800 causing a steady decrease in $\mathrm{T}_{3}$. Distinct transients are apparent on Figures 21,22 and 80124 (medium and high irradiance tests) during forward-to-reverse mode switching 802 which causes temporarily high heat loss fluxes (up to $-q_{12} / A_{p} \approx 150 \mathrm{~W} \cdot \mathrm{m}^{-2}$ ) to occur 803 immediately following each solar simulator switch-off event. These transients are 804 caused by unwanted reverse mode latent heat transfer which occurs when residual 805 liquid on the condenser-tank plate flashes off causing vapour to flow across the cavity 806 and condense on the absorber-evaporator plate. The phenomenon is typically 807 sustained for about half an hour at a steadily decreasing rate until the condenser-tank 808 plate eventually becomes dry causing latent heat transfer to cease. 


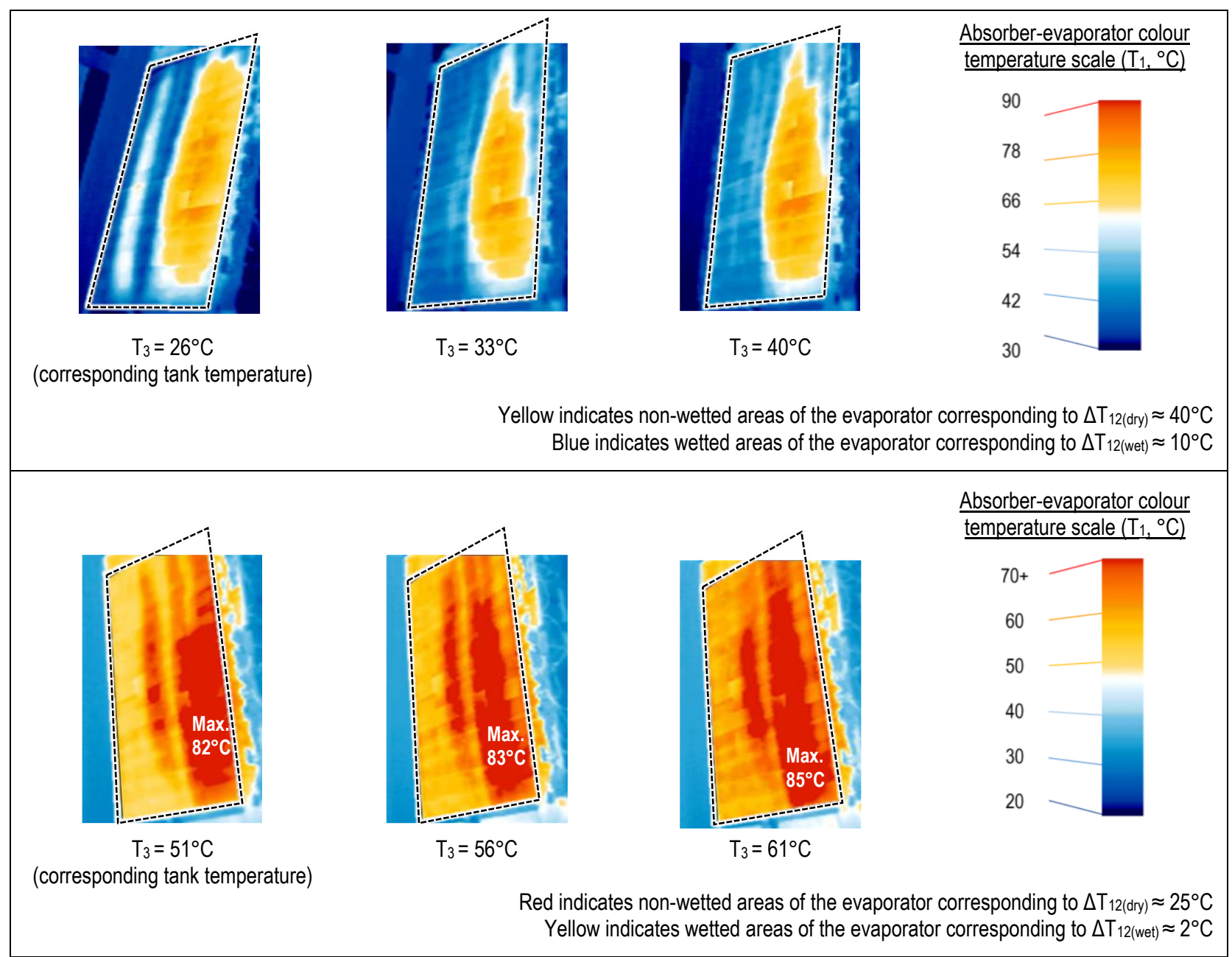

811 Figure 25 - Infrared thermographic images of the absorber-evaporator plate during high irradiance tests

813 A thermographic camera (Testo 875-1i) was used to evaluate absorber-evaporator 814 plate temperature uniformity (see Figure 25) with the primary aim of ascertaining the 815 effectiveness of the evaporator wetting mechanism. During forward mode operation, 816 dry areas of the evaporator will be much hotter than the wetted areas owing to lack of

817 latent heat removal. Image analysis using specialist software (Testo SuperResolution) 818 enabled wetted proportions of the evaporator ( $A \%$ wet $)$ to be estimated. Only $\sim 10 \%$ 819 appears to be fully wetted at low temperatures $\left(T_{3} \approx 15^{\circ} \mathrm{C}\right)$ but this increases to $\sim 75 \%$ 820 at $\mathrm{T}_{3} \approx 45^{\circ} \mathrm{C}$, seemingly due to improved spreading/adhesion to the evaporator surface 821 as fluid viscosity and surface tension reduce with increasing temperature. Evaporator 822 dry-out was observed to occur during high temperature and high irradiance conditions, 
823 seemingly caused by evaporator wetter pump malfunction (audible noise and reduced

824 current draw). Possible reasons for the malfunction include cavitation (fluid vapourising

825 on the pump impeller) and lack of liquid in the working fluid reservoir (more fluid exists

826 as vapour when operating at high temperatures). Detailed inspection of $>100$

827 thermographic images (Pugsley, 2017) suggests that the degree of apparent

828 evaporator wetting correlates reasonably well with the condenser temperature

829 according to the relation $A \%_{\text {wet }} \approx-0.086\left(\mathrm{~T}_{2}\right)^{2}+7.2\left(\mathrm{~T}_{2}\right)-80$ (valid for $15<\mathrm{T}_{2}<65$ ).

830 Wetted region temperatures (Figure 25) typically correspond to minimum absorber-

831 evaporator plate temperatures recorded by the datalogged thermocouples ( $T_{1(\min )}$ on

832 Figures 21-24). Reverse mode thermal conductances $\left(U_{r}\right)$ are presented on Figure 26

833 with reference to average PLVTD operating temperature $T_{12}=\left(T_{1 \text { (avg) }}+T_{2}\right) / 2$. Reported

834 results are raw datapoints calculated using Equations 1 and 23 with plate-to-plate

835 temperature difference derived from plate spatial averages $\left(\Delta \mathrm{T}_{12}=\mathrm{T}_{1(\mathrm{avg})}-\mathrm{T}_{2}\right)$. Measured

836 results for quasi-steady state conditions (typically $\mathrm{U}_{\mathrm{r}} \approx 1.6 \mathrm{~W} \cdot \mathrm{m}^{-2} \mathrm{~K}^{-1}$ at low temperatures

837 increasing to $\mathrm{U}_{\mathrm{r}} \approx 1.9 \mathrm{~W} \cdot \mathrm{m}^{-2} \mathrm{~K}^{-1}$ at high temperatures) are very similar to model

838 predictions $\left(1.7<\mathrm{U}_{\mathrm{r}}<2.5 \mathrm{~W} \cdot \mathrm{m}^{-2} \mathrm{~K}^{-1}\right.$ on Figure 17$)$. Forward-to-reverse mode switching

839 transients caused by the abrupt loss of input heat flux associated with solar simulator

840 switch-off are clearly apparent on Figure 26 as vertical steaks with magnitudes in the

841 range $0.5<U_{r}<278 \mathrm{~W} \cdot \mathrm{m}^{-2} \mathrm{~K}^{-1}$ which have been excluded from the quasi-steady state

842 dataset. These transients illustrate the PLVTD's forward-to-reverse mode switching

843 behaviour whereby the flashing of residual condensate temporarily causes unwanted

844 latent heat transfer in the reverse direction until condenser dry-out occurs and reverse

845 mode heat transfer behaviour reaches the quasi-steady state (typically after a period

846 of between 30 and 90 minutes).

847 


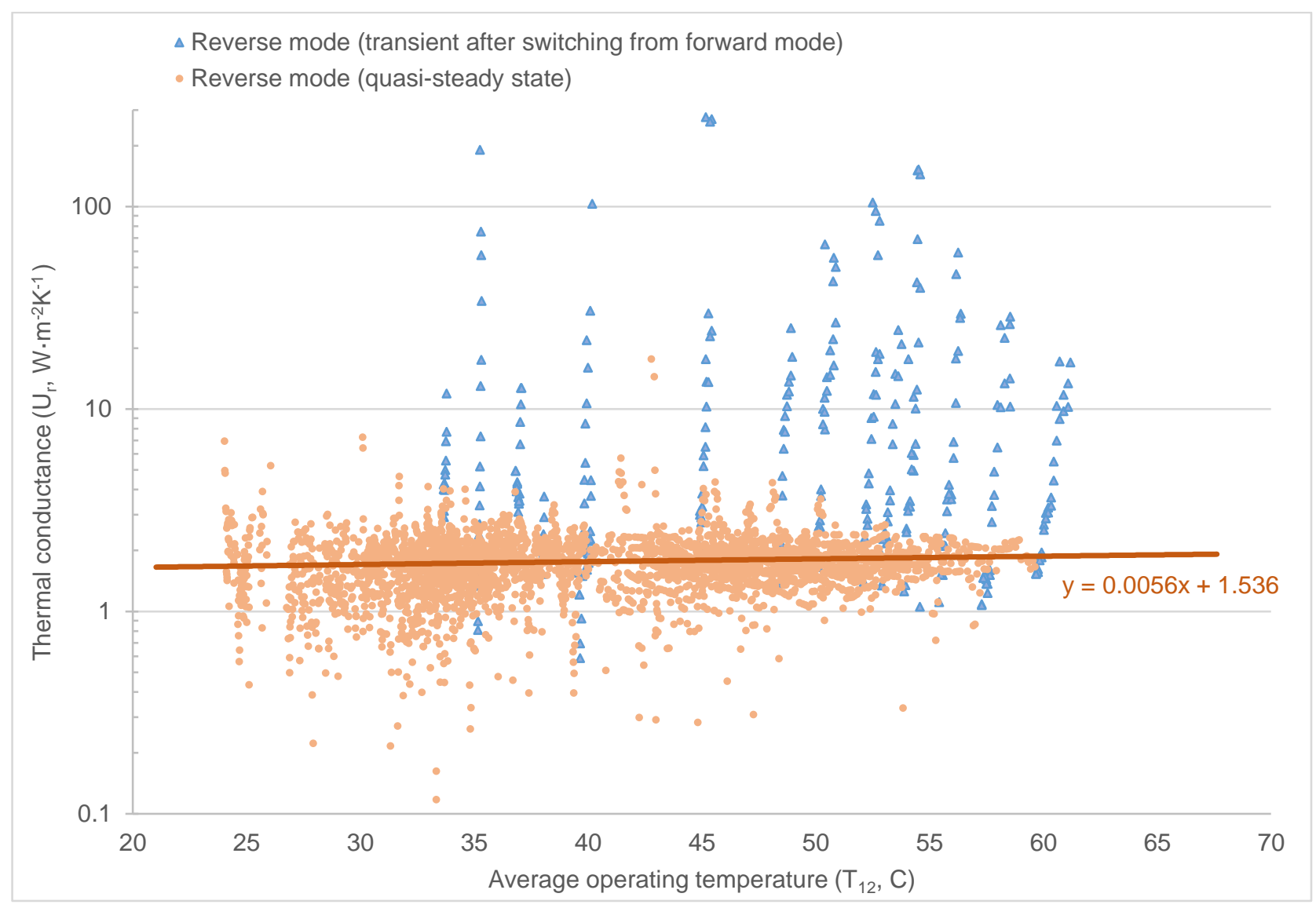

849 Figure 26 - Thermal conductances across the PLVTD in reverse mode

851 Forward mode thermal conductance measurement results $\left(\mathrm{U}_{\mathrm{f}}\right)$ are presented on

852 Figure 27 and compared to four example predictions from the model (red datapoints 853 which corresponding directly to red datapoints highlighted on Figures $15 \& 16$ ).

854 Measured thermal conductances would have ideally been derived according to 855 Equations 1 and 24 based on the measured thermal power flowing through the PLVTD $856\left(\mathrm{q}_{12}\right)$, the average plate-to-plate temperature difference $\left(\Delta \mathrm{T}_{12}=\mathrm{T}_{1}-\mathrm{T}_{2}\right)$, and the overall 857 PLVTD plate area $\left(A_{p}\right)$, as was the case for the reverse mode results reported on 858 Figure 26. However, owing to aforementioned issues concerning non-uniform 859 evaporator wetting, the forward mode results reported on Figure 27 have been 860 calculated based on the minimum plate-to-plate temperature difference $861 \Delta T_{12(\min )}=T_{1(\min )}-T_{2}$ and the estimated heat transfer area $A_{p} \cdot A \%_{\text {wet }}$ (estimated using the $862 A \%_{\text {wet }} \approx-0.086\left(\mathrm{~T}_{2}\right)^{2}+7.2\left(\mathrm{~T}_{2}\right)-80$ relation determined from the thermographic 863 analysis) to enable non-wetted parts of the evaporator to effectively be ignored. Owing 
864 to significant scatter in the dataset, and the inherent limited ability to exert 865 independent control over PLVTD heat flux and plate temperatures during solar 866 simulator tests, thermal conductances have been reported as group average values 867 calculated by sorting the dataset into $\mathrm{q}_{12} / \mathrm{A}_{\mathrm{p}} \pm 50 \mathrm{~W} \cdot \mathrm{m}^{-2}$ and $\mathrm{T}_{2} \pm 3^{\circ} \mathrm{C}$ bins (as denoted by 868 the horizontal bars on Figure 27) enabling trends to be identified.

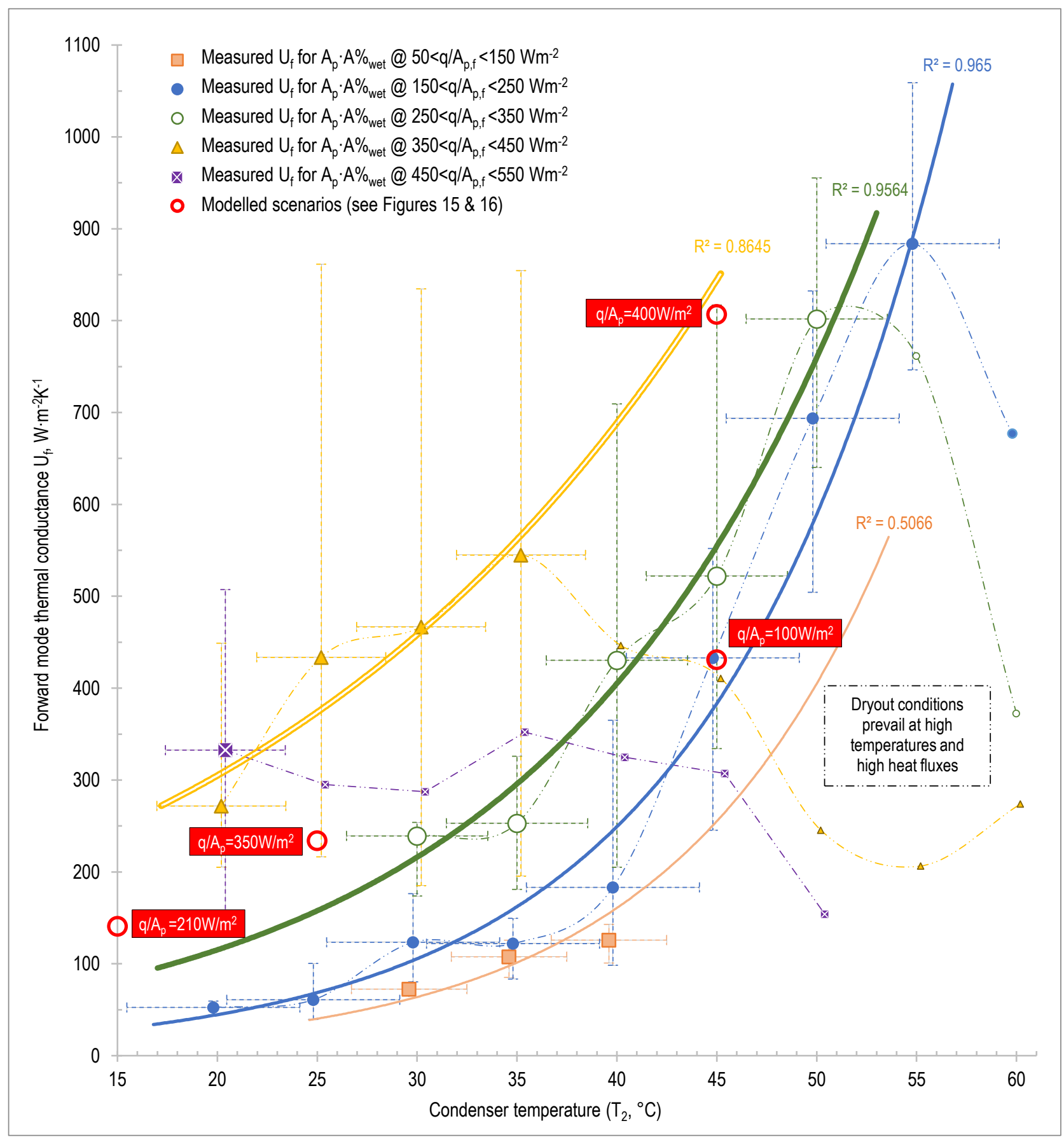

871 Figure 27 - Measured forward mode thermal conductances (wetted areas only) compared to four modelled operating scenarios 
872 Thermal conductances increase from $\mathrm{U}_{\mathrm{f}} \approx 50 \mathrm{~W} \cdot \mathrm{m}^{-2} \mathrm{~K}^{-1}$ at low temperatures and low heat

873 fluxes up to $U_{\mathrm{f}} \approx 900 \mathrm{~W} \cdot \mathrm{m}^{-2} \mathrm{~K}^{-1}$ at the highest reliably measurable temperatures and heat

874 fluxes. Results for $T_{2}>55^{\circ} \mathrm{C}$ at $q_{12} / A_{p}>200 W \cdot m^{-2}, T_{2}>50^{\circ} \mathrm{C}$ at $q_{12} / A_{p}>300 W \cdot m^{-2}$,

$875 \mathrm{~T}_{2}>35^{\circ} \mathrm{C}$ at $\mathrm{q}_{12} / \mathrm{A}_{\mathrm{p}}>400 \mathrm{~W} \cdot \mathrm{m}^{-2}$, and almost all data for $\mathrm{q}_{12} / \mathrm{A}_{\mathrm{p}}>500 \mathrm{~W} \cdot \mathrm{m}^{-2}$ were affected

876 by evaporator dry-out and are therefore excluded from calculated trends. Comparison

877 with the four modelled datapoints indicates good correspondence at $\mathrm{T}_{2}=45^{\circ} \mathrm{C}$ for

$878 q_{12} / A_{p}=350 \mathrm{~W} / \mathrm{m}^{2}, T_{2}=25^{\circ} \mathrm{C}$ for $q_{12} / A_{p}=400 \mathrm{~W} / \mathrm{m}^{2}$ and $T_{2}=25^{\circ} \mathrm{C}$ for $q_{12} / A_{p}=210 \mathrm{~W} / \mathrm{m}^{2}$ but

879 suggests the prototype performs worse than expected at $\mathrm{T}_{2}=45^{\circ} \mathrm{C}$ for

$880 \mathrm{q}_{12} / \mathrm{A}_{\mathrm{p}}=100 \mathrm{~W} / \mathrm{m}^{2}$. The model suggests that performance at low temperatures and low

881 heat fluxes is determined primarily by vapour mass flow dynamics (thermal resistance

$882 R_{e c}$ ) which may have been adversely affected by evaporator plate temperature non-

883 uniformities (see Figure 25). It must be remembered that results reported on Figure 27

884 represent thermal conductances associated with wetted areas of the evaporator only.

885 Calculated true overall forward mode performances evaluated for the whole PLVTD 886 plate area ( $A_{p}$, inclusive of non-wetted parts of the evaporator) typically ranged from $887 \mathrm{U}_{\mathrm{f}} \approx 10 \mathrm{~W} \cdot \mathrm{m}^{-2} \mathrm{~K}^{-1}$ at low temperatures up to $\mathrm{U}_{\mathrm{f}} \approx 85 \mathrm{~W} \cdot \mathrm{m}^{-2} \mathrm{~K}^{-1}$ at high temperatures as 888 reported by Pugsley et al. (2016 and 2017).

889 Trends exhibited by the measured thermal conductances are summarised on Figure 28 890 along with the corresponding diodicities (calculated according to Equation 2). Maximum 891 diodicity occurs at the highest condenser temperatures $\left(s=99.9 \%\right.$ at $\left.T_{2}=60^{\circ} \mathrm{C}\right)$ where 892 it is largely independent of heat flux. Diodicity is reduced at lower temperatures and 893 exhibits strong dependency upon the forward mode heat flux such that relatively high 894 diodicity $\left(\varsigma=99.5 \%\right.$ at $\left.T_{2}=20^{\circ} \mathrm{C}\right)$ is maintained at $\mathrm{q} / \mathrm{A} \approx 400 \mathrm{~W} \cdot \mathrm{m}^{-2}$ but this is 895 significantly reduced $\left(s=88.2 \%\right.$ at $T_{2}=20^{\circ} \mathrm{C}$ ) at $\mathrm{q} / \mathrm{A} \approx 100 \mathrm{~W} \cdot \mathrm{m}^{-2}$. The suggested targets 896 of $\varsigma>97 \%$ for CCBE applications and $\varsigma>99 \%$ for BISTS/BIPV applications (refer to 897 Section 2.2) appear to be achievable provided that the intended heating temperature 898 is high enough $\left(\mathrm{T}_{2}>25^{\circ} \mathrm{C}\right.$ for $\mathrm{CCBE}$ and $\mathrm{T}_{2}>40^{\circ} \mathrm{C}$ for BISTS) and available heat flux is 
$899 \mathrm{q} / \mathrm{A}>250 \mathrm{~W} \cdot \mathrm{m}^{-2}$, as would typically be the case. The aforementioned diodicities were 900 calculated with reference to the forward mode thermal conductances for wetted areas 901 of the evaporator only in order to represent what would occur in a PLVTD with uniform 902 evaporator wetting. Calculated diodicites are notably lower $\left(s=72.5 \%\right.$ at $\mathrm{T}_{2}=20^{\circ} \mathrm{C}$, 903 rising to $\varsigma=95.7 \%$ at $\mathrm{T}_{2}=60^{\circ} \mathrm{C}$ ) when non-wetted parts of the evaporator are accounted 904 for, which highlights the importance of ensuring uniform evaporator wetting.

905

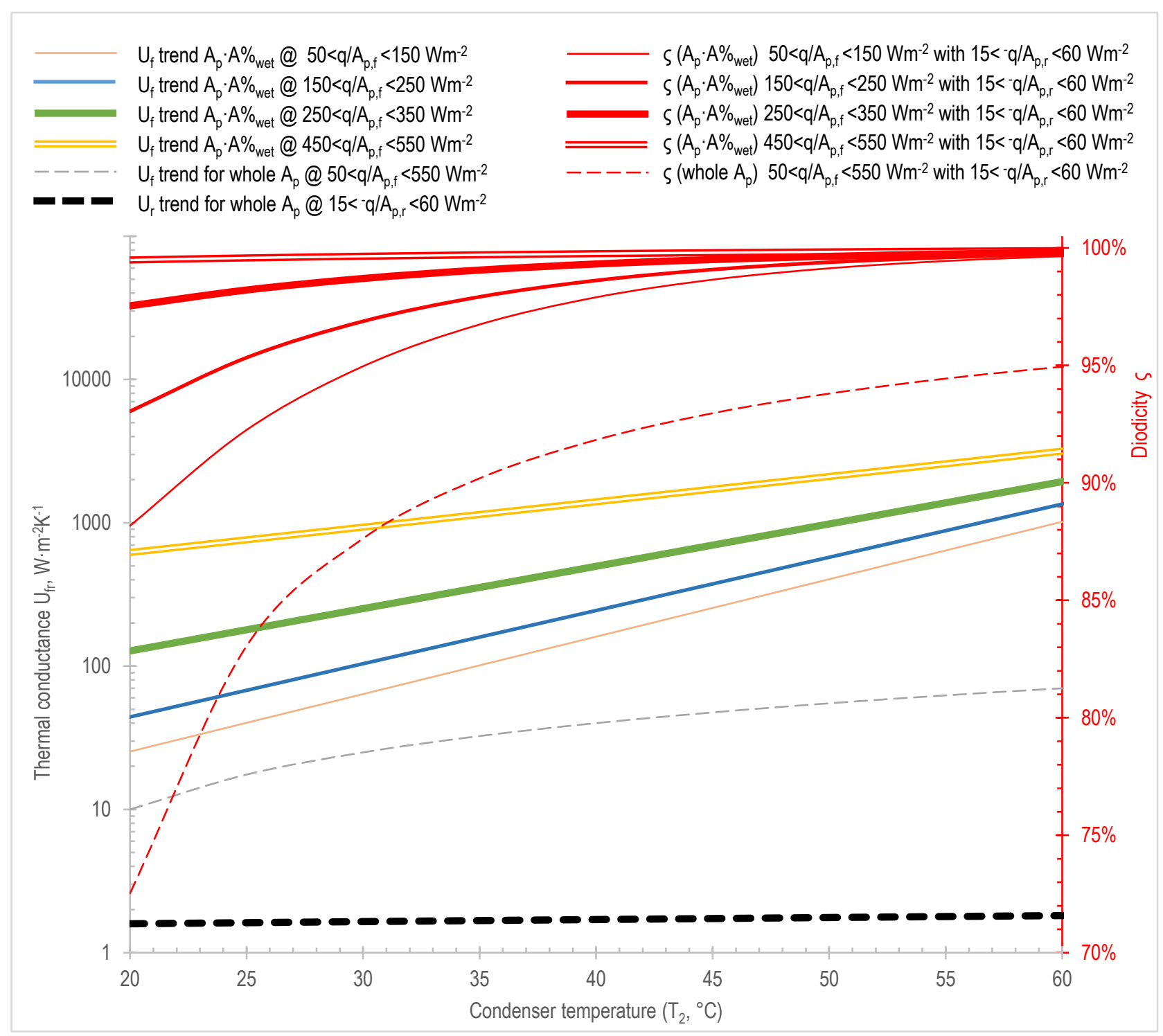




\section{$909 \quad 5.4 \quad$ Future improvements}

910 Future PLVTD design development could investigate the use of superhydrophillic

911 evaporator surfaces (Boreyko and Chen, 2013) or capillary wicks (Souliotis et al.,

912 2011; Muhumuza et al., 2019), together with nozzle design and flow rate optimization

913 to improve wetting uniformity. The large stainless steel PLVTD suffered more problems

914 with wetting uniformity than the initial smaller aluminium prototype, partly because

915 the wetter nozzle was difficult to fabricate accurately at a larger size (aperture width

916 varied along the length and was wider than intended in several places) but also perhaps

917 due to differing evaporator surface hydrophillicities. Preliminary investigations on

918 evaporator wetter flow rates reported by Pugsley (2017) suggested that doubling $M_{\llcorner} / y$

919 from 0.08 to $0.16 \mathrm{~kg} \cdot \mathrm{m}^{-1} \mathrm{~s}^{-1}$ more than doubled $U_{\mathrm{f}}$ in a stainless steel PLVTD with poor

920 wetting uniformity, and likewise, halving to $\mathrm{M}_{\mathrm{L}} / \mathrm{y}=0.04 \mathrm{~kg} \cdot \mathrm{m}^{-1} \mathrm{~s}^{-1}$ reduced $\mathrm{U}_{\mathrm{f}}$ by $\sim 50 \%$.

921 The effect was less significant for the PLVTD with a uniformly wetted aluminium

922 evaporator where varying flow rate in the range $0.03<M_{\llcorner} / y<0.07 \mathrm{~kg} \cdot \mathrm{m}^{-1} \mathrm{~s}^{-1}$ influenced

$923 U_{f}$ by only $\pm 25 \%$ relative to the $M_{\llcorner} / y=0.05 \mathrm{~kg} \cdot \mathrm{m}^{-1} \mathrm{~s}^{-1}$ baseline. It may be possible to

924 eliminate the need for a wetter pump (and its associated parasitic power needs) by

925 employing a suitable capillary wick, thereby making the vertical PLVTD an entirely

926 passive device akin to the horizontal PLVTD investigated Pugsley et al. (2019). A

927 suitable wick would need to achieve capillary lift across the full height of the evaporator

928 at a flow rate sufficient to prevent dry-out. This may necessitate reduction of

929 evaporator plate height (z) which would also affect PLVTD aspect ratios. The model

930 suggests that increasing cavity depth $(x)$ improves reverse mode performance by

931 increasing thermal resistances $R_{v}, R_{w}$ and $R_{s}$ whilst also improving forward mode

932 performance by decreasing $R_{e c}$. However, reducing aspect ratio $(z / x)$ to make the

933 PLVTD less slender has the opposite effect. Future PLVTD research and development

934 should investigate transient behaviour in more detail. It should be possible to reduce

935 unwanted reverse mode latent heat transfer (transients occurring after forward-to- 
936 reverse mode switching) by increasing condenser plate hydrophobicity (coatings or

937 surface treatments) to minimise the amount of residual condensate clinging to the

938 plate surface. Results also indicate a degree of performance lag during reverse-to-

939 forward mode switching which is probably associated with the thermal masses

940 (evaporator plate and working fluid) that must be heated to enable evaporation to

941 occur. Total thermal mass can be reduced by minimizing evaporator plate thickness

$942\left(\mathrm{x}_{\mathrm{pe}}\right)$, minimizing the amount of vapour contained in the cavity $\left(\mathrm{m}_{\mathrm{v}}\right)$ and minimizing

943 the amount of liquid held in the working fluid reservoir $\left(m_{L}\right)$. Unfortunately, each of

944 these approaches have knock-on effects on other PLVTD design aspects. For example,

945 reducing $x_{p e}$ will reduce plate strength and increase requirements for internal structural

946 support (reduced $d_{s s}$ and increased $N_{s}$ ) resulting in worsened $U_{s}$ thermal bridging.

947 Reducing $\mathrm{m}_{\vee}$ requires cavity dimensions (particularly $\mathrm{x}$ ) to be minimized which impairs

948 reverse mode performance. The degree to which $m_{L}$ can be reduced is constrained by

949 the need to avoid dry-out during high temperature operation (ie when $\mathrm{m}_{\mathrm{v}}$ is highest).

950 The small aluminium PLVTD which contained $\mathrm{m}_{\mathrm{Lv}} / \mathrm{yz}=1.7 \mathrm{~kg} / \mathrm{m}^{2}$ suffered fewer dry-out

951 problems than the larger stainless steel PLVTD which contained only $\mathrm{m}_{\mathrm{Lv}} / \mathrm{yz}=0.9 \mathrm{~kg} / \mathrm{m}^{2}$.

952 Investigations by Pugsley (2017) found that increasing working fluid quantity to

$953 \mathrm{~m}_{\mathrm{Lv}} / \mathrm{yz}=1.1 \mathrm{~kg} / \mathrm{m}^{2}$ in the stainless steel PLVTD reduced occurrence of pump malfunction

954 and apparent evaporator dry-out.

\section{$9556 \quad$ Conclusions}

956 Theoretical and experimental investigations were undertaken to examine behaviour of

957 a vertical Planar Liquid Vapour Thermal Diode (PLVTD) with a pumped falling film

958 evaporator wetter and its application in Climate Control Building Envelopes (CCBE) and 959 Integrated Collector-Storage Solar Water Heaters (ICSSWH).

960 - Theoretical model development: The horizontal PLVTD model proposed by 961 Pugsley et al. (2019) was augmented by introducing falling film evaporation and 
condensation, vapour convection in vertical and tilted rectangular enclosures,

963 an iteration methodology for evaluating working fluid temperatures, and 964 expressions accounting for non-condensable gas effects.

965 - Model validation for vertical orientation scenarios: Forward and reverse 966 mode thermal conductances of a small $\left(A_{p}=0.15 \mathrm{~m}^{2} \quad x=22 \mathrm{~mm}\right)$ vertical aluminium PLVTD were measured and compared against model predictions. The model predicts reverse mode performance accurately $\left(U_{r}=12 \mathrm{~W} \cdot \mathrm{m}^{-2} \mathrm{~K}^{-1}\right)$ across the range of operating conditions tested $\left(\Delta \mathrm{T}_{12}=20^{\circ} \mathrm{C}\right.$ and $\left.25<\mathrm{T}_{2}<65^{\circ} \mathrm{C}\right)$ and also reliably predicts forward mode performance $\left(U_{f} \approx 400 \mathrm{~W} \cdot \mathrm{m}^{-2} \mathrm{~K}^{-1}\right)$ for heat fluxes and condenser temperatures $\left(T_{2}=33 \pm 4^{\circ} \mathrm{C}\right.$ and $200<\mathrm{q} / \mathrm{A}<1000 \mathrm{~W} \cdot \mathrm{m}^{-2}$ corresponding to $0.5<\Delta T_{12}<2.5^{\circ} \mathrm{C}$ ) in the range of interested for CCBE and ICSSWH applications. The trend for proportionally increasing conductance $\left(175<\mathrm{U}_{\mathrm{f}}<730 \mathrm{~W} \cdot \mathrm{m}^{-2} \mathrm{~K}^{-1}\right)$ with increasing temperature $\left(15<\mathrm{T}_{2}<60^{\circ} \mathrm{C}\right.$ for fixed $\left.\Delta \mathrm{T}_{12}=4.5 \pm 1.5^{\circ} \mathrm{C}\right)$ is successfully predicted and appears to be related to vapour viscosity and its influence on the working fluid vapour flow resistance $\left(R_{e c}\right)$. The highest recorded thermal conductance was $\mathrm{U}_{\mathrm{f}} \approx 1200 \mathrm{~W} \cdot \mathrm{m}^{-2} \mathrm{~K}^{-1}$ at $\mathrm{T}_{2} \approx 55^{\circ} \mathrm{C}$ with $\Delta \mathrm{T}_{12} \approx 2.2^{\circ} \mathrm{C}$ corresponding to $\mathrm{q}_{\mathrm{HC}} / \mathrm{A}_{\mathrm{p}} \approx 2800 \mathrm{~W} \cdot \mathrm{m}^{-2}$.

- Model interrogation examining parametric design influences: The influence of PLVTD parametric design variables such as dimensions, orientation, temperature and heat flux was examined. Vertical PLVTDs achieve lower vapour convection thermal resistances $\left(R_{v}\right.$ and $\left.R_{e c}\right)$ than horizontal PLVTDs giving them worse reverse and better forward mode performances, especially when cavity depths are large $\left(x>50 \mathrm{~mm}, \mathrm{q} / \mathrm{A}>50 \mathrm{~W} / \mathrm{m}^{2}, \mathrm{~T}_{2}>25^{\circ} \mathrm{C}\right)$. Reverse mode performance is sensitive to cavity depth, especially when the cavity is small $(x<40 \mathrm{~mm})$ and behaviour is dominated by gaseous conduction and thermal bridging through sidewalls/structure. Forward mode performance depends on temperature, heat flux and dimensions, with high temperatures, high heat 
fluxes, large cavity depths $(x \approx 150 \mathrm{~mm})$ and high aspect ratios $(z / x>10)$ being

990 generally preferable for vertical and tilted PLVTDs.

991 - Testing of a large PLVTD integrated into a solar collector: The model was 992 used to develop the design of a large-scale prototype PLVTD $\left(A_{p}=0.98 \mathrm{~m}^{2}\right.$ and $993 \mathrm{x}=70 \mathrm{~mm}$ ) which was fabricated from $0.9 \mathrm{~mm}$ stainless steel sheet and integrated 994 into a novel PLVTD-ICSSWH hybrid solar collector with $100 \mathrm{~L}$ water storage tank. 995 Multiday tests consisting of consecutive 6-hour heating and 18-hour cooling cycles using a solar simulator $\left(\mathrm{G}=870,610\right.$ and $\left.370 \mathrm{~W} \cdot \mathrm{m}^{-2}\right)$ were undertaken to characterise PLVTD behaviour under quasi-steady heat fluxes of 998 $50<\mathrm{q} / \mathrm{A}<600 \mathrm{~W} \cdot \mathrm{m}^{-2}$ in forward mode $\left(3<\Delta \mathrm{T}_{12}<30^{\circ} \mathrm{C}\right)$ and $15<-\mathrm{q} / \mathrm{A}<60 \mathrm{~W} \cdot \mathrm{m}^{-2}$ in reverse mode $\left(5<-\Delta \mathrm{T}_{12}<25^{\circ} \mathrm{C}\right)$ for condenser temperatures ranging from $15<\mathrm{T}_{2}<60^{\circ} \mathrm{C}$. Reverse mode thermal conductances increased slightly with increasing temperature in the range $1.6<\mathrm{U}_{\mathrm{r}}<1.9 \mathrm{~W} \cdot \mathrm{m}^{-2} \mathrm{~K}^{-1}$ as predicted by the model. Transient heat loss fluxes (up to $-\mathrm{q} / \mathrm{A} \approx 150 \mathrm{~W} \cdot \mathrm{m}^{-2}$ ) were observed during forward-to-reverse mode switching representing unintended reverse mode latent heat transfer associated with flashing of residual condensate. Forward mode thermal conductances (considering wetted parts of the evaporator only) ranged from $\mathrm{U}_{\mathrm{f}} \approx 50 \mathrm{~W} \cdot \mathrm{m}^{-2} \mathrm{~K}^{-1} \quad$ (at $\mathrm{T}_{2}=20^{\circ} \mathrm{C}$ and $\mathrm{q} / \mathrm{A}<100 \mathrm{~W} \cdot \mathrm{m}^{-2}$ ) up to $\mathrm{U}_{\mathrm{f}} \approx 900 \mathrm{~W} \cdot \mathrm{m}^{-2} \mathrm{~K}^{-1}$ at higher temperatures and heat fluxes. Most results were in good agreement with the modelling predictions. Non-uniform evaporator wetting was observed to be problematic, especially at low temperatures. Evaporator dry-out occurred under certain conditions (notably for $\mathrm{q}_{12} / \mathrm{A}_{\mathrm{p}}>500 \mathrm{~W} \cdot \mathrm{m}^{-2}$ and $\mathrm{T}_{2}>55^{\circ} \mathrm{C}$ ). Provided that uniform evaporator wetting can be accomplished, results indicate that target diodicities ( $\varsigma>97 \%$ for CCBE and $\varsigma>99 \%$ for BISTS/BIPV applications) can be achieved during operation at relevant temperatures and heat fluxes. 
1015 It is anticipated that study findings, together with subsequent research inspired by 1016 the proposed parametric design approach, will have significant impacts in the 1017 context of the climate crisis by enabling development of new components and 1018 systems for Net Zero Energy Buildings. Future PLVTD design development work 1019 should target improvements in evaporator wetting (eg superhydrophillic surfaces, 1020 capillary wicks, wetter nozzle design, and flow rate optimization) and dimensional 1021 optimizations with regard to real-life application scenarios. Further research 1022 investigating the transient behaviour of PLVTDs should be undertaken with the aim 1023 of quantifying and reducing unwanted transient effects associated with thermal 1024 mass (eg superhydrophobic condensers, optimization of working fluid quantity and 1025 cavity depth).

\section{Acknowledgements}

1027 This research was enabled in its early stages by studentship funding support from the

1028 Northern Ireland Department for the Economy. The work was subsequently progressed 1029 with funding support from SolaForm Ltd and was completed as part of the 1030 "SolaNetwork" project funded by the UKRI Engineering and Physical Sciences Research 1031 Council (EP/T004819/1). The authors would also like to thank networking support 1032 funded by the European Union FP7 COST Action TU1205 "Building Integration of Solar 1033 Thermal Systems" and for the helpful contributions of reviewers prior to publication.

\section{Nomenclature}

\section{Latin symbols}

1036 A Surface area $\left[\mathrm{m}^{2}\right]$

1037 A\%wet Percentage of evaporator plate wetted by working fluid

$1038 \quad c_{p} \quad$ Specific heat capacity at constant pressure $\left[\mathrm{J}^{\mathrm{kg}} \mathrm{kg}^{-1} \mathrm{~K}^{-1}\right]$

1039 d Distance [m]

1040 D Mass diffusivity $\left[\mathrm{m}^{2} \cdot \mathrm{s}^{-1}\right]$

$1041 \mathrm{~g} \quad$ Acceleration due to gravity $\left(\mathrm{g}=9.81 \mathrm{~m} \cdot \mathrm{s}^{-2}\right.$ on earth at sea level)

$1042 \quad G \quad$ Solar irradiance $\left[\mathrm{W} \cdot \mathrm{m}^{-2}\right]$

$1043 \quad \mathrm{~h}\left\llcorner\mathrm{v} \quad\right.$ Latent heat of liquid-vapour phase change $\left[\mathrm{J} \cdot \mathrm{kg}^{-1}\right]$ 


\begin{tabular}{|c|c|c|}
\hline 1044 & k & Thermal conductivity $\left[\mathrm{W} \cdot \mathrm{m}^{-1} \mathrm{~K}-{ }^{-1}\right]$ \\
\hline 1045 & $k^{*}$ & Complex thermal conductivity with sensible \& latent components [W. $\left.\mathrm{m}^{-1} \mathrm{~K}^{-1}\right]$ \\
\hline 1046 & $\mathrm{~K}_{\mathrm{sf}}$ & Nucleate boiling surface constant \\
\hline 1047 & L & Characteristic dimension of Nusselt number [m] \\
\hline 1048 & M & Mass flow rate $\left[\mathrm{kg} \cdot \mathrm{s}^{-1}\right]$ \\
\hline 1049 & $\mathrm{n}_{\mathrm{sf}}$ & Nucleate boiling surface exponent \\
\hline 1050 & Ns & Number of struts in structural support array \\
\hline 1051 & $\mathrm{Nu}$ & Nusselt number \\
\hline 1052 & $P$ & Pressure $[\mathrm{Pa}]$ \\
\hline 1053 & $\operatorname{Pr}$ & Prandtl number \\
\hline 1054 & q & Thermal power [W] \\
\hline 1055 & $\mathrm{R}$ & Thermal resistance $\left[\mathrm{K} \cdot \mathrm{W}^{-1}\right]$ \\
\hline 1056 & $\mathrm{Ra}$ & Rayleigh number \\
\hline 1057 & $\mathrm{Ra}^{*}$ & Modified Rayleigh number accounting for pressure-driven vapour flow \\
\hline 1058 & $\operatorname{Re}$ & Reynolds number \\
\hline 1059 & Sc & Schmidt number \\
\hline 1060 & $\mathrm{t}$ & Time $[s]$ \\
\hline 1061 & $\mathrm{~T}$ & Temperature $\left[{ }^{\circ} \mathrm{C}\right]$ except for Equation 10 which uses absolute $[\mathrm{K}]$ \\
\hline 1062 & $U$ & Thermal conductance or heat transfer coefficient $\left[\mathrm{W} \cdot \mathrm{m}^{-2} \mathrm{~K}^{-1}\right]$ \\
\hline 1063 & v & Kinematic viscosity $\left[\mathrm{m}^{2} \cdot \mathrm{s}^{-1}\right]$ \\
\hline 1064 & $x$ & Mole fraction of working fluid in mixture with non-condensable gas \\
\hline 1065 & $x$ & Distance along an axis which is parallel to the PLVTD depth [m] \\
\hline 1066 & y & Distance along horizontal axis perpendicular to PLVTD depth [m] \\
\hline 1067 & z & Distance along an axis which is perpendicular to $\mathrm{x}$ and $\mathrm{y}$ axes [m] \\
\hline
\end{tabular}

\section{Greek and other symbols}

$1069 \varepsilon \quad$ Emissivity

$1070 \mu \quad$ Dynamic viscosity $\left[\mathrm{kg} \cdot \mathrm{m}^{-1} \mathrm{~s}^{-1}\right]$

$1071 \mathcal{M} \quad$ Molecular weight $\left[\mathrm{g} \cdot \mathrm{mol}^{-1}\right]$

$1072 \mathcal{R} \quad$ Universal gas constant $\left(8.314 \mathrm{~J} \cdot \mathrm{mol}^{-1} \mathrm{~K}^{-1}\right)$

1073 ๆ $\quad$ Thermal diffusivity $\left[\mathrm{m}^{2} \mathrm{~s}^{-1}\right]$

$1074 \Delta \mathrm{P} \quad$ Pressure difference $[\mathrm{Pa}]$

$1075 \Delta \mathrm{T} \quad$ Temperature difference $\left[{ }^{\circ} \mathrm{C}\right]$

$1076 \varsigma \quad$ Diodicity [\%]

$1077 \sigma \quad$ Surface tension $\left[\mathrm{N} \cdot \mathrm{m}^{-1}\right]$

$1078 \quad \beta \quad$ Coefficient of volumetric expansion $\left[\mathrm{K}^{-1}\right]$

$1079 \rho \quad$ Density $\left[\mathrm{kg} \cdot \mathrm{m}^{-3}\right]$

$1080 \chi \quad$ Stefan Boltzmann constant $\left(5.67 \times 10^{-8} \mathrm{Wm}^{-2} \mathrm{~K}^{-4}\right)$

$1081 \theta \quad$ Tilt angle relative to horizontal [ $\left.{ }^{\circ}\right]$

1082

\section{Subscripts}

$1084 \quad 1$

$1085 \quad 2$

10863

$1087 \quad 12$

$1088 \quad a$

1089 B

$1090 \quad \mathrm{C}$
Plate 1 which is the evaporator in forward mode

Plate 2 which is the condenser on forward mode

Thermal storage water tank

Between (or average of) the two plates

Ambient environment

Back of plate

Condenser, condensate or condensation 


\begin{tabular}{|c|c|c|}
\hline 1091 & $\mathrm{cr}$ & Critical (angle) \\
\hline 1092 & C & Cold water feed or cooled return \\
\hline 1093 & $\mathrm{CH}$ & Cooling plate or cooling water circuit \\
\hline 1094 & $\mathrm{D}$ & Edge of plate \\
\hline 1095 & e & Evaporator, evaporation or evaporator liquid film \\
\hline 1096 & ec & Between (or average of the evaporator and condenser surfaces \\
\hline 1097 & $f$ & Forward mode \\
\hline 1098 & $\mathrm{~h}$ & Horizontal orientation \\
\hline 1099 & $\mathrm{H}$ & Hot water feed or heated return \\
\hline 1100 & $\mathrm{HC}$ & Heating plate of heated water circuit \\
\hline 1101 & $\mathrm{~L}$ & Working fluid liquid state property \\
\hline 1102 & I & Losses to ambient environment \\
\hline 1103 & L1 & Liquid on the evaporator \\
\hline 1104 & L2 & Liquid on the condenser \\
\hline 1105 & LCS & Liquid working fluid (condensate) flowing from condenser to reservoir (sump) \\
\hline 1106 & LSe & Liquid working fluid flowing (pumped) from reservoir (sump) to evaporator \\
\hline 1107 & LeS & Liquid working fluid (run-off) flowing from evaporator to reservoir (sump) \\
\hline 1108 & Lv & Latent property of working fluid at the liquid-vapour saturation point \\
\hline 1109 & LvL & Liquid-vapour-liquid transition \\
\hline 1110 & ncg & Non-condensable gas \\
\hline 1111 & $\mathrm{Nu}$ & Nucleate boiling \\
\hline 1112 & $\mathrm{p}$ & Plate \\
\hline 1113 & $r$ & Reverse mode \\
\hline 1114 & $\mathrm{R}$ & Radiative component \\
\hline 1115 & $\mathrm{Ra}$ & Natural convection determined by Rayleigh number \\
\hline 1116 & $\operatorname{Re}$ & Forced convection determined by Reynolds number \\
\hline 1117 & $\mathrm{~s}$ & Structural element(s) such as internal support struts \\
\hline 1118 & sf & Evaporator plate surface condition \\
\hline 1119 & ss & Between two adjacent struts (centre-to-centre distance) \\
\hline 1120 & sw & Strut tube wall (thickness) \\
\hline 1121 & sxy & Between the xy-sidewall and the closest strut (distance along the z-axis) \\
\hline 1122 & sxz & Between the $x z$-sidewall and the closest strut (distance along the $y$-axis) \\
\hline 1123 & trans & Transition Rayleigh number $\left(\mathrm{Ratrans}=5 \times 10^{6}\right)$ \\
\hline 1124 & $v$ & Working fluid vapour state property \\
\hline 1125 & $\mathrm{~V}$ & Vertical orientation \\
\hline 1126 & w & Sidewalls of the PLVTD \\
\hline 1127 & $x$ & Mixture of working fluid and non-condensable gas \\
\hline 1128 & $x$ & In the direction parallel to the PLVTD depth \\
\hline 1129 & $\mathrm{y}$ & In the direction of the horizontal axis perpendicular to PLVTD depth \\
\hline $\begin{array}{l}1130 \\
1131\end{array}$ & $\mathrm{z}$ & In the direction of the axis which is perpendicular to $x$ and $y$ axes \\
\hline
\end{tabular}

\section{References}

1133 Agathokleous, R., Barone, G., Buonomano, A., Forzano, C., Kalogirou, S., Palombo, A. (2019). Building façade integrated solar 1134 thermal collectors for air heating: experimentation, modelling and applications. Applied Energy 239 (2019) 658-679

1135 Aguilar, F., Aledo, S. Quiles, P. (2016). Experimental study of the solar photovoltaic contribution for the domestic hot water production 1136 with heat pumps in dwellings. Applied Thermal Engineering 101, 379-89 
Ascione, F., De Masi, R., Rossi, F., Ruggiero, S., Vanoli, G. (2016). Optimisation of building envelope design for nZEBs in Mediterranean climate: Performance analysis of residential case study. Applied Energy 183 (2016) 938-957

1139

1140

1141

1142

1143

1144

1145

1146

1147

1148

1149

1150

1151

1152

1153

1154

1155

1156

1157

1158

1159

1160

1161

1162

1163

1164

1165

1166

1167

1168

1169

1170

1171

1172

1173

1174

1175

1176

1177

1178

1179

1180

1181

1182

1183

1184

1185

1186

Avanessian, T. \& Hwang, G. (2018). Thermal diode using controlled capillary in heterogeneous nanopores. International Journal of Heat and Mass Transfer 124 (2018) 201-209

Baïri, A., Zarco-Pernia, E., García de María, J. (2014). A review on natural convection in enclosures for engineering applications. The particular case of the parallelogrammic diode cavity. Applied Thermal Engineering 63 (2014) 304-322

Beausoleil-Morrison, I., Kemery, B., Wills, A., Meister, C. (2019). Design and simulated performance of a solar-thermal system employing seasonal storage for providing the majority of space heating and domestic hot water heating needs to a single-family house in a cold climate. Solar Energy 191 (2019) 57-69

Ben-Abdallah, P and Biehs, S. (2013). Phase-change radiative thermal diode. Applied Physics Letters 103 (19)

Berge, A., Hagentoft, C., Wahlgren, P., Adl-Zarrabi, B. (2015). Effect from a Variable U-Value in Adaptive Building Components with Controlled Internal Air Pressure (6th International Building Physics Conference, IBPC 2015). Energy Procedia 78 (2015) 376-381

Bilardo, M., Fraisse, G., Pailha, M., Fabrizio, E. (2019). Modelling and performance analysis of a new concept of integral collector storage (ICS) with phase change material. Solar Energy 183 (2019) 425-440

Blet, N., Lips, S., Sartre, V. (2017). Heats pipes for temperature homogenization: A literature review. Applied Thermal Engineering 118 (2017) 490-509

Borello, D., Corsini, A., Delibra, G., Evangelisti, S., Micangeli, A. (2012). Experimental and computational investigation of a new solar integrated collector storage system. Applied Energy 97 (2012) 982-989

Boreyko, J. \& Chen, C. (2013). Vapor chambers with jumping-drop liquid return from superhydrophobic condensers. International Journal of Heat and Mass Transfer 61 (2013) 409-418

Boreyko, J., Zhao, Y., Chen, C. (2011). Planar jumping-drop thermal diodes. Applied Physics Letters 99, 234105

Buonomano, A., Calise, F., Palombo, A., Vicidomini, M. (2016). BIPVT systems for residential applications: An energy and economic analysis for European climates. Applied Energy 184 (2016) 1411-1431

Calise, F., d'Accadia, M, Figaj, R., Vanoli, L., (2016). A novel solar-assisted heat pump driven by photovoltaic/thermal collectors: Dynamic simulation and thermoeconomic optimization. Energy 95, 346-66

Cengel, Y., Boles, M., (2006). Thermodynamics an Engineering Approach, 5th Edition. McGraw-Hill, New York.

Charisi, S. (2017). The Role of the Building Envelope in Achieving Nearly-Zero Energy Buildings (International Conference on Sustainable Synergies from Buildings to the Urban Scale, SBE16). Procedia Environmental Sciences 38 ( 2017 ) 115 - 120

Chen, K., Chailapo, P., Chun, W., Kim, S., Lee, K. (1998). The Dynamic Thermosiphon of a bayonet-type thermal diode. Solar Energy 64 (4-6) 257-263

Chen (2012). Patent Application for Thermal Diode Device and Methods. US2012/0012804 Al

Collins, R. \& Fischer-Cripps, A. (1991). Design of Support Pillar Arrays in Flat Evacuated Windows. Australian Journal of Physics 1991 (44) 545-63

Corcione (2003). Effects of the thermal boundary conditions at the sidewalls upon natural convection in rectangular enclosures heated from below and cooled from above. International Journal of Thermal Sciences 42 (2003) 199-208.

Cui, H., Overend, M. (2019). A review of heat transfer characteristics of switchable insulation technologies for thermally adaptive building envelopes. Energy \& Buildings 199 (2019) 427-444

De Beijer, H. (1998). Product development in solar water heating. Renewable Energy 5 (1998) 201-204

Deng, J., O'Donovan, T., Tianc, Z., King, J., Speake, S. (2019). Thermal performance predictions and tests of a novel type of flat plate solar thermal collectors by integrating with a freeze tolerance solution. Energy Conversion and Management 198 (2019) 111784

Dos Santos Bernardes, M. (2014). Experimental evidence of the working principle of thermal diodes based on thermal stress and thermal contact conductance - Thermal semiconductors. International Journal of Heat and Mass Transfer 73 (2014) 354-357

Drosou, V., Tsekouras, P., Oikonomou, T., Kosmopoulos, P., Karytsas, C. (2014). The HIGH-COMBI project: High solar fraction heating and cooling systems with combination of innovative components and methods. Renewable and Sustainable Energy Reviews 29 (2014) $463-472$

Dupeyrat, P., Menezo, C., Rommel, M., Henning, H. (2011). Efficient single glazed flat plate photovoltaic-thermal hybrid collector for domestic hot water systems. Solar Energy $85,1457-68$

Faiman, D., Hazan, H. and Laufer, I. (2001). Reducing the Heat Loss at Night from Solar Water Heaters of the Integrated CollectorStorage Variety. Solar Energy, 71 (2) 87-93

Fang, X. and Xia, L. (2010). Heating performance investigation of a bidirectional partition fluid thermal diode. Renewable Energy 35 (2010) 679-684 
Fang, Y., Hyde, T., Arya, F., Hewitt, N., Eames, P., Norton, B., Miller, S. (2014). Indium alloy-sealed vacuum glazing development and context. Renewable and Sustainable Energy Reviews 37 (2014) 480-501

Ganguli, A., Pandit, A., Joshi, J. (2009). CFD simulation of heat transfer in a two-dimensional vertical enclosure. Chemical Engineering Research and Design 87 (2009) 711-27

Garnier, C., Currie, J., Muneer,T. (2009). Integrated collector storage solar water heater: Temperature stratification. Applied Energy 86 (2009) 1465-1469

1193 Gerstmann, J. \& Griffith, P. (1967). Laminar Film Condensation on the Underside of Horizontal and Inclined Surfaces. International Journal of Heat and Mass Transfer 10 (1967) 567-80.

Go, D. \& Sen, M. (2010). Thermal Rectification Using Bulk Materials. ASME Journal of Heat Transfer 132 (12) 124502

Good, C., Andresen, I., Hestnes, A. (2015). Solar energy for net zero energy buildings - A comparison between solar thermal, PV and photovoltaic-thermal (PV/T) systems. Solar Energy 122, 986-96

He, W., Hong, X., Zhao, X., Zhang, X., Shen, J., Ji, J. (2015). Operational performance of a novel heat pump assisted solar façade loop-heat-pipe water heating system. Applied Energy 146 (2015) 371-38

$\mathrm{Hu}, \mathrm{Z}$., He, W., Ji, J., Hu, D., Shen, Z. (2017). Comparative study on the annual performance of three types of building integrated photovoltaic (BIPV) Trombe wall system. Applied Energy 194 (2017) 81-93 IEA - International Energy Agency (2018). Key World Energy Statistics 2018. Paris, France: IEA.

IEA/UN - International Energy Agency and the United Nations Environment Programme (2018). 2018 Global Status Report: towards a zero-emission, efficient and resilient buildings and construction sector. Paris, France: IEA for the Global Alliance for Buildings and Construction (GlobalABC). ISBN: 978-92-807-3729-5.

Inan, T., Basaran, T. (2019). Experimental and numerical investigation of forced convection in a double skin façade by using nodal network approach for Istanbul. Solar Energy 183 (2019) 441-452

1210 A parametric study for a temperate climate. Energy 127 (2017) 634-649

1211 Kilaire, A., Stacey, M. (2017). Design of a prefabricated passive and active double skin façade system for UK offices. Journal of 1212 Building Engineering 12 (2017) 161-170

Kimber, M., Clark, W., Schaefer, L. (2014). Conceptual analysis and design of a partitioned multifunctional smart Insulation. Applied Energy 114 (2014) 310-319

Koenders, S., Loonen, R., Hensen, J. (2018). Investigating the potential of a closed-loop dynamic insulation system for opaque building elements. Energy \& Buildings 173 (2018) 409-427

Kolodziej, A. and Jaroszynski, M. (1997). Performance of liquid convective diodes. Solar Energy 61 (5) 321-326

Li, S., Zhang, Y., Zhang, K., Li, X., Li, Y., Zhang, X. (2013). Study on performance of storage tanks in solar water heater system in charge and discharge progress (SHC 2013, International Conference on Solar Heating and Cooling for Buildings and Industry). Energy Procedia 48 (2014) 384-393 doi: 10.1016/j.egypro.2014.02.045

Li, X., Lin, A., Young, C., Dai, Y., Wang, C. (2019). Energetic and economic evaluation of hybrid solar energy systems in a residential net-zero energy building. Applied Energy 254 (2019) 113709

Masoso, O., Grobler, L. (2008). A new and innovative look at anti-insulation behaviour in building energy consumption. Energy and Buildings 40 (2008) 1889-1894

Mehdaoui, F., Hazami, M., Messaouda, A., Guizani, A. (2019). Performance analysis of two types of Solar Heating Systems used in buildings under typical North-African climate (Tunisia). Applied Thermal Engineering (AIP) https://doi.org/10.1016/j.applthermaleng.2019.114203

Menyhart, K., Krarti, M. (2017). Potential energy savings from deployment of Dynamic Insulation Materials for US residential buildings. Building and Environment 114 (2017) 203-218.

\section{Mohamad, A. (1997). Integrated Solar Collector-Storage Tank System with Thermal Diode. Solar Energy 61 (3) 211-218}

Muhumuza, R., Zacharopoulos, A., Mondol, J., Smyth, M. (2019a). Experimental study of heat retention performance of thermal diode Integrated Collector Storage Solar Water Heater (ICSSWH) configurations. Sustainable Energy Technologies and Assessments 34 (2019) 214-219

Muhumuza, R., Zacharopoulos, A., Mondol, J., Smyth, M., Pugsley, A., Giuzio, G., Kurmis, D. (2019b). Experimental investigation of horizontally operating thermal diode solar water heaters with differing absorber materials under simulated conditions. Renewable Energy, Volume 138, August 2019, Pages 1051-1064 
O'Hegarty, R., Kinnane, O., McCormack, S. (2014). A Case for façade located solar thermal collectors. (International Conference on Solar Heating and Cooling for Buildings and Industry, SHC 2014). Energy Procedia 70 (2015) 103-110 doi: 10.1016/j.egypro.2015.02.104

Pei, W., Zhang, M., Li, S., Lai, Y., Jin, L., Zhai, W., Yu, F., Lu, J. (2017). Geotemperature control performance of two-phase closed thermosyphons in the shady and sunny slopes of an embankment in a permafrost region. Applied Thermal Engineering 112 (2017) 986-998

Pflug, T., Nestle, N., Kuhn, T., Siroux, M., Maurer, C. (2018). Modelling of facade elements with switchable U-value. Energy \& Buildings 164 (2018) 1-13

Peterson, P. (1996). Theoretical basis for the Uchida correlation for condensation in reactor containments. Nuclear Engineering and Design 162 (1996) 301-306.

Poppi, S., Bales, C., Haller, M., Heinz, A. (2016). Influence of boundary conditions and component size on electricity demand in solar thermal and heat pump combisystems. Applied Energy 162 (2016) 1062-73

Pugsley, A., Mondol, J., Smyth, M., Zacharopoulos, A. \& Di Mattia, L. (2016). Experimental characterisation of a flat panel integrated collector-storage solar water heater featuring a photovoltaic absorber and a planar liquid-vapour thermal diode. Proceedings of 11 th ISES EuroSun Conference: Palma (Mallorca), Spain from 11 to 14 October 2016. Martinez, V. \& Gonzalez, J. (eds.). energy storage via a planar liquid-vapour thermal diode. Ulster University PhD Thesis (uk.bl.ethos.713462) published July 2017.

Pugsley, A., Zacharopoulos, A., Mondol, J., Smyth, M. (2019). Theoretical and experimental analysis of a horizontal 1 Planar LiquidVapour Thermal Diode (PLVTD). International Journal of Heat and Mass Transfer 144 (2019) 11866

Qu, M., Chen, J., Nie, L., Li, F., Yu, Q., Wang, T. (2016). Experimental study on the operating characteristics of a novel photovoltaic/thermal integrated dual-source heat pump water heating system. Applied Thermal Engineering 94, 819-26

Quinlan, P. (2010). The Development of a Novel Integrated Collector Storage Solar Water Heater (ICSSWH) Using Phase Change

Reay, D., Kew, P., McGlen, R. (2014). Heat Pipes - Theory, Design and Applications (6th edition). London, UK: Butterworth-

Rhee, J., Campbell, A. Mariadass, A. and Morhous, B. (2010). Temperature stratification from thermal diodes in solar hot water storage tank. Solar Energy 84 (2010) 507-511

Roberts, N. \& Walker, D. (2011). A review of thermal rectification observations and models in solid materials. International Journal of Thermal Sciences 50 (2011) 648-62.

Rupp, S., Krarti, M. (2019). Analysis Of Multi-Step Control Strategies For Dynamic Insulation Systems. Energy \& Buildings (2019 AIP) doi.org/10.1016/j.enbuild.2019.109459

Schmidt, F., Henderson, R. and Wolgemuth, C. (1993). Introduction to thermal sciences - Thermodynamics, Fluid dynamics, Heat transfer (2nd ed.). London: John Wiley \& Sons.

Singh, R., Lazarus, I., and Souliotis, M. (2016). Recent developments in integrated collector storage (ICS) solar water heaters: A review. Renewable \& Sustainable Energy Reviews 54, 270-98

Smyth, M., Eames, P. and Norton, B. (1999). A comparative performance rating for an integrated solar collector/storage vessel with inner sleeves to increase heat retention. Solar Energy 66 (4) 291-303.

Smyth, M., Eames, P. and Norton, B. (2006). Integrated Collector Storage Solar Water Heaters. Renewable and Sustainable Energy Review 10 (6) 503-538

1275 Smyth, M. (2015a). A solar water heater. Patent WO2010052010 held by Ulster University.

Smyth, M., Besheer, A., Zacharopoulos, A., Mondol, J., Pugsley, A., Novaes, M. (2015b). Experimental evaluation of a Hybrid Photovoltaic/Solar Thermal (HyPV/T) Façade Module. Proceedings EURO ELECS Conference 21-23 July 2015, Guimarães, Portugal.

Smyth, M., Quinlan, P., Mondol, J., Zacharopoulos, A., McLarnon, D., Pugsley, A. (2017). The evolutionary thermal performance \& development of a novel thermal diode pre-heat solar water heater under simulated heat flux conditions. Renewable Energy 113 (2017) 1160-1167

Smyth, M., Quinlan, P., Mondol, J., Zacharopoulos, A., McLarnon, D., Pugsley, A. (2018). The experimental evaluation and improvements of a novel thermal diode pre-heat solar water heater under simulated solar conditions. Renewable Energy 121 (2018) 116-122

Smyth, M., Pugsley, A., Hanna, G., Zacharopoulos, A., Besheer, A., Savvides, A. (2019). Experimental performance characterisation of a Hybrid Photovoltaic/Solar Thermal Façade module compared to a flat Integrated Collector Storage Solar Water Heater module. Renewable Energy 137 (2019) 137-143 integrated storage system. Renewable Energy 29 (2004) 1421-1430 
Souliotis, M., Papaefthimiou, S., Caouris, Y., Zacharopoulos, A., Quinlan, P., Smyth, M. (2017). Integrated collector storage solar water heater under partial vacuum. Energy 139 (2017) 991-1002

1292 Stazi, F., Vegliò, A., Perna, C., Munafò, P. (2012). Retrofitting using a dynamic envelope to ensure thermal comfort, energy savings and low environmental impact in Mediterranean climates. Energy and Buildings 54 (2012) 350-362.

1294 Stein, R., Cho, D., Lambert, G. (1985). Condensation on the underside of a horizontal surface in a closed vessel (CONF-8508101295 27). Argonne, Illinois, USA: Argonne National Laboratory. Available at: www.osti.gov/scitech/biblio/5207060

1296 Traipattanakul, B., Tso, C., Chao, C. (2019). A phase-change thermal diode using electrostatic-induced coalescing jumping droplets. International Journal of Heat and Mass Transfer 135 (2019) 294-304

1298 Tripanagnostopoulos, Y. and Souliotis, M. (2006). ICS Solar Systems with Two Water Tanks. Renewable Energy 29 (1) 13-38

1299 Tsilingiris, P. (2008). Thermophysical and transport properties of humid air at temperature range between 0 and $100^{\circ} \mathrm{C}$. Energy 1300 Conversion and Management 49 (2008) 1098-1110.

1301 Twidell, J. \& Weir, T. (2006). Renewable Energy Resources (2nd ed.) London: Taylor Francis. ISBN13:9-78-0-419-25330-3

1302 Varga, S., Oliveira, A., Afonso, C. (2002). Characterisation of thermal diode panels for use in the cooling season in buildings. Energy 1303 and Buildings 34 (2002) 227-235

1304 Villeneuve, T., Boudreau, M., Dumas, G. (2017). The thermal diode and insulating potentials of a vertical stack of parallelogrammic 1305 air-filled enclosures. International Journal of Heat and Mass Transfer 108 (2017) 2060-2071

1306 Wong, M., Traipattanakul, B., Tso, C., Chao, C., Qiu, H. (2019). Experimental and theoretical study of a water-vapor chamber thermal 1307 diode. International Journal of Heat and Mass Transfer 138 (2019) 173-183

1308 Yu, B., Li, N., Ji, J. (2019). Performance analysis of a purified Trombe wall with ventilation blinds based on photo-thermal driven 1309 purification. Applied Energy 255 (2019) 113846.

1310 Zaitsev, D., Kabov, O. and Evseev, A. (2003). Measurement of locally heated liquid film thickness by a double-fiber optical probe. 1311 Experiments in Fluids 34 (6) 48-754.

1312 Zhou, D., Gambaryan-Roisman, T. and Stephan, P. (2009). Measurement of water falling film thickness to flat plate using confocal 1313 chromatic sensoring technique. Experimental Thermal and Fluid Science 33, 273-283.

1314 Ziapour, B., Palideh, V., Mohammadnia, A. (2014). Study of an improved integrated collector-storage solar water heater combined 1315 with the photovoltaic cells. Energy Conversion and Management 86 (2014) 587-594. 
1317 Equations for evaluating vapour mass flow thermal resistance ( $\left.R_{\text {ec }}\right)$ when 1318 the PLVTD contains a mixture of working fluid and non-condensable gases

1320 It is widely recognised that non-condensable gases reduce rates of liquid-vapour-liquid

1321 heat transfer and the effect was noted by Boreyko \& Chen (2013) during their thermal

1322 diode experiments. Cengel \& Boles (2006) suggests that the non-condensable gases

1323 form a barrier layer near the condenser surface which imposes a resistance to the flow

1324 of vapour between the evaporator and the condenser. The resistance is highest when

1325 the vapour velocity is low and the non-condensable gas concentration is high. Stein et

1326 al. (1985) attempted to model the effect for condensation on the underside of a

1327 horizontal plate by considering mass diffusivity within the air-water gas mixture using

1328 a Sherwood number mass transfer approach (analogous to the Nusselt number heat

1329 transfer approach). A similar approach adopted by Peterson (1996) described the 1330 effect on a vertical condenser using its height as the characteristic dimension $(L=z)$.

1331 Both models represent gas mixture (water vapour and non-condensable gas) as a 1332 barrier layer which covers the condenser surface. Water vapour produced at the 1333 evaporator must pass through the barrier layer prior to condensing.

1334 Both the Peterson (1996) and Stein et al. (1985) models define the Rayleigh number 1335 according to Equation $A 1$ in terms of the difference $\left(\rho_{\times 2}-\rho_{\times 1}\right)$ between the density of 1336 the gas mixture near the condenser surface and the density of the gas mixture near 1337 the evaporator surface. The terms used in Equation A1 are the dimensionless Schmidt 1338 number $(\mu / \rho D)$ which is the mass transfer equivalent of the Prandtl number, mixture 1339 densities $(\rho x)$, gravitational acceleration $(g)$, characteristic dimension $(L=x)$, average 1340 mixture viscosity $(\mu x)$, and mixture mass diffusivity $\left(D_{x}\right)$. Peterson (1996) suggests 1341 that the mixture densities can be evaluated using Equations A2 and A3 where the 
1342 terms $\dot{\mathcal{M}}_{v}$ and $\dot{\mathcal{M}}_{n c g}$ are the respective molecular masses of water and the non-

1343 condensable gas. The terms $X_{n c g 1}$ and $X_{n c g}$ represent the mole fractions of non-

1344 condensable gas present in the mixture at the respective evaporator $\left(T_{1}\right)$ and

1345 condenser $\left(T_{2}\right)$ temperatures. The ambient temperature $\left(T_{a}\right)$ is used as a convenient

1346 point of reference for determining the hypothetical saturated water vapour density

1347 ( $\left.\rho_{\text {LvXa }}\right)$ which would occur at a total pressure $\left(P_{X a}=P_{\text {Lva }}+P_{n c g a}\right)$ equal to the sum of the

1348 saturated water vapour and non-condensable gas partial pressures at the ambient

1349 temperature $\left(T_{a}\right)$. The reference temperature $T_{\text {ref }}=273.16 \mathrm{~K}$ is the freezing point of

1350 water in Kelvin. Stein et al. (1985) suggest that the mass diffusivity of a mixture of air

1351 and water vapour can be estimated with sufficient reliability using Equation A4 where

1352 the constants are given as $D_{\text {ref }}=2.2 \times 10^{-5} \mathrm{~m}^{2} / \mathrm{s}$ and $P_{a t m}=100 \mathrm{kPa}$.

1353

1354

1355

$$
R a^{*}=\left(\frac{\rho_{X} g L^{3}\left(\rho_{X 2}-\rho_{X 1}\right)}{\mu_{X}^{2}}\right)\left(\frac{\mu_{X}}{\rho_{X} D_{X}}\right)=\frac{g L^{3}\left(\rho_{X 2}-\rho_{X 1}\right)}{\mu_{X} D_{X}}
$$

Equation A1

1356

$$
\rho_{X 1}=\frac{\rho_{L v X a}\left(T_{a}+T_{r e f}\right)}{\left(T_{1}+T_{r e f}\right)}\left[X_{n c g 1} \frac{\dot{\mathcal{M}}_{n c g}}{\dot{\mathcal{M}}_{v}}\right]
$$

Equation A2

$$
\rho_{X 2}=\frac{\rho_{L v X a}\left(T_{a}+T_{r e f}\right)}{\left(T_{2}+T_{r e f}\right)}\left[1+X_{n c g 2}\left(\frac{\dot{\mathcal{M}}_{n c g}}{\dot{\mathcal{M}}_{v}}-1\right)\right]
$$

Equation A3

1357 The thermal conductivity of the gas mixture (working fluid vapour plus non-

1358 condensable gases) involved in the liquid-vapour-liquid heat transfer process $\left(\mathrm{k}^{*}\right)$ is

1359 defined according to Equation A5 where $\vartheta_{x}, D_{x}$ and $k_{x}$ respectively are the thermal

1360 diffusivity, mass diffusivity, and thermal conductivities of the gas mixture and kxLv is

1361 the latent heat thermal conductivity of the vapour defined by Equation A6 which is

1362 similar to Equation 18 with the addition of a term ( $\phi \times$ calculated using Equation A7)

1363 describing the mole fraction ratio of the gas mixture.

$$
k_{X}^{*}=k_{X}\left(\frac{D_{X}}{\vartheta_{X}}\right)^{1 / 3}+k_{X L v}
$$




$$
\phi_{X}=-1\left(\frac{\ln \left[\left(1-X_{\left.\left.n c g_{1}\right) /\left(1-X_{n c g 2}\right)\right]}\right.\right.}{\ln \left(X_{n c g_{1}} / X_{n c g 2}\right)}\right)
$$

1367 Numbers used in subscripts in Equations A1 to A7 denote whether properties should 1368 be evaluated at the evaporator $\left(T_{1}\right)$ or condenser $\left(T_{2}\right)$ temperature. Properties with no 1369 numbers in the subscript should be evaluated at the average operating temperature $1370 T_{12}=\left(T_{1}+T_{2}\right) / 2$. The subscripts $v$, ncg and $X$ respectively refer to water vapour, non1371 condensable gas and the mixture of two fluids. Gas mixture properties $\rho_{x}, \mu_{x}, k_{x}, \vartheta_{x}$, $1372 X_{n c g}$ and $X_{v}$ can be determined using Wilke's rule and other expressions presented by 1373 Tsilingiris (2008), which are reproduced in Table A1. 
Table A1 - Equations for determining the properties of gas mixtures

\begin{tabular}{|c|c|}
\hline Property & Expression \\
\hline Density $\left(\rho_{X}\right)$ & $\rho_{X}=\frac{P_{L v}+P_{n c g}}{\dot{\mathcal{R}}\left(T+T_{0}\right)} \dot{\mathcal{M}}_{n c g}\left[1-X_{v}\left(1-\frac{\dot{\mathcal{M}}_{v}}{\dot{\mathcal{M}}_{n c g}}\right)\right]$ \\
\hline Dynamic viscosity $\left(\mu_{X}\right)$ & $\mu_{X}=\frac{\left(1-X_{v}\right) \mu_{n c g}}{\left(1-X_{v}\right)+X_{v} \Phi_{n c g-v}}+\frac{X_{v} \mu_{v}}{X_{v}+\left(1-X_{v}\right) \Phi_{v-n c g}}$ \\
\hline Thermal conductivity $\left(k_{X}\right)$ & $k_{X}=\frac{\left(1-X_{v}\right) k_{n c g}}{\left(1-X_{v}\right)+X_{v} \Phi_{n c g-v}}+\frac{X_{v} k_{v}}{X_{v}+\left(1-X_{v}\right) \Phi_{v-n c g}}$ \\
\hline Specific heat capacity $\left(c_{p, X}\right)$ & $c_{p, X}=c_{p, v} X_{v}\left(\frac{\dot{\mathcal{M}}_{v}}{\dot{\mathcal{M}}_{v}+\dot{\mathcal{M}}_{n c g}}\right)+c_{p, n c g} X_{n c g}\left(\frac{\dot{\mathcal{M}}_{n c g}}{\dot{\mathcal{M}}_{v}+\dot{\mathcal{M}}_{n c g}}\right)$ \\
\hline $\begin{array}{l}\text { Ratio of mass diffusivity }\left(D_{x}\right) \\
\text { to thermal diffusivity }\left(\vartheta_{X}\right)\end{array}$ & $\frac{P r_{X}}{S c_{X}}=\frac{D_{X}}{\vartheta_{X}}=\frac{D_{X} \rho_{X} c_{p, X}}{k_{X}}$ \\
\hline $\begin{array}{l}\text { Non-condensable gas mole } \\
\text { fraction }\left(X_{n c g}\right)\end{array}$ & $X_{n c g}=\frac{P_{n c g}}{P_{L v}+P_{n c g}}$ \\
\hline $\begin{array}{l}\text { Water vapour mole fraction } \\
\left(X_{v}\right)\end{array}$ & $X_{v}=\frac{P_{L v}}{P_{L v}+P_{n c g}}$ \\
\hline \multirow{2}{*}{$\begin{array}{l}\text { Wilke's coefficients for } \\
\text { non-condensable gas } \\
\text { mixed with water vapour } \\
\left(\Phi_{n c g-v} \text { and } \Phi_{v-n c g}\right)\end{array}$} & $\Phi_{n c g-v}=0.354\left(1+\frac{\dot{\mathcal{M}}_{n c g}}{\dot{\mathcal{M}}_{v}}\right)^{-0.5}\left[1+\left(\frac{\mu_{n c g}}{\mu_{v}}\right)^{0.5}\left(\frac{\dot{\mathcal{M}}_{v}}{\dot{\mathcal{M}}_{n c g}}\right)^{0.25}\right]^{2}$ \\
\hline & $\Phi_{v-n c g}=0.354\left(1+\frac{\dot{\mathcal{M}}_{v}}{\dot{\mathcal{M}}_{n c g}}\right)^{-0.5}\left[1+\left(\frac{\mu_{v}}{\mu_{n c g}}\right)^{0.5}\left(\frac{\dot{\mathcal{M}}_{n c g}}{\dot{\mathcal{M}}_{v}}\right)^{0.25}\right]^{2}$ \\
\hline
\end{tabular}

